\section{Abstract}

\title{
Modelled and observed sea-spray icing in Arctic-Norwegian waters
}

\author{
Eirik Mikal Samuelsen $^{\mathrm{a}, \mathrm{b}, 1, *}$, Kåre Edvardsen ${ }^{\mathrm{a}}$, Rune Grand Graversen ${ }^{\mathrm{a}}$ \\ ${ }^{a}$ UiT - The Arctic University of Norway, P.O. Box 6050 Langnes, NO-9037 Troms $\phi$, Norway \\ ${ }^{b}$ MET Norway - Norwegian Meteorological Institute, P.O. Box 6314 Langnes, NO-9293 Troms $\varnothing$, Norway
}

Hazardous marine icing is a major concern for ships operating in Arctic waters during freezing conditions. Sea spray generated by the interaction between a ship and ocean waves is the most important water source in these dangerous icing events. Although there exist several data sets with observations of ice accretion in conjunction with meteorological and oceanographic parameters, these data sets often have shortcomings and only a few are obtained in Arctic-Norwegian waters. In this study, icing rates from a large coast-guard vessel type, the KV Nordkapp class, are used for verification of a newly proposed Marine-Icing Model for the Norwegian COast Guard (MINCOG). Ship observations, NOrwegian ReAnalysis $10 \mathrm{~km}$ data (NORA10), and wave data based on empirical statistical relationships between wind and waves are all applied in MINCOG and the results are compared. The model includes two different empirically-derived formulations of spray flux. It is found that in general the best results for different verification scores are obtained by using a combination of observed atmosphere and ocean-wave parameters from the ships, and wave period and direction from NORA10, regardless of the spray-flux formulation applied. Furthermore, the results illuminate that wave parameters derived from formulas based on empirical relationships between the local wind speed and significant wave height and wave period, compared to those obtained from observations or NORA10, considerably worsen icing-rate predictions in Arctic-Norwegian waters when applied in MINCOG.

Keywords: Marine icing, Polar meteorology, Hazardous weather events, Barents Sea, Maritime transportation, Safety risk

\footnotetext{
${ }^{*}$ Corresponding author

Email addresses: eirik.m.samuelsen@uit.no; eiriks@met.no; eirik_samuelsen@hotmail.com; (Eirik Mikal Samuelsen), kare.edvardsen@uit .no (Kåre Edvardsen), rune.graversen@uit.no (Rune Grand Graversen)

${ }^{1}$ Phone: +47 77644000/+47 77621300/+47 48137141; Fax: +47 77621401;

${ }^{2}$ Abbreviations used throughout the paper:

NORA10: NOrwegian ReAnalysis $10 \mathrm{~km}$ hindcast archive (Reistad et al. 2011), MINCOG: Marine-Icing Model for the Norwegian COast Guard, USCGC: United States Coast Guard Cutter, MFV: Medium-sized fishing vessel, nm: nautical miles, WMO: World Meteorological Organization, SVIM: Nordic $4 \mathrm{~km}$ ocean model hindcast archive (Lien et al. 2013), ERA40 and ERA-Interim: European Centre for Medium-Range Weather Forecasts Reanalyses (Uppala et al. 2005, Dee et al. 2011), CFD: Computational Fluid Dynamics, OBS, N10, HYBRID1, HYBRID2, ZAKR, HORJEN: Different sources for model-input (see section 3.2, PC: Proportion Correct, HSS: Heidke Skill Score, PSS: Pierce Skill Score, GMSS: Gandin-Murphy Skill Score, N: no icing, L: light icing, M: moderate icing, S: severe icing
} 
NOMENCLATURE

A Albedo of freezing surface

BIAS Mean error: $\frac{1}{n^{\prime}} \sum_{i=1}^{n^{\prime}}\left(P_{i}-O_{i}\right)$,

$n^{\prime}$ number of events, $P_{i}$ predictions, $O_{i}$ observations

Drag coefficient

$C_{I} \quad$ Ice concentration (code/fraction)

$c \quad$ Wave-phase speed $\left(\mathrm{m} \mathrm{s}^{-1}\right)$

Wave-group speed $\left(\mathrm{m} \mathrm{s}^{-1}\right)$

Specific heat capacity of air $\left(1004 \mathrm{~J} \mathrm{~kg}^{-1}{ }^{\circ} \mathrm{C}^{-1}\right)$

Specific heat capacity of sea water $\left(4000 \mathrm{~J} \mathrm{~kg}^{-1}{ }^{\circ} \mathrm{C}^{-1}\right)$

Freezing plate width $(4 \mathrm{~m})$

Wind direction $\left({ }^{\circ}\right)^{* *}$

Wave direction $\left({ }^{\circ}\right)^{* *}$

Ship direction $\left({ }^{\circ}\right)^{* *}$

Water depth (m)

Droplet diameter $(2.0 \mathrm{~mm})$

Collection efficiency

Ice-accumulation thickness $(\mathrm{cm})$

Saturation vapour pressure $(\mathrm{hPa})$

Gravitational acceleration $\left(9.81 \mathrm{~m} \mathrm{~s}^{-2}\right)$

Effective gravitational acceleration of droplet $\left(\mathrm{m} \mathrm{s}^{-2}\right)$

Icing rate $\left(\mathrm{cm} \mathrm{h}^{-1}\right)$

Heat-transfer coefficient $\left(\mathrm{W} \mathrm{m}^{-2}{ }^{\circ} \mathrm{C}^{-1}\right)$

$h_{a}$ for droplet cooling $\left(\mathrm{W} \mathrm{m}^{-2}{ }^{\circ} \mathrm{C}^{-1}\right)$

Evaporative heat-transfer coefficient $\left(\mathrm{W} \mathrm{m}^{-2} \mathrm{hPa}^{-1}\right)$

$h_{e}$ for droplet cooling $\left(\mathrm{W} \mathrm{m}^{-2} \mathrm{hPa}^{-1}\right)$

Significant wave height (m)

Swell-wave height (m)

Wind-wave height $(\mathrm{m})$

Icing cause (code)

Interfacial distribution coefficient (0.3)

Thermal conductivity of air $\left(0.023 \mathrm{~W} \mathrm{~m}^{-1}{ }^{\circ} \mathrm{C}^{-1}\right)$

Latent heat of freezing of saline water $\left(\mathrm{J} \mathrm{kg}^{-1}\right)$

Latent heat of freezing of fresh water $\left(3.33 \times 10^{5} \mathrm{~J} \mathrm{~kg}^{-1}\right)$

Latent heat of vaporisation $\left(2.5 \times 10^{6} \mathrm{~J} \mathrm{~kg}^{-1}\right)$

Liquid water content in spray $\left(\mathrm{kg} \mathrm{m}^{-3}\right)$

$\uparrow \mathrm{LW}$ Incoming and outgoing longwave radiation $\left(\mathrm{W} \mathrm{m}^{-2}\right)$

MAE Mean absolute error: $\frac{1}{n^{\prime}} \sum_{i=1}^{n^{\prime}}\left|P_{i}-O_{i}\right|$

MASE Mean absolute scaled error: $\frac{\text { MAE }}{\frac{1}{n^{\prime}-1} \sum_{i=2}^{n^{\prime}}\left|O_{i}-O_{i-1}\right|}$

$\overrightarrow{n_{1}}$

$N$

$\mathrm{Nu}$

$\mathrm{Nu}$

$\operatorname{Pr}$

$\operatorname{Pr}$
$P_{s}$

$P_{\mathrm{sW}}$

$P_{\mathrm{ws}}$

$p \quad$ Air pressure at mean sea level $(\mathrm{hPa})$

$Q_{c} \quad$ Convective heat flux $\left(\mathrm{W} \mathrm{m}^{-2}\right)$

$Q_{\mathrm{cd}} \quad$ Convective heat flux for droplets $\left(\mathrm{W} \mathrm{m}^{-2}\right)$

$Q_{\text {cond }} \quad$ Conductive heat flux $\left(\mathrm{W} \mathrm{m}^{-2}\right)$

$Q_{d} \quad$ Heat flux from incoming water droplets $\left(\mathrm{W} \mathrm{m}^{-2}\right)$

$Q_{e} \quad$ Evaporative heat flux $\left(\mathrm{W} \mathrm{m}^{-2}\right)$

$Q_{\text {ed }} \quad$ Evaporative heat flux for droplets $\left(\mathrm{W} \mathrm{m}^{-2}\right)$

Normal vector towards freezing plate

Droplet Nusselt number

Prandtl number (0.715)

Significant wave period (s)

Swell-wave period (s)
$Q_{f}$

$Q_{r}$

$R^{2}$

$R_{\mathrm{cV}}^{2}$

$\operatorname{Re}$

$\operatorname{Re}_{d}$

$R_{i}$

$R_{S}$

$R_{w}$

$R_{H}$

$R_{R}$

$S_{b}$

$\mathrm{Sc}$

$S_{i}$

$S_{w}$
Heat flux released by freezing $\left(\mathrm{W} \mathrm{m}^{-2}\right)$

Radiative heat flux $\left(\mathrm{W} \mathrm{m}^{-2}\right)$

Coefficient of determination

Leave one out cross-validated $R^{2}$

Reynolds number

Droplet Reynolds number

Ice accretion flux $\left(\mathrm{kg} \mathrm{m}^{-2} \mathrm{~s}^{-1}\right)$

Visually estimated icing rate (code)

Spray flux $\left(\mathrm{kg} \mathrm{m}^{-2} \mathrm{~s}^{-1}\right)$

Relative humidity of air (fraction)

Accumulated water-equivalent precipitation $(\mathrm{mm})$

Salinity of brine (\%o)

Schmidt number (0.595)

Salinity of ice $(\%$ )

Salinity of sea water (\%o)

Incoming and reflected shortwave radiation $\left(\mathrm{W} \mathrm{m}^{-2}\right)$

Distance from freezing plate to gunwale $(\mathrm{m})$

Collection time of spray (s)

Air temperature at $850 \mathrm{hPa}\left({ }^{\circ} \mathrm{C}\right)$

Air temperature at ship level $\left({ }^{\circ} \mathrm{C}\right)$

Droplet temperature $\left({ }^{\circ} \mathrm{C}\right)$

Freezing temperature of sea water $\left({ }^{\circ} \mathrm{C}\right)$

Freezing temperature of brine $\left({ }^{\circ} \mathrm{C}\right)$

Sea-surface temperature $\left({ }^{\circ} \mathrm{C}\right)$

Time duration of spray cloud (s)

Time interval between a collision between a ship and waves (s)

Time difference between two $E_{S}$-observations (h)

Droplet velocity in coordinate system following ship

Relative velocity between droplets and wind

Absolute wind velocity

Absolute wind speed $\left(\mathrm{m} \mathrm{s}^{-1}\right)$

Relative speed between a ship and an oncoming wave $\left(\mathrm{m} \mathrm{s}^{-1}\right)$

Relative speed between a ship and wave groups $\left(\mathrm{m} \mathrm{s}^{-1}\right)$

Ship speed $\left(\mathrm{m} \mathrm{s}^{-1}\right)$

Visibility (code)

Wind velocity in coordinate system following ship

Relative speed between a ship and wind or

wind speed in coordinate system following ship $\left(\mathrm{m} \mathrm{s}^{-1}\right)$

Present weather (code)

$3 \mathrm{D}$ position vector in coordinate system following ship

Height above sea level (6.5-8.5 m)

Non-dimensional height above significant waves $\left(z^{*}=\frac{2 z}{H_{s}}-1\right)$

Angle between a ship and waves $\left(^{\circ}\right)$

Angle between a ship and wind $\left(^{\circ}\right)$

Tilt angle between the freezing plate and the horizontal $\left(85^{\circ}\right)$

Ratio of molecular weights of water and air (0.622)

Wave length (m)

Kinematic viscosity $\left(1.2 \times 10^{-5} \mathrm{~m}^{2} \mathrm{~s}^{-1}\right)$

Density of air $\left(1.3 \mathrm{~kg} \mathrm{~m}^{-3}\right)$

Density of ice $\left(890 \mathrm{~kg} \mathrm{~m}^{-3}\right)$

Density of sea water $\left(1028 \mathrm{~kg} \mathrm{~m}^{-3}\right)$

Stefan-Boltzmann constant $\left(5.67 \times 10^{-8} \mathrm{~W} \mathrm{~m}^{-2} \mathrm{~K}^{-4}\right)$

Droplet flight time (s)

Heading relative to wind in coordinate system following ship $\left(^{\circ}\right)$

** defined in wind-direction notation, i.e. azimuth of incoming direction. 


\section{Introduction}

Icing at sea can be a hazardous phenomenon which under the most dramatic circumstances may cause capsizing and the loss of lives. According to Stallabrass (1971), 40 Canadian fishermen died due to icing in the 1960s. Icing on ships can be divided into sea-spray icing, where wave-ship-collision-generated sea spray is reckoned as being the most important water source in dangerous icing events (Lozowski et al., 2000; Stallabrass, 1980, Zakrzewski, 1987), and into atmospheric icing where the water source is either fog, typically Arctic sea smoke, rain/drizzle or snow (Stallabrass, 1980). Icing can also be a result of a combination of both. From the 1960 s to the 1980 s there was extensive work in different countries trying to collect icing data for use in prediction of dangerous icing events. The data were used either to create statistical relationships between different environmental parameters and observed icing rates, e.g. Mertins (1968), or as input to wave-ship-collision-generated freezing sea-spray algorithms, e.g. Stallabrass (1980). Overland et al. (1986) on the other hand, use a combination of both. Brown and Roebber (1985) estimate that around 7000 questionnaire responses from the USA, Canada, Japan, the former Soviet Union, Sweden and Germany were used to collect icing data. Unfortunately little of these data have been made accessible for use.

An article review has revealed that 516 cases of ice accretion are available from the east coast of Canada and Alaska. For the east coast of Canada 3 papers include the following numbers of icing events: 39 cases in Stallabrass (1980), 45 cases in Zakrzewski et al. (1989) and 307 cases in Roebber and Mitten (1987). The Alaskan data are only published in Pease and Comiskey (1985) and 58 of them were selected and applied in Overland et al. (1986). In addition, Zakrzewski and Lozowski (1989) have collected 115 cases by translating Russian papers from the 1970s. Common to most of these data sets are that cases from different ship types are merged together. Due to variations in bow shape and ship size, spray characteristics and spray icing resulting from collisions between ship and wave, may be different among ship types. Zakrzewski et al. (1989) is the only data set where all 45 cases are from a single ship type. The data here are from a 19-day cruise by the stern trawler MT Zanberg, February 1988. The maximum number of observations from the same ship type from the remaining data sets, is 18, taken from the tugboat Justine Foss in the Pease and Comiskey (1985) data set. The other data sets contain a maximum of 10 cases from the same ship type. In Norwegian waters there is a sparse amount of icing data currently available. The only events found in the literature are the two recordings in Horjen (2013, 1990) from the whaling vessel Endre Dyrøy, and the 12 recordings of total ice accumulation merged inside Eide (1983), and used in Hansen (2012), from the stationary weather-ship AMI.

In order to calculate icing rates precisely, information from different atmospheric and oceanographic parameters, e.g. temperature, humidity, pressure, wind speed and direction, wave height, wave period, wave direction, water depth, sea-surface temperature, and sea-water salinity, is ideally required. In addition, information on ice-accumulation rate, ship type, ship speed and direction, and the location on the ship where the ice accumulation has taken place, is also necessary. Information of spray characteristics from the mentioned ship type, is advantageous. Unfortunately none of the mentioned data sets include measurements of these parameters. The wave period in Horjen (1990) is for instance both estimated from an empirical relationship between wave height and wave period from observations on Tromsøflaket, and by following the Pierson-Moscowich spectrum (Pierson and Moskowitz, 1964) based on a fully developed sea meaning that waves are in equilibrium with the local prevailing wind. In newer studies considering icing 
on ships and rigs in the Barents Sea (Hansen, 2012, Kulyakhtin and Tsarau, 2014; Teigen et al., 2015), parameters from Norwegian Reanalysis $10 \mathrm{~km}$ hindcast archive (NORA10) have been used as input for icing calculations. Although NORA10 data are in fairly good agreement with observed wind and wave data (Reistad et al., 2011), the quality of these data in icing situations is unknown. This is important since Reistad et al.(2011) underline that these data clearly underestimate higher wind speeds at the coast of Northern Norway and in some polar-low situations offshore.

In the current study, 37 cases with ice accumulation from the three similar Norwegian Coast Guard vessels: KV Andenes, KV Nordkapp and KV Senja (KV Nordkapp class, Figure 1) in the period 1983-1998, are published. Observed values of different meteorological and oceanographic parameters are published together with ice-accumulation data taken routinely on a fixed position on the ship. Weather information like visibility, cloud cover and precipitation type is also included. The observations are collected routinely, mainly every three hours, and observations from 1986-1995 are double-checked by comparison with the original handwritten data. All observations from the Norwegian Coast Guard are in general classified as restricted information, but the Norwegian Coast Guard allowed publication of these data for scientific purposes. Due to the substantial lack of icing data in Norwegian waters, the full data set is presented in this article. Furthermore, a new icing model: Marine-Icing model for the Norwegian COast Guard (MINCOG), is also presented. This model is a further development of the T1-model published in Samuelsen et al. (2015), and is mainly a combination of models presented by Lozowski et al. (2000), Makkonen (1987), Stallabrass (1980) and Zakrzewski (1987). Spray-flux formulations are derived from two different sources of spray data (Borisenkov et al., 1975, Horjen et al. (1986) and icing-rate calculations are made applying both formulations. Comparison is made between observed icing rates and calculated icing rates from MINCOG. Moreover, calculated icing rates by using alternative sources as input parameters, including NORA10 and statistical relationships between wind and waves, are also tested against the observed icing rate. All calculations are additionally verified based on a multi-categorically approach and by including 41 cases of no-accretion. The goal with MINCOG is to be able to routinely forecast icing rates in the three categories: light, moderate, and severe, at the position of the ship where ice accumulation has been recorded. This may be included as a part of operational weather forecasting where the input to the icing model is output from numerical prediction models from the ocean and the atmosphere.

\section{Icing model (MINCOG)}

\subsection{Wave-ship-interaction icing}

When ships interact with waves, most of the sea spray is generated during collision (Figure 2). Sea spray is also generated by strong winds ripping off small droplets from the crest of breaking waves, but the amount of water generated in this process is much smaller compared to the wave-ship-collision-generated sea spray, especially at the lower parts of the ship which are being considered in this study (Brown and Roebber, 1985, Horjen, 1990). Figure 2 illustrates that waves with a certain wave-phase speed $(c)$ and a wave height $\left(H_{s}\right)$ hit a ship with a certain speed $\left(V_{s}\right)$. The wave-phase speed $(c)$ is dependent of the water depth $\left(D_{p}\right)$ of the ocean and the wave period $\left(P_{s}\right)$. In reality, the ocean surface has series of waves with varying heights and periods. Nevertheless, the wave characteristics are here represented with the significant wave height and wave period with a certain mean direction $\left(D_{W}\right)$. The spray-cloud, which is generated 
during collision, has a salinity $\left(S_{w}\right)$ and sea-surface temperature $\left(T_{w}\right)$. Droplets in the spray-cloud are transported by the air with a wind velocity $(\vec{V})$, temperature $\left(T_{a}\right)$, relative humidity $\left(R_{H}\right)$, and pressure $(p)$, and settled onto different surfaces of the ship. During the flight-time of the droplets $(\tau)$, the droplets in the spray travel a distance $(s)$, and are cooled by the air to a new droplet temperature $\left(T_{d}\right)$. The amount of water brought by the wind creates a spray flux $\left(R_{w}\right)$, and the fraction of the spray flux that freezes $(n)$, is the icing flux $\left(R_{i}\right)$. The icing measurements in consideration are taken on the almost vertical plate $\left(\gamma=85^{\circ}\right)$ from the front deck to the cannon deck marked with a black line in Figure 2. The plate is approximately $2 \mathrm{~m}$ high $(z=6.5 \mathrm{~m}$ to $z=8.5 \mathrm{~m})$ and $4 \mathrm{~m}$ wide, when measured from the General arrangement of the ship (Figure 3,. Icing-rates $\left(\frac{d h}{d t}=\frac{R_{i}}{\rho_{i}}\right.$ ) are calculated as a mean value vertically, and at the mid point in the horizontal direction, i.e. along the y-axis in Figure 3. Other details about the ship can be found in Samuelsen et al. (2015). Incoming longwave radiation ( $\downarrow$ LW) from the atmosphere is absorbed on the plate. Incoming shortwave radiation $(\downarrow \mathrm{SW})$ is partly reflected depending of the surface Albedo $(A)$ of the ice. The plate radiates back ( $\uparrow$ LW) depending on its surface temperature $\left(T_{S}\right)$ and its emissivity.

\subsection{Spray-flux calculations}

\subsubsection{Available spray data}

In order to get information about the amount of water that is available for freezing, one has to calculate the spray flux $\left(R_{w}\right)$ at this location of the ship. Measurements of sea spray do not exist for the KV Nordkapp ships, and an exact formulation of the spray flux is difficult to obtain. In the literature there are three data sets for collected spray for three different ship types (Table 1). For the Borisenkov and the Horjen data there exist different formulations providing empirical relationships between meteorological, oceanographic and ship parameters, and expected liquid water content $\left(l_{\mathrm{wc}}\right)$ or spray flux $\left(R_{w}\right)$ for different heights above deck or sea level. Ryerson (1995) on the other hand provides 39 cases of $l_{\mathrm{wc}}$ taken from a fixed position $\mathrm{z}=10 \mathrm{~m}$ above sea level, at a distance $30 \mathrm{~m}$ from the bow, without giving a specific relationship between measured $l_{\mathrm{wc}}$ and the environmental parameters. Since the United States Coast Guard Cutter (USCGC) Midgett is a coast guard ship with approximately the same length as KV Nordkapp, simple feasible statistical relationships between the $l_{\mathrm{wc}}$-data and the other parameters observed in Ryerson (1995) were tested. However, there was no success in finding an acceptable expression for $l_{\mathrm{wc}}$ from these data based on linear regression modelling. For this reason, spray flux was calculated by applying expressions from the Borisenkov and Horjen data (Table 1).

\subsubsection{Spray flux derived from Borisenkov data}

When using the Borisenkov data one has to derive an expression for the spray flux that could be applicable for the KV Nordkapp ship type. Since spray is not delivered to the ship continuously, a time-averaged spray flux is used (Zakrzewski, 1987):

$$
\begin{aligned}
R_{w} & =E\left(\vec{V}_{d} \cdot \vec{n}_{1}\right) l_{\mathrm{wc}} N t_{\mathrm{dur}} \\
\vec{n}_{1} & =[\sin \gamma, 0, \cos \gamma]
\end{aligned}
$$


Table 1: Overview of spray data available in the literature. Different expressions for liquid water content and spray flux derived from the data are also included.

\begin{tabular}{|c|c|c|c|c|}
\hline Name & Ship & Length & $R_{w} / l_{\mathrm{wc}}$ expression & Reference \\
\hline Borisenkov data & MFV Narva & $39 \mathrm{~m}$ & $l_{\mathrm{wc}}=2.36 \times 10^{-5} \exp (-0.55 z)^{\dagger}$ & \begin{tabular}{|l|} 
Borisenkov et al. (1975) citet in \\
Zakrzewski and Lozowski (1989)
\end{tabular} \\
\hline \multirow{3}{*}{ Horjen data } & \multirow{3}{*}{ Endre Dyrøy } & \multirow{3}{*}{$63.6 \mathrm{~m}^{\dagger \dagger}$} & $\begin{array}{l}l_{\mathrm{wc}}=6.36 \times 10^{-5} H_{s} V_{r}^{2} \exp (-0.55 z) \\
l_{\mathrm{wc}}=1.3715 \times 10^{-5} H_{s}^{2.5} \exp (-0.55 z)\end{array}$ & \begin{tabular}{|l|l|} 
Zakrzewski (1987) \\
Roebber and Mitten (1987) \\
\end{tabular} \\
\hline & & & $\begin{array}{l}R_{w} \text { derived from event }-l_{\mathrm{wc}} \text { data } \\
\frac{R_{w}}{f}=A\left(z^{*}\right)^{B}, \phi_{r} \leq 50^{\circ} \dagger \dagger\end{array}$ & $\begin{array}{l}\text { Horjen et al. }(1986) \\
\text { Horjen (1990); Horjen and Carstens } 1989\end{array}$ \\
\hline & & & $\frac{R_{w}}{f}=\left\{\begin{array}{l}A\left(z^{*}\right)^{B}, \phi_{r}<20^{\circ} \\
\left(A z^{*}+B\right), \phi_{r} \in\langle 40,50\rangle^{\circ}\end{array}\right.$ & Horjen (2013) \\
\hline Ryerson data & USCGC Midgett & $115 \mathrm{~m}$ & Event $-l_{\mathrm{wc}}$ data & Ryerson (1995) \\
\hline
\end{tabular}

$\dagger$ Units $\mathrm{cm}^{3} \mathrm{~cm}^{-3}$ instead of $\mathrm{kg} \mathrm{m}^{-3}$

$\dagger$ The Norwegian Directorate of Fisheries (2016)

t† $f=\frac{\rho_{w} H_{s}^{2}}{P_{s}^{2} V^{2}}\left(c_{g}-V_{s} \cos (\alpha)\right)$, where $\alpha\left(\phi_{r}\right), c_{g}\left(P_{s}\right)$

$E$ is the collection or collision efficiency, $\vec{V}_{d}=\left[u_{d}, v_{d}, w_{d}\right]$ is the droplet speed at impact in a coordinate system following the ship, which is multiplied with the normal component $\left(\vec{n}_{1}\right)$ towards the plate tilting $85^{\circ}$ from the horizontal, $l_{\mathrm{wc}}$ is the liquid water content of the spray, and $N t_{\mathrm{dur}}$ is a time-averaging term, where $N$ is the spray frequency and $t_{\text {dur }}$ the spray-cloud duration time. Collection efficiency is assumed to be unity following Finstad (1995) for droplets above $500 \mu \mathrm{m}$. Borisenkov et al. (1975) obtained a relationship between observed $l_{\mathrm{wc}}$ from spray observations on MFV (medium-sized fishing vessel) Narva, and height above deck level. However, the original formulation does not include any relationship between the environmental conditions, ship motions and the observed water content (Table 1 ). Zakrzewski (1987) proposed a formulation for $l_{\mathrm{wc}}$ which includes the significant wave height and the relative speed $\left(V_{r}\right)$ between a ship and an oncoming wave:

$$
l_{\mathrm{wc}}=6.36 \times 10^{-5} H_{s} V_{r}^{2} \exp (-0.55(z-3.5)), z \geq 3.5
$$

The constant was slightly corrected due to a calculation error mentioned in Samuelsen et al. (2015), and $z$ is here adjusted to be taken from the sea level instead of deck level using the free-board height of $3.5 \mathrm{~m}$ on an MFV (Zakrzewski and Lozowski, 1989). The distance from the sea level of KV Nordkapp to the vertical mid point of the freezing plate is measured from the GA to be $7.5 \mathrm{~m}$ with a draught of $4.5 \mathrm{~m}$ (Figure $3 \mathrm{a}$ )). When applying Equation 2 in icing calculations, icing is calculated from $z=6.5 \mathrm{~m}$ to $8.5 \mathrm{~m}$, and the average icing rate from these levels is applied. Although MFV Narva is different from the longer and broader KV Nordkapp, the shape of the bow of a typical $39 \mathrm{~m}$ long MFV (Figure 3.1 in Zakrzewski and Lozowski (1989)) and the shape of the bow on KV Nordkapp (Figure 1 and (2) has similarities, at least when seen from the side. The plate in consideration is also a maximum of $19.7 \mathrm{~m}$ from the gunwale, hence not far in the back of the $105 \mathrm{~m}$ long ship, and this will probably make the use of the $l_{\mathrm{wc}}$ from the MFV Narva less unreasonable than otherwise. The relative speed between the wave phase and the ship is calculated from Aksyutin (1979); Comstock (1967):

$$
V_{r}=c-V_{s} \cos \alpha
$$


$\alpha$ is the difference between the wave direction $\left(D_{W}\right)$ and the mean ship direction $\left(D_{\text {ir }}\right)$. Generally the wave phase speed $(c)$ is a function of water depth $\left(D_{p}\right)$ and wave period $\left(P_{s}\right)$ (e.g. Equation 7.41 (Cohen and Kundu, 2004)):

$$
c=\frac{g}{2 \pi} P_{s} \tanh \frac{2 \pi D_{p}}{\lambda}, \quad \lambda=c P_{s}
$$

In all but one of the cases (start position of case $\mathrm{nr}$ 2), deep-water approximation was valid and $c$ could be calculated from the wave period alone. Thus, in order for the model to be applicable in areas where deep-water approximation is not valid, the general term for $c$ is applied instead of only the deep-water version; so far only the latter version has been applied in marine icing studies (Horjen, 2013; Lozowski et al., 2000). The inclusion of the general term of wave phase speed is important since dangerous icing events in shallower waters, like the fjords of Northern Norway, are reported from time to time (Jørgensen, 1981, Norwegian Broadcasting Corporation (NRK), 2010). The expression for the $l_{\mathrm{wc}}$ that is only dependent of the wave height suggested by Roebber and Mitten (1987), was not considered in the current study.

Although $l_{\mathrm{wc}}$ is taken from a smaller ship type than the KV Nordkapp, ship-spray frequency $(N)$ and spray-cloud duration time $\left(t_{\text {dur }}\right)$ may be adjusted to get a more realistic overall spray flux for this larger ship type. According to Aksyutin (1979), the time interval $\left(t_{\text {int }}\right)$ between successive ship-wave collisions is determined by the wave length $(\lambda)$ and $V_{r}$ :

$$
t_{\text {int }}=\frac{\lambda}{V_{r}}=\frac{c P_{s}}{V_{r}}
$$

Since spray is not produced continuously and not during every ship-wave encounter (Horjen, 1990, Zakrzewski et al. 1993, $N$ is less than $\frac{1}{t_{i n t}}$. Ryerson (2013) provides a relationship between ship speed and $N$ from the measurements on USCGC Midgett (Ryerson, 1995; Ryerson and Longo, 1992). However, Ryersons formula is not valid for ship speeds below $1.7 \mathrm{~m} \mathrm{~s}^{-1}$, and this was the situation in 7 of the 37 cases in the current study. Spray-frequency measurements from MFVs are also available from Panov (1971) cited in Zakrzewski and Lozowski (1989). An average value of these data shows that spray jet is generated for every second ship-wave encounter. Lozowski et al. (2000) state that the spray jet on average is generated with every fourth ship-wave encounter on a large whaling vessel, and this expression for spray frequency is applied in the model for the USGCG Midgett (Lozowski et al., 2000):

$$
N=\frac{1}{4 t_{\text {int }}}
$$

Applying this expression for spray frequency is probably more realistic for the large KV Nordkapp ships than the empirical derived expression for MFVs used in Samuelsen et al. (2015).

There are also several different formulations of the spray-cloud-duration time in the literature. Zakrzewski (1987) uses mean observed spray-cloud-duration time of an MFV. He proposes the following formula using Buckingham $\Pi$-theorem dimensional analysis, based on observations of $V_{s}, V$ and $D_{W}$ :

$$
t_{\text {dur }}=20.62 \frac{V_{r} H_{s}}{V^{2}}
$$


$V_{r}$ and $H_{s}$ were in Equation 7 derived by assuming a fetch of 200 nautical miles (nm). Lozowski et al. (2000) adjusted the constant $\left(\right.$ Const. $\left.=\frac{t_{\text {dur }} V^{2}}{H_{s} V_{r}}\right)$ from the Ryerson data providing the current expression for spray-cloud duration time:

$$
t_{\text {dur }}=\text { Const. } \frac{V_{r} H_{s}}{V^{2}}=10.0 \frac{V_{r} H_{s}}{V^{2}}
$$

Exactly how this Const.-adjustment is carried out, is not explained in Lozowski et al. (2000). When investigating the observations in Ryerson (1995), and extracting values for $V, V_{r}$ and $H_{s}{ }^{3}$, the mean value for Const. was calculated to be approximately 10 (Figure 4 a)). On the other hand, Figure 4 a) illustrates that there is no clear linear relationship between the observed $t_{\text {dur }}$ in Ryerson (1995) and calculated $t_{\text {dur }}$ from Equation 8 since the Const. is in fact not constant, rather a variable taking values from approximately 0 to 35 with a standard deviation of 7 . This indicates that Equation 8 is not valid for these data. Simple linear regression models adopting $\frac{V_{r} H_{s}}{V^{2}}$ as a predictor and $t_{\text {dur }}$ as a response variable, also reveal a p-value of 0.736 which is clearly not significant ( $5 \%$ level). A negative $R_{c v}^{2}$ and a $R^{2}$ of 0.004 confirm this weak linear relationship between $t_{\mathrm{dur}}$ and $\frac{V_{r} H_{S}}{V^{2}}$. When trying out other factors as input to a simple linear regression model, the best fit (i.e highest $R_{c v}^{2}$ ) was found when $\frac{V_{r} H_{s}}{V}$ was used as a predictor instead. Removing two possible outliers in $\mathrm{nr} 10$ and 19, the final regression model was:

$$
\begin{aligned}
& t_{\mathrm{dur}}=b_{0}+b_{1} \frac{V_{r} H_{s}}{V} \\
& b_{0}=0.1230 \mathrm{~s} \\
& b_{1}=0.7009 \mathrm{~s} \mathrm{~m}^{-1}
\end{aligned}
$$

The model was now more robust with a positive leave-one-out cross-validated determination coefficient $\left(R_{c v}^{2}\right)$ of 0.119 . However, there is still not a strong linear relationship between $t_{\text {dur }}$ and the new predictor, indicated by an $R^{2}$ of only 0.218 (Figure $4 \mathrm{~b}$ )). The overall p-value from F-statistics was 0.006 indicating a significant non-zero slope. The residuals of the model were also checked and no clear violations of normality, homoscedasticity, linearity and independence were found. When tested on the observed values from the 37 cases in the current study, the time duration from this formula was $t_{\mathrm{dur}} \in[0.20,6.90] \mathrm{s}, t_{\mathrm{dur}}^{-}=2.28 \mathrm{~s}$. This is comparable to the values of Ryerson $(1995): t_{\mathrm{dur}} \in[0.47,5.20] \mathrm{s}$, $t_{\mathrm{dur}}^{-}=2.69 \mathrm{~s}$. Since the factor $V^{2}$ is replaced by $V$, this formulation is also more robust at lower wind speeds; applying Equation 7 and 8 would greatly enhance the spray flux for low wind speeds, which is a problem when applying the model to areas with dominating swell waves and an imbalance between the wave and wind field.

The last component in the spray-flux term (Equation 1), is the component of the droplet speed normal to the freezing plate $\left(\vec{V}_{d} \cdot \vec{n}_{1}\right) . V_{d}$ is dependent of the droplet diameter $\left(d_{r}\right)$, and the spray cloud contains droplets of various sizes (Ryerson, 1995). Droplets with different sizes also have different droplet flight-times, and hence different droplet temperatures $\left(T_{d}\right)$. On the other hand, in order to reduce calculation-complexity, it was decided to use a constant droplet size $\left(d_{r}\right)$ of $2 \mathrm{~mm}(0.002 \mathrm{~m})$, following the typical droplet size of 1.5-2.0 $\mathrm{mm}$ used in other studies (Horjen,

\footnotetext{
${ }^{3} W_{r}, V_{s}, H_{\mathrm{ws}}, H_{\mathrm{sw}}$ and relative directions between bow, wind and waves were measured. Deep-water approximation was assumed and $P_{S}$ was calculated from $V$ and an assumed fetch of 100 nautical miles $(\mathrm{nm})$ (Zakrzewski 1987). $H_{s}$ was calculated from $H_{s}=\sqrt{H_{\mathrm{ws}}^{2}+H_{\mathrm{sw}}^{2}}, \alpha$ was taken as $180^{\circ}$ minus the mean value between relative wind-wave and swell-wave direction. In addition, observations which contain double splashes or lack wave information, are removed ( $\mathrm{nr} 10,12,13$, and 23)
} 
1990, Lozowski et al. 2000, Stallabrass, 1980). $\vec{V}_{d}$ was then calculated according to the equation of motion used in Lozowski et al. (2000), assuming that drag force and gravity are the only forces acting on the droplets during the flight:

$$
\begin{aligned}
& \frac{d \vec{V}_{d}}{d t}+\frac{3}{4} \frac{C_{d}}{D} \frac{\rho_{a}}{\rho_{w}}\left|\vec{V}_{\text {rel }}\right| \vec{V}_{\text {rel }}-\vec{g}^{*}=0 \\
& \text { where } \\
& \vec{V}_{\text {rel }}=\vec{V}_{d}-\vec{W}_{r}, \vec{g}^{*}=\vec{g}\left(1-\frac{\rho_{a}}{\rho_{w}}\right), \operatorname{Re}_{d}=\frac{d_{r}\left|\vec{V}_{\text {rel }}\right|}{v} \\
& C_{d}=\frac{24}{\operatorname{Re}_{d}}+\frac{4.73}{\operatorname{Re}_{d}^{0.37}}+6.24 \times 10^{-3} \operatorname{Re}_{d}^{0.38} \\
& \frac{\overrightarrow{d x}}{d t}=\vec{V}_{d}
\end{aligned}
$$

The equations are solved on component form in 3 dimensions where $\vec{x}=(x, y, z), \vec{V}_{d}=\left(u_{d}, v_{d}, w_{d}\right)$ and $\vec{W}_{r}=\left(W_{\mathrm{rx}}, W_{\mathrm{ry}}, 0\right)$ (assuming only horizontal winds).

A mathematical expression in polar coordinates for the distance $s$ from the mid point of the plate to the gunwale of the front part of the ship (Figure 3), was found to be:

$$
s=\frac{s_{0} 2 b^{2} \cos \beta+c}{\left(b^{2}-a^{2}\right) \cos 2 \beta+a^{2}+b^{2}}
$$

where

$$
\begin{aligned}
& s_{0}=13.18, a=32.88, b=6.605, \beta \in[90,180]^{\circ}, \\
& c=\sqrt{2} a b \sqrt{\left(b^{2}-a^{2}\right) \cos 2 \beta+a^{2}+b^{2}-2 s_{0}^{2} \sin ^{2} \beta}
\end{aligned}
$$

The expression is adjusted to fit $\beta$ to be the angle between the ship and the wind, and this is always between $90^{\circ}$ and $180^{\circ}$ when the ship is going against the wind. $s$ is the distance from the mid point of the plate to the gunwale, and $x$ and $y$ in Figure 3 b) can be found when converting from polar to Cartesian coordinates: $x=-s \cos \beta$, and $y= \pm s \sin \beta$. Since the wind is carrying the droplets to the freezing plate, it is in this context assumed that the splash created from the waves also origins from the same position as the wind at the gunwale of the ship. This expression was found to fit the shape of the gunwale in Figure 3 b) better than the assumed ellipse in Samuelsen et al. (2015). Notice that the minimum distance is around $\beta=95^{\circ}$. The droplets were further assumed to be initial at rest according to a coordinate system following the boat, i.e. equal to $V_{s}$ in an absolute coordinate system. Since the boat is moving, the droplets will not follow a straight line. To find the initial position of droplets that would hit the mid point of the plate from a given $\vec{W}_{r}$, a given $\beta_{0}>\beta$, and the corresponding $\left(x_{0}, y_{0}\right)$ along the gunwale that would yield a final $x=0$ and $y$ close to 0 , was found (backward calculation). Only for an initial $\beta$ close to $90^{\circ}$, low $V$ and high $V_{s}$, the droplets would not hit the mid point of the freezing plate with a fixed accuracy. For the 37 cases, all droplets hit the centre of the freezing plate \pm 0.1 $\mathrm{m}$ in the $\mathrm{y}$-direction. 


\subsubsection{Spray flux derived from Horjen data}

Alternatively to the spray flux calculated from the Borisenkov data, a time-averaged spray-flux expression derived from spray observations from Endre Dyrøy was also applied. Although the length of Endre Dyrøy is about $60 \%$ of the 105 $\mathrm{m}$ long KV Nordkapp, the spray data were collected in the front of the ship, only $17.2 \mathrm{~m}$ from the vessel bow (Horjen. 2013). This is not far from the $19.7 \mathrm{~m}$ from the bow to the freezing plate on KV Nordkapp (Figure 3). Horjen provides two expressions for the time-averaged spray flux: one in a paper from 1989 (Horjen and Carstens, 1989) applied in his doctoral thesis (Horjen, 1990), and one in a newer paper from 2013 (Horjen, 2013). Horjen and Carstens (1989) claim that wave height is the only oceanographic parameter observed, and use the Pierson-Moscowich spectrum for waveperiod calculation (Pierson and Moskowitz, 1964). However, the table with the raw data in Horjen et al. (1986), lists only wind speed, ship speed and relative heading. In Horjen (2013) both wave height and wave period are determined from the wind speed, but now by applying a different energy spectrum. Since the actual wave height and wave period could be quite different than these parameters calculated from energy spectra, the observed wave height and wave period from Endre Dyrøy were retrieved from the Norwegian Meteorological Climate database for observations nearby in time (Norwegian Meteorological Institute, 2016). The observed wave height and wave period were in the mean 1.6 $\mathrm{m}$ and $3.1 \mathrm{~s}$ lower than the values obtained using the relationship in Horjen (2013) (Equation 34 and 35). More details about how the data were extracted and the final data set obtained, are presented in Appendix B A reproduction of the data and data fit in Horjen (2013) and a new data fit obtained with the observed values of $H_{S}$ and $P_{s}$, can be seen in Figure 5. Following Horjen (2013), values for the three different heading angles in a coordinate system following the boat $\left(\phi_{r}\right)$ are plotted separately. Notice that $\phi_{r}$ is defined different from $\beta$ (like in Horjen (2013)), e.g. $\phi_{r}=0^{\circ}$ is heading against the wind. The new data set suggests a power law fit for all three $\phi_{r}$, and the lower $H_{s}$ results in higher $z^{*}$ values. When converting the power-law fit to a logarithmic scale, $R^{2}$-values were calculated. The $R^{2}$-values in Figure 5 a) were the same as reported by Horjen (2013) except for $\phi_{r}=0$ where the $R^{2}$ actually was higher. When comparing the new data fit in Figure 5 b) with Figure 5 a), it is clear that the determination coefficient for $\phi_{r}=45^{\circ}$ and $15^{\circ}$ is better in the new model. However, for $\phi_{r}=0^{\circ}$ the new $R^{2}$ is lower, but the combined $R^{2}$ for $\phi_{r}=15^{\circ}$ and $0^{\circ}$ is the same between the two models $\left(R^{2}=0.66\right)$. The determination coefficient for $\phi_{r}=45^{\circ}$ alone is enhanced from 0.35 to 0.84 when applying the observed values of $H_{S}$ and $P_{S}$ instead of the statistical relationship between wind and waves. The overall new model fit was also very good with $R^{2}=0.81$ and $R_{c v}^{2}=0.72$. The new updated spray-flux formulation can be formulated as follows:

$$
\begin{aligned}
R_{w} & =f_{1} A\left(z^{*}\right)^{B}, f_{1}=\frac{g \rho_{w} H_{s}^{2}}{\lambda V^{2}} V_{\mathrm{gr}} \\
V_{\mathrm{gr}} & =c_{g}-V_{s} \cos \alpha, c_{g}=\frac{c}{2}\left(1+\frac{\frac{4 \pi D_{p}}{\lambda}}{\sinh \frac{4 \pi D_{p}}{\lambda}}\right) \\
A & =2.6739 \times 10^{-5}, B=-1.3563, \text { for } \phi_{r}<7.5^{\circ} \\
A & =2.2008 \times 10^{-4}, B=-2.4082, \text { for } \phi_{r} \in[7.5,30\rangle^{\circ} \\
A & =1.7899 \times 10^{-3}, B=-2.9612, \text { for } \phi_{r} \geq 30^{\circ}
\end{aligned}
$$




$$
\begin{aligned}
R_{w} & =f_{1} A\left(z^{*}\right)^{B} \cos \phi_{r} \\
\phi_{r} & =\arccos \left(\frac{V}{W r} \cos (180-\beta)+\frac{V_{s}}{W_{r}}\right)
\end{aligned}
$$

The relative speed between the wind and the ship is given as:

$$
\begin{aligned}
& W_{r}=\sqrt{V^{2}+V_{s}^{2}-2 V_{s} V \cos \beta} \\
& \text { where } \\
& W_{r x}=V \cos \beta-V_{s} \\
& W_{r y}= \pm V \sin \beta
\end{aligned}
$$

$\beta$ is the difference between the wind direction $\left(D_{D}\right)$ and the mean ship direction $\left(D_{\mathrm{ir}}\right)$ and is between $90^{\circ}$ and $180^{\circ}$ since it is assumed that the ship is going against the wind. The direction angles were in all circumstances calculated using wind-direction notation. Both $W_{r}$ in Equation 17 and $V_{r}$ in Equation 3 are calculated in the start and end position of the trip using the mean value of the ship speed and the mean direction of the ship as input to the calculations.

\subsection{Heat balance}

\subsubsection{Main equation}

From the average spray flux $\left(R_{w}\right)$ on the freezing plate, icing rate can be calculated by taking into account the different heat fluxes involved in the icing process on the freezing surface. The heat equation when only taking into account the most important fluxes (Lozowski et al. 2000), is given as:

$$
Q_{f}=Q_{c}+Q_{e}+Q_{d}+Q_{r}
$$

The left hand side of Equation 18, $Q_{f}$, is the energy that is released by freezing:

$$
Q_{f}=L_{\mathrm{fs}} R_{i}=\left(1-k^{*}\right) L_{f} R_{i}
$$


The expression for the latent heat of freezing for saline ice $\left(L_{\mathrm{fs}}\right)$ is taken from Makkonen (1987) and the interfacial distribution coefficient $\left(k^{*}\right)$, i.e. the fraction of entrapped brine inside the ice, is set to 0.3 (mean value of Horjen (2013) and Makkonen (2010, 1987)). The heat fluxes on the right hand side of Equation 18, are given by:

$$
\begin{aligned}
Q_{c} & =h_{a}\left(T_{s}-T_{a}\right) \\
Q_{e} & =h_{e}\left(e_{s}\left(T_{s}\right)-R_{H} e_{s}\left(T_{a}\right)\right) \\
Q_{d} & =R_{w} c_{w}\left(T_{s}-T_{\mathrm{sp}}\right) \\
Q_{r} & =\uparrow \mathrm{LW}-\downarrow \mathrm{LW}+\uparrow \mathrm{SW}-\downarrow \mathrm{SW} \\
& =\sigma\left(T_{S}+273.15\right)^{4}-\downarrow \mathrm{LW}-(1-A) \downarrow \mathrm{SW}
\end{aligned}
$$

$Q_{c}$ is the convective or sensible cooling from the air to the freezing brine, $Q_{e}$ is the evaporative cooling of the brine, $Q_{d}$ is a term representing the heating or cooling from the sea water to the brine, and $Q_{r}$ is the incoming and outgoing longwave (LW) and shortwave (SW) radiative heat fluxes. Notice that these $Q$-fluxes are defined positive when they contribute to cooling, and negative if they contribute to heating.

A more thorough list of fluxes involved in the freezing process, could be found in Jessup (1985). According to Kulyakhtin et al. (2016) conduction through the ice $\left(Q_{\text {cond }}\right)$ should be taken into account during periodic spray-icing events. However, for simplicity, the model build on the assumption of continuous spray icing using a time-averaged spray flux, which does not separate heat-flux calculation in periods with and without spraying. For continuous spray icing, conduction through the ice could be neglected. Thus, conduction through the structure could also be important in the beginning of the freezing process. However, in all 37 icing cases, ice thickness is above $1 \mathrm{~cm}$ initially, and only in 5 of the cases, the initial thickness is below $2 \mathrm{~cm}$ (Table C.2-C.4). Conduction through the structure is therefore neglected.

\subsubsection{Heat-transfer coefficients}

The heat transfer between the freezing plate and the atmosphere, is governed by turbulent eddies. Turbulence in the atmosphere is mainly generated by mechanical shear and buoyancy (Stull, 1988). By assuming neutral static stability, buoyancy is set to 0 . In reality the turbulence is greater since the atmosphere is statically unstable under the cold-air outbreaks considered in the current study. However, neutral conditions is a reasonable assumption some distance above the layers closest to the ocean. The mechanical shear production is governed by the surface roughness of the ocean, the ship and the plate itself. Since there is no exact information of the turbulence intensity in the area of the freezing plate, heat transfer must be parametrized. It is then assumed that there is a steady horizontal flow which is uniform with height at a distance away from the plate, and which represents the flow that is governing the heat transfer between the atmosphere and the brine. This relative wind velocity has two components: a cross-flow component normal to the plate, and an along-flow component tangential to the plate. For the along-flow component, the average value of the 
heat-transfer coefficient for a flat plate parallel to a turbulent flow is applied (Stallabrass, 1980):

$$
h_{\mathrm{ay}}=\frac{k_{a} \mathrm{Nu}_{y}}{D}=0.036 \operatorname{Pr}^{\frac{1}{3}} \frac{k_{a}}{v^{0.8}} \frac{\left|W_{\mathrm{ry}}\right|^{0.8}}{D^{0.2}}=4.85\left|W_{\mathrm{ry}}\right|^{0.8}
$$

where

$$
\mathrm{Nu}_{y}=0.036 \operatorname{Pr}^{\frac{1}{3}} \operatorname{Re}_{y}^{0.8}, \operatorname{Re}_{y}=\frac{\left|W_{\mathrm{ry}}\right| D}{v}
$$

For the cross-flow component, the average value for the heat-transfer coefficient for a turbulent flow over grassland normal to a 10x10x10 $\mathrm{m}^{3}$ cube derived from computation fluid dynamics (CFD) simulations (Defraeye et al. 2010) is used, adjusted to be applied for a $4 \mathrm{~m}$ wide plate:

$$
h_{\mathrm{ax}}=7.78 \frac{\left|W_{\mathrm{rx}}\right|^{0.82}}{D^{0.18}}=6.06\left|W_{\mathrm{rx}}\right|^{0.82}
$$

The overall heat-transfer coefficient $\left(h_{a}\right)$ is then calculated by weighting the $\mathrm{x}$ and $\mathrm{y}$-component of the relative wind speed:

$$
h_{a}=w_{1} h_{\mathrm{ax}}+w_{2} h_{\mathrm{ay}}
$$

where

$$
w_{1}=\frac{\left|W_{\mathrm{rx}}\right|}{\left|W_{\mathrm{rx}}\right|+\left|W_{\mathrm{ry}}\right|}, w_{2}=\frac{\left|W_{\mathrm{ry}}\right|}{\left|W_{\mathrm{rx}}\right|+\left|W_{\mathrm{ry}}\right|}
$$

The evaporative heat-transfer coefficient $\left(h_{e}\right)$ is then calculated from the parameterization of the $h_{a}$ :

$$
h_{e}=\left(\frac{\operatorname{Pr}}{\mathrm{Sc}}\right)^{0.63} \frac{\varepsilon L_{v}}{c_{p} p} h_{a}=\frac{1738.6}{p} h_{a}
$$

Furthermore, the saturation vapour pressure $\left(e_{s}\right)$ was taken from Bolton (1980). The effect of salinity on $e_{s}$ (Makkonen, 1987) was neglected since its maximum effect was not more than a $6.3 \%$ reduction of $e_{s}$ for the maximum salinities considered in the current study (Section 2.3.5 and Equation 32).

\subsubsection{Radiative heat flux $\left(Q_{r}\right)$}

The radiative heat flux consists of incoming longwave radiation $(\downarrow L W)$, outgoing longwave radiation $(\uparrow L W)$, and incoming and reflected shortwave radiation $((1-A) \downarrow S W)$. It is assumed that the emissivity of the freezing brine in the longwave range is approximately 1 . In other marine icing studies, e.g. Lozowski et al. (2000), it is also assumed that everything radiates back with an atmospheric temperature with a total emissivity of 1 . According to Herrero and Polo (2012) the emissivity of the atmosphere could be as low as 0.4 with an average value of 0.7 . Humidity and temperature variations with height, cloud amount and elevation would effect the emissivity (Konzelmann et al., 1994). In order to take into account a more realistic emissivity of the atmosphere including the vertical change of temperature and humidity and clouds, the incoming longwave radiation was derived from the NORA10 hincast archive. It was then assumed that the radiation towards the tilting plate in consideration, was the same as the one received from the 
atmosphere towards a horizontal plate. Some radiation from the sea surface and the components of the ship, were therefore neglected. The shortwave radiation was also derived from NORA10. Only in a few cases (in April) the effect was considerable, but in these situations there were cloudy skies in the model, so the radiation was mainly considered diffuse. Since diffuse radiation is approximately isotropic, a view factor of $V_{f}=\frac{1+\cos \gamma}{2}$ was multiplied to the incoming shortwave radiative component on a horizontal surface to get the amount of diffuse radiation toward the tilting plate (Pandey and Katiyar, 2009). As albedo $(A)$ for the freezing brine, an albedo for sea ice equal to 0.56 was applied (Curry and Webster, 1999). Details about of how the data were derived can be seen in Appendix A.4

\subsubsection{Spray temperature $\left(T_{s p}\right)$}

As a first approximation one can assume that the spray temperature is equal to the droplet temperature $\left(T_{d}\right)$ that individual droplets would reach when they are cooled down (or heated) by the atmosphere during their flight. The droplet-cooling equation when taking into account convective and evaporative heat fluxes is then (Stallabrass, 1980):

$$
\begin{aligned}
& \frac{d T_{d}}{d t}=\frac{6}{\rho_{w} c_{w} d_{r}}\left(Q_{\mathrm{cd}}+Q_{\mathrm{ed}}\right) \\
& \quad \text { where } \\
& \begin{aligned}
Q_{\mathrm{cd}} & =h_{\mathrm{ad}}\left(T_{a}-T_{d}\right)=\frac{\mathrm{Nu}_{d} k_{a}}{d_{r}}\left(T_{a}-T_{d}\right) \\
& =\frac{0.37 \operatorname{Re}_{d}^{0.6} k_{a}}{d_{r}}\left(T_{a}-T_{d}\right) \\
Q_{\mathrm{ed}} & =h_{\mathrm{ed}}\left(R_{H} e_{s}\left(T_{a}\right)-e_{s}\left(T_{d}\right)\right) \\
& =h_{\mathrm{ad}} \varepsilon \frac{L_{v}}{c_{p} p}\left(R_{H} e_{s}\left(T_{a}\right)-e_{s}\left(T_{d}\right)\right)
\end{aligned}
\end{aligned}
$$

Notice that the heat fluxes are here defined as negative if they contribute to cooling in order to reduce the droplet temperature, and positive otherwise. Even if the droplet albedo was set to 0, the contribution both from the longwave and the shortwave radiation was calculated to change the droplet temperature by a maximum of $0.06^{\circ} \mathrm{C}$. The radiative heat flux was therefore neglected in the droplet-cooling equation. Furthermore, this equation was solved together numerically with the system of equation in the trajectory model (Equation 10 and 11) when using both formulations for spray flux, to find an estimate for the droplet flight time for individual droplets in the air. Since the equations are solved together, there is no need to approximate $\vec{V}_{\text {rel }}$ to the terminal velocity of the droplet to find $\operatorname{Re}_{d}$, like in $\operatorname{Stallabrass}$ (1980). The trajectory model further assumes a potential for a spray jet of infinite height, and that the droplets are taken from a random position vertically. This was not considered as a problem, since the final spray flux at a certain position of the ship is controlled by either Equation 2 or Equation 13 where the amount of water drops off exponentially with height or with a power-law decay. Finally, since droplets do not necessarily fly as individual droplets, but together with other droplets in a dense spray cloud, the droplets are probably not cooled down as much as suggested by Equation 28. Following an argumentation from Horjen (2015) that half of the spray cloud is not undergoing any cooling at all, the final spray temperature $\left(T_{\mathrm{sp}}\right)$ is approximated as an average value of the initial droplet temperature and the droplet 
temperature calculated through Equation 28

$$
T_{\mathrm{sp}}=\frac{1}{2}\left(T_{w}+T_{d}\right)
$$

\subsubsection{Brine temperature $\left(T_{s}\right)$}

The surface temperature of the brine $\left(T_{s}\right)$ is assumed to be at its freezing temperature. Since salt is expelled during freezing, this temperature is controlled by the brine salinity $\left(S_{b}\right)$ which is higher than the salinity of the incoming sea water $\left(S_{w}\right)$. Makkonen (1987) provides a relationship between $S_{b}, S_{w}, k^{*}$, and the freezing fraction $n$, i.e. the fraction between the freezing flux $R_{i}$ and the spray flux $R_{w}$ (Equation 32). $T_{s}$ is then calculated from $S_{b}$ taken from Forest et al. (2005) (Equation 33). Since $k^{*}$ is set equal to $0.3, S_{b}$ is maximum $117 \%$ o $(n=1)$ when $S_{w}$ is maximum $35.1 \%$, and the second expression in Equation 33 is not applied for salinities considered in this study.

$$
\begin{aligned}
S_{b} & =\frac{S_{w}}{1-n\left(1-k^{*}\right)} \\
T_{s} & =-54.1126\left(\frac{S_{b}}{1000-S_{b}}\right), \text { for } S_{b} \in[0,124.7] \% o \\
T_{s} & =\frac{63.0-1.063 S_{b}}{0.01031 \times\left(1000-S_{b}\right)}, \text { for } S_{b} \in\langle 124.7,230.8] \% o
\end{aligned}
$$

Equation 18 is then solved iteratively controlling $n$ between 0 and 1, applying a combination of bisection, secant and inverse quadratic interpolation methods (Brent, 1973; Forsythe et al., 1977) and searching for an optimized initial guess. If $n>1$ and $n<0, n$ is hence set to 1 and 0 . The icing rate $\frac{d h}{d t}$ is found from $\frac{d h}{d t}=\frac{R_{i}}{\rho_{i}}=\frac{n R_{w}}{\rho_{i}}$. A constant density of the ice $\left(\rho_{i}=890 \mathrm{~kg} / \mathrm{m}^{3}\right)$ is applied, and when multiplying with $3.6 \times 10^{5}$ one get the units in $\mathrm{cm} \mathrm{h}^{-1}$.

Figure 6 provides an overview in what manner different input parameters contribute to the final calculation of icing rate. Blue arrows mark processes only involved when using Equation 1 derived from the Borisenkov data, and grey arrows mark processes only involved when the spray flux is calculated through Equation 15 derived from the Horjen data. Black arrows illustrate processes involved when applying both spray-flux formulations. From $D_{p}, S_{w}$ and $R_{w}$ dotted arrows are used to illustrate a more indirect or weaker effect. $D_{p}$ contributes for instance to the calculation of $c$ and $c_{g}$, but in deep water this effect is negligible. $S_{w}$ is only used to determine the initial $T_{s}$ in the calculation of the heat fluxes, but during the calculation process $T_{s}$ is determined by $S_{b}$. The final $R_{i}$ and hence the $\frac{d h}{d t}$ is determined by the heat fluxes, but at the same time $R_{i}$ cannot exceed $R_{w}(n \leq 1)$, thus $R_{w}$ sets an upper limit for $R_{i}$.

\section{Data selection}

\subsection{Selection of icing cases}

Observations from the Norwegian coast guard are stored in an electronic climate database at MET Norway. Icing was included in the WMO (World Meteorological Organization) ship-synop code as an optional parameter in the 1960s (World Meteorological Organization, 1962), but no registrations of icing are found from any ships in the Norwegian climate database until the late 1970s or early 1980s. After the observation procedure on the coast guard ships was automatized during the beginning of the twenty-first century, most of the registration of icing stopped. The 3 ships 
among the KV Nordkapp-class have for this reason only observations of icing from 1983 to 2000. Ice accretion is reported in the ship-synop code as group $6 I_{s} E_{s} E_{S} R_{s} . I_{s}$ is the cause of icing in a code format from 1 to $5\left(I_{s}: 1=\right.$ Icing from ocean spray, 2 = Icing from fog, 3 = Icing from spray and fog, $4=$ Icing from freezing rain, 5 = Icing from spray and freezing rain (World Meteorological Organization, 2015). $E_{S}$ (registered with 2 digits $E_{S} E_{S}$ ) is the total ice-accumulation thickness in whole centimetres measured with a ruler. $R_{S}$ is a visual estimation of ice-accretion rate in a code format from 0 to $4\left(R_{s}: 0=\right.$ Ice not building up, $1=$ Ice building up slowly, $2=$ Ice building up rapidly, $3=$ Ice melting or breaking up slowly, 4 = Ice melting or breaking up rapidly (World Meteorological Organization, 2015)). From the ship-synop code it is not clear at which location on the ship ice thickness is measured. On the other hand, according to World Meteorological Organization (1962), the initial intention of this group was to give "an indication of the thickness of ice when icing on ships' superstructures is being encountered". For the KV Nordkapp-class the icing measurements were conducted at a fixed rectangular plate between the front deck and the cannon deck (L. Kjøren 2014, Retired officer Norwegian coast guard, pers. comm., 4 November).

When selecting cases with icing, all observations that had registered some information on either $I_{s}, E_{s}$ or $R_{s}$ were at first sorted out. This revealed about 1151 cases from $69^{\circ} \mathrm{N}$ to $81^{\circ} \mathrm{N}$ and from $5^{\circ} \mathrm{W}$ to $37^{\circ} \mathrm{E}$ from 1983 to 2000 (Figure 7 b)). For comparison all observations from the ships in the same square during the same years were also plotted (Figure 7 a)). There were now two options to find information about ice-accretion rate: either use the information about iceaccretion rate taken visually $\left(R_{S}=1\right.$ or 2$)$, or selecting cases where an increase in ice-accretion thickness $\left(E_{S}\right)$ had occurred for two consecutive observations nearby in time. While the $R_{s}$ parameter could provide valuable information about icing or no-icing (Figure $7 \mathrm{c}$ )), the parameter was considered to be too crude for icing-rate-verification purposes. It gives information only about slow or fast accretion; it does not state anything or providing any standard about what should be considered slow or fast accretion. For this reason the latter method of applying information from the change in the $E_{s}$-parameter was preferred. In addition, only those observations were included which had reported sea spray as the primary cause of icing, either as the only water source or together with fog or freezing rain $\left(I_{S}=1,3\right.$ or 5$)$ at least in the end of the trip. The final observed icing rate was calculated from the difference between the $E_{S}$-observations divided by the time difference between the two observations (Figure $7 \mathrm{~d}$ )). Observations of the atmosphere and oceanwave parameters from the same position in time and space as the icing data were applied as input into MINCOG and icing rate was calculated and compared with this observed icing rate. Ship speed and direction were then calculated from the position data. In addition, a correction method was applied to the visual estimated wave parameters. More details about the data selection and quality control of the data collected, can be seen in Appendix A

\subsection{Model-input sources}

Icing rate was also calculated by applying only NORA10 data as input. Combinations of the observations, NORA10data, and statistical methods between wind, wave height, and wave period were also tested as input to the calculations. However, for the incoming longwave and shortwave radiation ( $\downarrow$ LW and $\downarrow$ SW) NORA10 data were applied as the only data source. In addition, salinity $\left(S_{w}\right)$ and bathymetry data $\left(D_{p}\right)$ from an ocean-model hindcast archive (SVIM) (Lien et al. 2013) were applied in all the methods. A total of 6 different sources and combination of sources for model 
input were tested for the two different spray-flux formulations applied. The abbreviations and content of these data sets are as follows (radiation, salinity and bathymetry not included):

- OBS: Observed values of all atmosphere and ocean-wave parameters.

- N10: Reanalysis data (NORA10) of all atmosphere and ocean-wave parameters.

- HYBRID1: Observed values of all atmospheric parameters. Reanalysis data for the wave parameters including mean direction, wave period and wave height.

- HYBRID2: Same as HYBRID1 except that the wave height is taken from observations.

- ZAKR: Following the methodology of Zakrzewski (1987) where $H_{S}$ and $P_{S}$ are calculated from the observed wind speed and a constant fetch using a polynomial fit based on data listed in a handbook of oceanographic tables (Bialek, 1966). 100 nautical miles (nm) was the smallest possible fetch in the equation and this value is applied here. The remaining parameters are taken from OBS.

- HORJEN: Following the methodology of Horjen (2013) where wave height is calculated from the relationship between measured wind and wave height from the drilling rig Treasure Scout at the Oseberg field in North Sea (Equation 34) (Jørgensen, 1985). Wave period is calculated from the relationship between wave height and wave period from observations at Tromsøflaket (Equation 35). Thus $H_{s}$ is calculated from the observed wind, and $P_{s}$ is calculated from the derived $H_{s}$. The remaining parameters are taken from OBS.

$$
\begin{aligned}
H_{s} & =0.752 V^{0.723} \\
P_{s} & =6.161 H_{s}^{0.252}
\end{aligned}
$$

The reason for testing a combination of the observed values and NORA10 wave data (HYBRID1), was the uncertainty in data quality of the visual estimated wave parameters. At the same time NORA10 underestimated strong winds (Section 4.1 and Table 2), and the wave height might therefore be underestimated in some cases. For this reason an additional data set was tested where the wave height was visually estimated and the wave period and direction collected from NORA10 (HYBRID2). Finally, two empirically-based statistical relationships between wind and wave parameters (ZAKR and HORJEN) were tested, since these kind of procedures are widely used in other marine-icing models (Horjen, 2013; Kulyakhtin and Tsarau, 2014, Zakrzewski, 1987). For the two spray flux formulations tested the following terms are applied:

Application of Equation 1 is referred to as the "Borisenkov spray-flux formulation", and application of Equation 15 the "Horjen spray-flux formulation". Notice that the methodology of applying Equation 34 and 35 is referred to as HORJEN, which is not the same as applying the Horjen-spray flux formulation.

\subsection{Verification methodology}

The icing rates from MINCOG were calculated as instantaneous values, and converted to the unit $\mathrm{cm} \mathrm{h}^{-1}$. The mean of the instantaneous values in both the start and end position of the trip, was calculated and compared to the observed 
ice accumulation divided by the time difference in hours. Another solution could be to calculate the icing rate from the mean of the input parameters. This calculation procedure was also tested, whereas the results did not yield any major differences with the aforementioned method. Actually the overall performance was slightly worse. The final calculated icing rates were verified against the observed icing rates examining the mean error (BIAS), mean absolute error (MAE), and the determination coefficient $\left(R^{2}\right)$. Next, the calculated icing rates were divided into four categories: none, light, moderate, severe, since these categories are used when predicting icing in operational weather forecasting (Norwegian Meteorological Institute, 2015, Nacional Oceanic and Atmospheric Administration, 2015). In the literature there exists several different definitions of what should be reckoned light, moderate and severe, with reference to the ice-accretion rate on the superstructure of a ship. Mertins (1968) uses a definition that defines icing rate per 24 hours, while Overland et al. (1986) use icing rate per hour. The hourly-rate definition was closer to the observed time difference, and this definition with the limits from Overland et al. (1986) was therefore selected for this study. The none category was chosen to be below $0.05 \mathrm{~cm} \mathrm{~h}^{-1}$ to avoid taking into account very small positive icing rates into the light category. After dividing the icing rates into categories, contingency tables where created by adding 41 icing cases with noaccumulation ${ }^{4}$ The Heidke Skill Score (HSS), Pierce Skill Score (PSS), and Gandin-Murphy Skill Score (GMSS) were calculated for both the 37 ice-accretion cases alone and for all 78 cases together. These scores were chosen since they are applicable to multi-categorical contingency tables (more than $2 \times 2$ ) and they are equitable, i.e. they penalize hits that could be achieved by chance. In addition, the overall percentage of hits, Proportion or Percent Correct (PC), was calculated. The definition of the scores and the naming are e.g. found in Wilks (2011) (Chapter 8). Nevertheless, a short explanation of the scores is given below:

If $p\left(y_{i}, o_{j}\right)$ is the proportion of elements relative to the total number of events in each entry of the contingency table, the PC can be formulated as the sum of the proportion of elements relative to the total number of events along the diagonal of the contingency table: $\sum_{i=1}^{I} p\left(y_{i}, o_{i}\right) . I$ is the total number of categories $(I=4$ in a $4 \times 4$ contingency table), and $y_{i}$ and $o_{j}$ represent the number of predicted and observed values in each category. However, since PC can be heavily influenced by the most common category, one needs to look at the accuracy of the forecast in predicting the right category, relative to that of random chance. A general definition of such a skill score is (Wilks, 2011): $\frac{A-A_{\text {ref }}}{A_{\text {perf }}-A_{\text {ref }}}$, where $A_{\text {perf }}$ is a perfect forecast and $A_{r e f}$ is a reference forecast that may be chosen as a random forecast. The perfect forecast has a skill score of 1 . A random reference forecast could be the joint distribution of observations and forecasts: $A_{\text {ref }}=\sum_{i=1}^{I} p\left(y_{i}\right) p\left(o_{i}\right)$. The Heidke Skill Score is defined in this manner according to the Proportion Correct $(A=\mathrm{PC})$ :

$$
\mathrm{HSS}=\frac{\sum_{i=1}^{I} p\left(y_{i}, o_{i}\right)-\sum_{i=1}^{I} p\left(y_{i}\right) p\left(o_{i}\right)}{1-\sum_{i=1}^{I} p\left(y_{i}\right) p\left(o_{i}\right)}
$$

The Peirce Skill Score (PSS) is similar to the HSS, but uses a reference forecast relative to PC in the denominator that is equal to the sample climatology $\left(\sum_{j=1}^{I} p\left(o_{j}\right)^{2}\right)$. The joint distribution of observations and forecasts are still applied as a reference forecast in the nominator. Both HSS and PSS reward hits for rare events more than hits for the more common

\footnotetext{
${ }^{4}$ Same selection method as the 37 cases was applied, but now only cases with no increase in $E_{S}$ between two consecutive observations with 3 hours in between, and only cases with $I_{S}=1$ were selected
} 
categories, but in the PSS such hits are rewarded more. While PC, HSS and PSS are characterised by rewarding hits on the diagonal, the Gandin-Murphy Skill Score (GMSS) take all entries in the contingency table into account by creating a scoring weight $s_{i j}$ for each element in the matrix based on sample climatology: $\sum_{i=1}^{I} \sum_{i=j}^{I} p\left(y_{i}, o_{j}\right) s_{i j}$. Misses for the less common categories close to the diagonal are weighted higher than misses for the more common categories, or misses further away from the diagonal. Hits for rare events are also rewarded more than in the HSS and PSS. In general GMSS is therefore not as conservative as HSS and PSS. Since there was only 1 single severe icing event (nr 15), an analysis where the categories moderate and severe were merged together, was also applied. This seemed reasonable since the GMSS was very sensitive to the performance of this single rare event when severe was treated as a category on its own.

\section{Results and analyses}

\subsection{Summary of atmosphere and ocean data during icing}

A summary of different atmospheric and oceanographic parameters during icing is described in Table 2 These variables are also applied as input parameters in the icing calculations in the 6 methods described in Section 3.2 . During the icing events the temperature had an average value of $-10^{\circ} \mathrm{C}$, the wind speed was around $16 \mathrm{~m} \mathrm{~s}^{-1}$, accompanied by an ocean surface of $+2^{\circ} \mathrm{C}$, and $4 \mathrm{~m}$ high waves. In all cases the wind direction was between north-west and east (Figure 12 a)). When comparing the environmental parameters in the reanalysis data (NORA10) with the observed values, there is a clear underestimation of the wind speed $(V)$ with a mean error (BIAS) of $-4.2 \mathrm{~m} \mathrm{~s}^{-1}$. The maximum $V$ is actually $8.7 \mathrm{~m} \mathrm{~s}^{-1}$ lower than the maximum $V$ observed, and these values are from two separate events. It is also seen from Table 2 that the temperature $\left(T_{a}\right)$ in NORA10 is on average $2.2^{\circ} \mathrm{C}$ higher than that observed if applying NORA10 data instead of observations into the icing model (Equation 20, This would potentially lead to a weaker convective heat flux $\left(Q_{c}\right)$. However, the overall difference in $Q_{c}$ between the methods applied, is also dependent on the difference in the brine-surface temperature $\left(T_{s}\right)$, which is ultimately dependent on the calculated freezing fraction $(n)$. Relative humidity $\left(R_{H}\right)$ in the reanalysis data (NORA10) is on average $0.18(18 \%)$ lower than the observed $R_{H}$. The combined effect of a smaller relative humidity and a higher temperature, is a reduction in the vapour pressure from $2.36 \mathrm{hPa}$, when applying the mean values from observations, to $2.25 \mathrm{hPa}$, when applying the mean values from reanalysis data. This would potentially lead to a stronger evaporative heat flux $\left(Q_{e}\right)$ in N10 compared to using observations. However, since evaporative heat-transfer cofficient $\left(h_{e}\right)$ is dependent on wind speed, which is lower in NORA10, the saturation vapour pressure of the brine $\left(e_{s}\left(T_{S}\right)\right)$ will determine if the $Q_{e}$ actually is higher or lower in N10 compared to the other methods. The other parameters have only minor mean errors below 1 unit $\left(\mathrm{m}, \mathrm{s}\right.$ or $\left.\mathrm{m} \mathrm{s}^{-1}\right)$ relative to the observations. It is for instance interesting to notice that wave height in NORA10 is only $0.7 \mathrm{~m}$ lower than the observed wave height, although the average difference in wind speed was $4.2 \mathrm{~m} \mathrm{~s}^{-1}$.

When determining the wave parameters from a statistical relationship between wind and waves (ZAKR and HORJEN), both wave height $\left(H_{S}\right)$ and period $\left(P_{S}\right)$ are in the mean overestimated during these 37 icing events. The largest errors are apparent in HORJEN where the empirical relationships between wind and waves from the North Sea and Tromsøflaket provide too high waves and too long periods compared to the observations and reanalysis data from the 
Table 2: Mean, median, maximum and minimum values of the environmental variables used as input to the icing caluclations. Both a summary of the observed values from the ship and the NORA10 hindcast values from the same geographical position is provided along with a calculation of the mean error (BIAS) and mean absolute error (MAE) for the differenet NORA10 parameters. Salnity $\left(S_{w}\right)$ and water depth $\left(D_{p}\right)$ are collected from SVIM (Lien et al. 2013). Incoming longwave $(\downarrow L W)$ and shortwave $(\downarrow S W)$ radiation are calculated values derived from net-radiation data in NORA10 Appendix A.4). In addition, wave height $\left(H_{s}\right)$, wave period $\left(P_{s}\right)$, wave phase speed $(c)$, and wave group speed $\left(c_{g}\right)$ from ZAKR and HORJEN, and the correponding BIAS and MAE, are presented. For NORA10 the BIAS and MAE are relative to observations. For ZAKR and HORJEN the left column of BIAS and MAE is relative to observations, and the right column relative to NORA10.

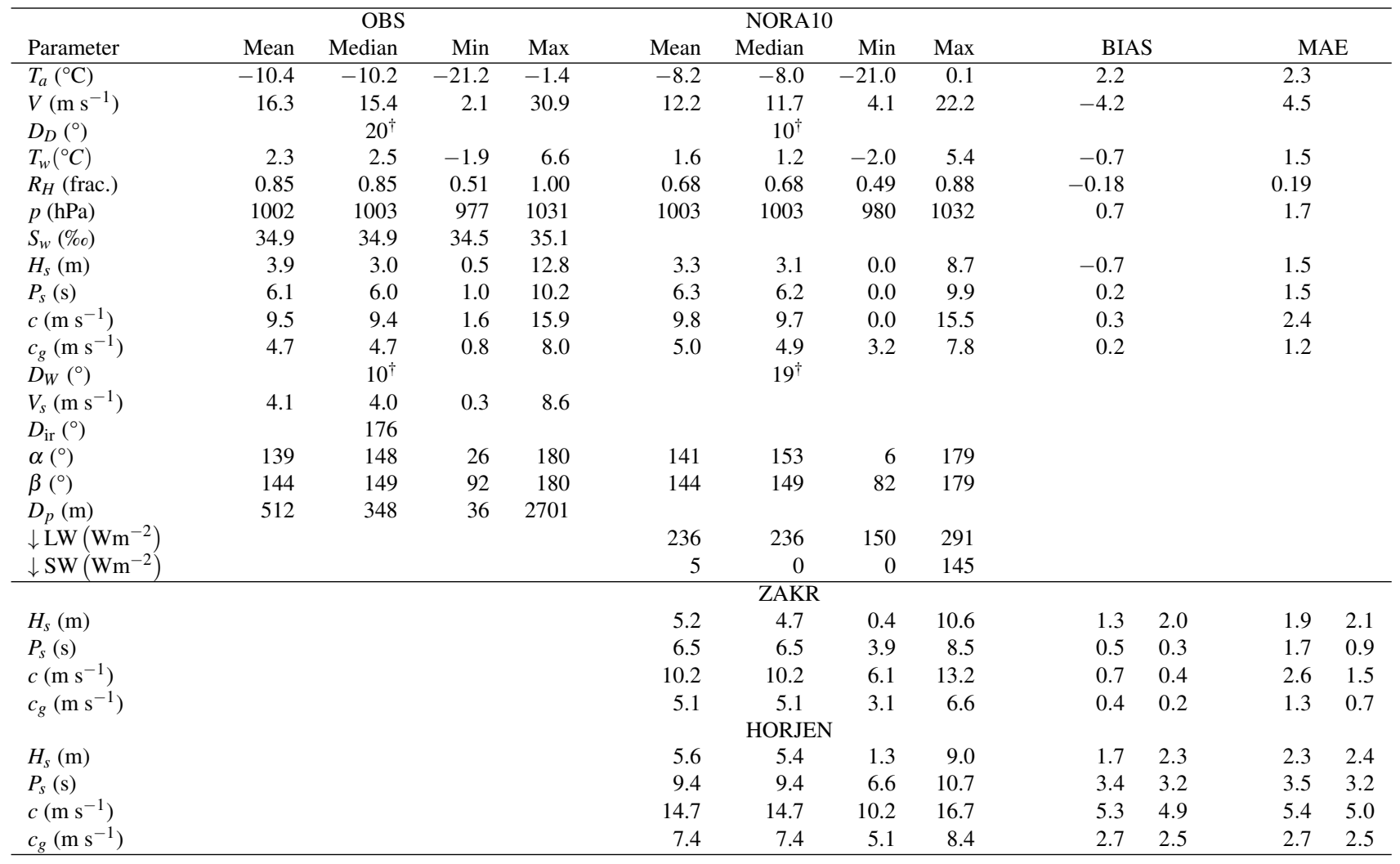

$\dagger$ Calculated by sorting the data from west to east according to the wind and wave roses presented in Figure 12

icing-event areas further north. Since some of these events were located close to or inside the marginal ice zone, and the prevailing winds and waves were from the north, it is especially important to take fetch into account. However, applying the fully developed sea assumption with a constant fetch of 100 nautical miles (ZAKR), was also providing too high waves and too long periods. The errors in the wave period are directly transferred to an error in wave-phase speed $(c)$ and wave-group speed $\left(c_{g}\right)$ since most of the cases were in deep waters. These parameters are again applied in the calculation of the relative speeds and spray fluxes for both spray-flux formulations applied. Since there are uncertainties related to the visual estimated wave parameters, BIAS and MAE relative to NORA10 are also presented for ZAKR and HORJEN in Table2. When comparing the BIAS and MAE for ZAKR and HORJEN relative to observations and relative to NORA10 it is apparent that the errors for wave periods are the lowest, and for wave height the highest relative to NORA10. Nevertheless, it is from this comparison alone not possible to conclude which of these two sources of wave parameters that are preferable.

By looking at the overall weather situation provided by NORA10 and observations, it is apparent that there were some common patterns. In most of the icing events there was a low-pressure system situated in or nearby the Barents Sea with a cold-air outbreak present on the west or north-west side of the low (not shown). The icing occurred in these cold air masses with a temperature in $850 \mathrm{hPa}\left(T_{850}\right)$ of around $-12^{\circ} \mathrm{C}$ or lower according to NORA10. This cold-air 
outbreak led to convection and wintry showers in many of the events, which is also seen from the observed present weather code where 15 of the 37 cases reported snow showers in either the start or end position. In 14 cases frontal snow was reported, but the snow may as well come from organized convective precipitation. In all but two of the cases, accumulated precipitation from NORA10 indicated that there was precipitation during the hours of the trip in either the start or end position (Table C.2 C.3 and C.47. Some cases also have fog in the present weather code. Since the sea-surface is much warmer than the overlying air in these cold-air-outbreak situations, the reported fog has to be of the type evaporation fog or sea smoke. Finally, 1 case (nr 32) indicates non-freezing rain (present weather synop code, $W_{W}=60$ ). This latter report seems unrealistic since $T_{a}$ was $-4.9^{\circ} \mathrm{C}$ at the same time, and it is possible that it should have been reported as freezing rain $\left(W_{W}=66\right)$. The complete data set of these 37 icing events is presented in Appendix C]

\subsection{Icing-rate calculations}

A comparison between the observed and predicted icing rates with the use of the 6 different methods of input parameters for the two different spray-flux formulations (Equation 1 and 15 is illustrated in Figure 8 . The mean absolute error (MAE) is the highest and the determination coefficient $\left(R^{2}\right)$ is the lowest when applying the Borisenkov spray-flux formulation and a statistical relationship between wind and waves (ZAKR and HORJEN). However, when applying the Horjen spray-flux formulation, the MAE and $R^{2}$, when using the ZAKR and HORJEN methods, are more comparable to using reanalysis data alone (N10) or using wave parameters from reanalysis data and the other parameters from observations (HYBRID1). Combining observations with reanalysis data of only wave period and direction (HYBRID2) is apparently the most preferable method since it has the overall highest or second highest determination coefficient for each of the spray-flux formulations applied, and the lowest and second lowest mean absolute error. Somewhat surprisingly, using only observations as input (OBS) provides a higher mean absolute error and lower determination coefficient than by using reanalysis data alone (N10) for the Borisenkov spray flux. On the contrary, for the Horjen spray flux OBS has both a lower MAE and higher $R^{2}$ than N10. Uncertainties associated with the visual estimated wave period and direction are a possible reason for this discrepancy. For the Borisenkov spray-flux formulation (Equation 1 and 2) the spray flux is dependent on $V_{r}^{2}$ where both the wave period and direction are important parameters (Equation 37. In addition, spray frequency (Equation 6) and spray-cloud duration time (Equation 9) are in deep waters dependent on wave period $\left(P_{s}\right)$ alone or together with the relative speed between a ship and waves $\left(V_{r}\right)$. Yet, the Horjen spray-flux formulation (Equation 13 and 15 is dependent on the relative speed between a ship and the group of waves $\left(V_{\mathrm{gr}}\right)$ and is dependent on $P_{s}^{-2}$ in deep waters. Problems related to uncertainties in wave period and direction are therefore of less importance in the Horjen compared to the Borisenkov spray-flux formulation.

The mean error (BIAS) provides information about the average under prediction or overestimation in the models. When applying the Horjen spray-flux formulation there is in general an average reduction in the calculated icing rates. This is further underlined by the reduction in BIAS of icing rates seen when comparing results between the two sprayflux formulations for all methods applied: For the first four there is a difference of a BIAS of around $\pm 0.1 \mathrm{~cm} \mathrm{~h}^{-1}$ for the Borisenkov spray-flux formulation, to an average underestimation of 0.2 to $0.4 \mathrm{~cm} \mathrm{~h}^{-1}$ when applying the Horjen spray-flux formulation. For ZAKR and HORJEN there is a difference in BIAS with an overestimation of $0.2 \mathrm{~cm} \mathrm{~h}^{-1}$ 
when applying the Borisenkov spray flux, to a BIAS of only 0.0 to $0.1 \mathrm{~cm} \mathrm{~h}^{-1}$ for the Horjen spray-flux formulation. As a consequence, it appears to be fewer predictions of moderate and severe icing when applying the Horjen spray-flux formulation. This is especially apparent when using renanalysis data alone (N10) where there are only 3 predictions of moderate icing, whereas a total of 9 cases were observed as moderate or severe. In addition, it is apparent that these predictions are all in the lower part of the moderate range (Figure 8).

To get an indication of the size of the error in the mean absolute errors presented, one can construct a dummy forecast by taking the mean of the absolute difference of the observed icing rates in a consecutive order (Hyndman and Koehler, 2006). If one divide the mean absolute error with this mean absolute error of this dummy forecast one can calculate a so-called mean absolute scaled error (MASE). The MASE indicates that the model has prediction quality when the score is below 1 . The dummy forecast from the 37 cases provides a mean absolute error of $0.51 \mathrm{~cm} \mathrm{~h}^{-1}$, which means that the MASE in HYBRID1, ZAKR and HORJEN is around or above 1; N10 and HYBRID2 are the only methods with a MASE below 1 for both spray-flux formulations.

Moreover, Figure 8 visualises the outcome of the prediction of the 37 cases when dividing the results into the icingrate categories: none, light, moderate and severe. The advantage of looking into these categories instead of the exact values in $\mathrm{cm} \mathrm{h}^{-1}$, is the opportunity of allowing for some variation in the prediction outcome inside each category. This is especially advantageous when the goal of the model is to see its ability of predicting the more dangerous moderate or severe icing events. The disadvantage is the large sensitivity to the boundary definition applied between the categories. From the categorical forecasting outcome one can create $4 \times 4$ contingency table for each of the $12(6 \times 2)$ methods for the input parameters. Applying multi-categorical skill scores is a condense way of summarising the results from these contingency tables (Figure 9p. Interestingly Figure 8 and Figure 9 have clear similarities. From both figures it is apparent that N10, HYBRID1 and HYBRID2 have the best scores for the Borisenkov spray-flux formulation, and ZAKR and HORJEN are providing the worst scores. However, for the Horjen spray-flux formulation the rankings are different for the different skill scores (Figure 9). While OBS has the highest proportion correct (PC), the HYBRID2 has the highest value among the other skill scores. The reason for this is that PC in contrast to the other scores, does not reward correct predictions for the more common categories differently than the more rare moderate or severe events; respectively 4 of the 15 hits in the HYBRID2 and 2 of the 19 hits in the OBS were in the moderate category. The Gandin-Murphy skill score (GMSS) also rewards hits for off-diagonal elements by creating a scoring matrix for each element in the contingency table. However, since none of the models are hitting the single rare severe event observed, this score is overall low for all the 12 methods. For this reason the result of the GMSS when merging the moderate and severe category together is also shown in Figure 9 . Now, the HYBRID2 has the highest GMSS for both spray-flux formulations. The difficulties that the N10-method has, when applying the Horjen spray-flux formulation in forecasting the moderate and severe events, are further underlined by the relatively large negative values of the Heidke, Peirce and Gandin-Murphy Skill Score.

\subsection{Including no-icing events}

Since the 37 icing events do not include cases without icing, the scores in the previous section do not give any information about the models ability to forecast no-icing events (N). 41 non-events with negative temperatures where $E_{S}$ was 
constant between two consecutive observations in time, were therefore included. Furthermore, the overall skill scores for the new contingency tables with all the 78 icing and no-icing events were calculated (Figure 10). Although all the models have more misses than hits of these non-events, the N10 and HYBRID2 have the most non-hits (18 of 41) for the Horjen spray-flux formulation, and the HYBRID2 (11 of 41) when applying the Borisenkov formulation. There is in particular a high amount of low-icing predictions when in fact there was no overall difference in ice-accretion thickness $\left(E_{S}\right)$ between these two observations 3 hours apart in time. A summary in general of Figure 10 is that ZAKR and HORJEN have the lowest scores regardless of spray-flux formulation; partly because they have more predictions of moderate and severe icing for the non-events. The only exception is the Gandin-Murphy Skill Scores of ZAKR and HORJEN for the Horjen spray-flux formulation where these scores are comparable to the Gandin-Murphy Skill Scores of N10 and HYBRID1. The HYBRID2 has the highest GMSS for both spray-flux formulation applied, but for the other scores the results are more comparable to the results of OBS, N10 and HYBRID1.

In order to test the sensitivity of changing the boundary between the icing categories, skill scores were also calculated when the boundary between light and moderate icing was reduced from $0.70 \mathrm{~cm} \mathrm{~h}^{-1}$ to $0.65 \mathrm{~cm} \mathrm{~h}^{-1}$ (2 decimal accuracy) for all 78 events including both icing and no icing. In Overland et al. (1986) the boundary of $0.7 \mathrm{~cm} \mathrm{~h}^{-1}$ is only given with 1 decimal accuracy, and there are 9 cases with an icing rate of $\frac{2}{3} \mathrm{~cm} \mathrm{~h}^{-1}$. In 8 of these cases $2 \mathrm{~cm}$ ice accumulated in 3 hours, and in 1 case $6 \mathrm{~cm}$ accumulated in 9 hours. By changing the boundary to $0.65 \mathrm{~cm} \mathrm{~h}^{-1}$ there were 9 more events that were defined as moderate instead of light. This resulted only in some minor changes for the skill scores applying both spray-flux formulations. Nevertheless, applying the Borisenkov spray-flux formulation together with the HYBRID2-method for input parameters into MINCOG, was the method with the highest equitable skill scores (not shown). Additionally, skill scores were calculated by applying a more strict selection method for the 37 cases, where only cases coming from pure spray icing (Icing cause synop code, $I_{S}=1$ ) were kept both in the start and the end position of the trip. The equitable skill scores for the remaining 65 cases including 24 icing and 41 noicing events were now in general higher. Similarly to the latter test, HYBRID2 together with the Borisenkov spray-flux formulation had the highest or second highest equitable skill scores (not shown).

\subsection{Spray fluxes, heat fluxes and other important parameters in icing calculations}

In order to understand some of the icing-rate results, one needs to investigate differences in spray fluxes, heat fluxes, and other important parameters applied in MINCOG. When plotting observed, reanalysis, or wind-derived wave heights, against the two spray-flux formulations applied (Equation 1 and 15), it is apparent that the Horjen spray flux has extreme values for wave heights above 5 to $7 \mathrm{~m}$ (Figure 11). For comparison the original spray-flux formulation from Horjen (2013) is also illustrated in Figure 11. Although the spray fluxes based on the Horjen (2013)-formulation are lower than the flux values of the updated Horjen formulation for low waves, this expression results in even higher values when the significant wave height exceed a certain threshold. The reason for the amplification of the flux values for the Horjen formulations is that the non-dimensional height above significant waves $\left(z^{*}=\frac{2 z}{H_{s}}-1\right)$ drops below 1 when $H_{s}$ exceeds $z$. Since the height of the plate in consideration is $z=6.5 \mathrm{~m}$ to $8.5 \mathrm{~m}$ above the sea level, there is an amplification of the spray flux due to the power-law expression having exponents in the range of -1.4 to -3.4 when $H_{s}$ approaches $z$. However, for the Horjen (2013)-formulation there is less amplification for $\phi_{r} \geq 30^{\circ}$ due to the linear 
Table 3: Mean values ${ }^{\dagger}$ of important parameters from the icing calculations. The following parameters are presented: Icing rate $\left(\frac{d h}{d t}, \mathrm{~cm}^{-1}\right)$, Heat fluxes $\left(Q_{i}, \mathrm{~W} \mathrm{~m}^{-2}\right)$, Heat-transfer coefficient $\left(h_{a}, \mathrm{~W} \mathrm{~m}^{-2}{ }^{\circ} \mathrm{C}^{-1}\right)$, Droplet flight time $(\tau, \mathrm{s})$, Spray temperature $\left(T_{\mathrm{sp}},{ }^{\circ} \mathrm{C}\right)$, Brine surface temperature $\left(T_{s},{ }^{\circ} \mathrm{C}\right)$, Spray-cloud duration time $\left(t_{\mathrm{dur}}, \mathrm{s}\right)$, Time between spray events $\left(N^{-1}, \mathrm{~s}\right)$, Icing flux $\left(R_{i}, \mathrm{~g} \mathrm{~m}^{-2} \mathrm{~s}^{-1}\right)$, Spray flux $\left(R_{w}, \mathrm{~g} \mathrm{~m}^{-2} \mathrm{~s}^{-1}\right), \mathrm{Ice} \mathrm{salinity}$ $\left(S_{i}, \%\right.$ o $)$, and Freezing fraction $(n)$. Both observed and calculated icing rates are presented. For the other parameters the calculated values from all 6 methods using the two different spray flux equations (Equation 1 and 15 are presented. The observed $R_{i}$ is derived from the observed $\frac{d h}{d t}$.

\begin{tabular}{|c|c|c|c|c|c|c|c|c|c|c|c|c|c|c|c|c|}
\hline Data set & $\frac{d h}{d t}$ & $Q_{f}$ & $Q_{c}$ & $Q_{e}$ & $Q_{d}$ & $Q_{r}$ & $h_{a}$ & $\tau$ & $T_{\mathrm{sp}}$ & $T_{s}$ & $t_{\mathrm{dur}}$ & $N^{-1}$ & $R_{i}$ & $R_{w}$ & $S_{i}$ & $n$ \\
\hline$\frac{d h}{d t}$ obs. & 0.65 & & & & & & & & & & & & 1.6 & & & \\
\hline \multicolumn{17}{|c|}{$R_{w}$ from Borisenkov data } \\
\hline N10 & 0.62 & 356 & 223 & 192 & -40 & 61 & 44.4 & 1.3 & -0.3 & -3.6 & 2.5 & 20.8 & 1.5 & 5.2 & 18.4 & 0.4 \\
\hline HYBRID1 & 0.79 & 456 & 360 & 200 & -50 & 59 & 52.6 & 1.1 & 0.2 & -4.0 & 2.0 & 20.8 & 2.0 & 4.3 & 20.4 & 0.5 \\
\hline HYBRID2 & 0.71 & 411 & 363 & 202 & -53 & 59 & 52.6 & 1.1 & 0.2 & -4.0 & 2.3 & 20.8 & 1.8 & 6.8 & 20.3 & 0.5 \\
\hline HORJEN & 0.88 & 508 & 437 & 245 & -158 & 67 & 52.6 & 1.1 & 0.2 & -2.3 & 4.5 & 32.7 & 2.2 & 19.1 & 12.4 & 0.2 \\
\hline \multicolumn{17}{|c|}{$R_{w}$ from Horjen data } \\
\hline OBS & 0.38 & 216 & 280 & 156 & -29 & 53 & 52.6 & 1.1 & 0.2 & -5.4 & 2.3 & 19.8 & 0.9 & 1.8 & 26.9 & 0.7 \\
\hline N10 & 0.28 & 161 & 129 & 138 & -19 & 53 & 44.4 & 1.3 & -0.3 & -5.5 & 2.5 & 20.8 & 0.7 & 0.9 & 27.1 & 0.7 \\
\hline HYBRID1 & 0.23 & 133 & 244 & 134 & -13 & 51 & 52.6 & 1.1 & 0.2 & -5.9 & 2.0 & 20.8 & 0.6 & 0.6 & 29.0 & 0.8 \\
\hline
\end{tabular}

$\dagger$ Median values of $Q_{d}$ and $R_{w}$

fit for these angles. In contrast the Borisenkov spray-flux formulation is less sensitive to wave height. In general the Borisenkov formulation has higher flux values for the lower wave heights, and lower flux values for the higher waves compared to the other two formulations. For low waves the Horjen formulations have several orders of magnitude lower spray flux than the observed icing flux $\left(R_{i}\right)$. The observed icing-flux can be regarded as the minimum expected spray flux when sea spray is the only water source (Figure 11].

Table 3 provides an overview of the mean values of the heat fluxes and some other important parameters from the icing calculations for all the 12 methods applied. Since the Horjen spray-flux formulation does not adequately take into account the very high waves observed in some of these icing events, the median values for the spray flux $\left(R_{w}\right)$ and the heat flux from the impinging sea water $\left(Q_{d}\right)$ are applied. The largest difference between the methods applying the Borisenkov spray-flux formulation and those applying the Horjen spray-flux formulation as a whole is that the latter compared to the former have more cases with lower spray fluxes, yielding an overall larger freezing fraction $(n)$, higher ice salinity $\left(S_{i}\right)$, and lower surface temperature of the freezing brine $\left(T_{S}\right)$. A lower $T_{S}$ results in a lower mean convective $\left(Q_{c}\right)$ and mean evaporative heat flux $\left(Q_{e}\right)$, since the other parameters in $Q_{c}$ and $Q_{e}$ remain constant for the same method of input parameters. This is in part compensated by a somewhat less negative $Q_{d}$. However, the overall freezing flux $\left(Q_{f}\right)$ is the largest when applying the Borisenkov spray flux. The radiative heat flux $\left(Q_{r}\right)$ is in the mean more than 30 $\mathrm{W} \mathrm{m}{ }^{-2}$ higher than the average value of $Q_{r}$ achieved if applying $\downarrow L W=\sigma\left(T_{a}+273.15\right)^{4}$ and if not taking shortwave radiation into account. The applied $Q_{r}$ with mean values of $50-60 \mathrm{~W} \mathrm{~m}^{-2}$ includes shortwave radiation which reduces the total heat loss in some of the cases. $Q_{r}$ was in the mean $17 \%$ of the value of $Q_{c}$. This is more than the $9 \%$ estimate reported by Kulyakhtin and Tsarau (2014) taking only longwave radiation into account. The maximum value of $Q_{r}$ was calculated to be $132 \mathrm{~W} \mathrm{~m}^{-2}$ for case $\mathrm{nr} 23$ when applying the OBS-method for the Borisenkov spray-flux formulation. For this single January event, the difference was $122 \mathrm{~W} \mathrm{~m}^{-2}$ between the $Q_{r}$ derived from NORA10 data and the value calculated from the normal $Q_{r}$-formulation applied in other marine-icing studies (e.g. Lozowski et al. (2000)). 
Furthermore, the mean values of about 2 to $3 \mathrm{~s}$ calculated from the new formulation for the spray-cloud duration time $\left(t_{\text {dur }}\right)$, applied in the Borisenkov spray-flux formulation, is comparable to those in Ryerson (1995) and the constant value of $2.9 \mathrm{~s}$ applied in Horjen (1990). The time interval between each spray jet $\left(N^{-1}\right)$ is around $20 \mathrm{~s}$ for the first 5 methods, and above $30 \mathrm{~s}$ when applying the Horjen formulation for wave heights and periods (Equation 34 and 35 ). The trajectory model in MINCOG resulted in a mean droplet cooling time $(\tau)$ of $1.3 \mathrm{~s}$ in N10, and the same value of 1.1 $\mathrm{s}$ in the other methods, as N10 is the only method using lower wind speeds. This results in lower spray temperatures $\left(T_{\mathrm{sp}}\right)$ in N10 and is also a contributing factor together with a lower $R_{w}$ to the least or second least negative $Q_{d}$ when applying only reanalysis data (N10) as input. The calculated ice salinities $\left(S_{i}\right)$ have values between $13.4 \%$ and $27.4 \%$ o which are comparable to the ice-salinities from experiments on USCGC Midgett in the range [7.0,25.4]\%o provided in Ryerson and Gow (2000). ZAKR and HORJEN have the highest median values for $R_{w}$ for both spray flux-formulations, which is in general a result of the overestimation of $H_{s}$ when applying a statistical relationship between wind and waves (Table 2).

When comparing the convective heat fluxes $\left(Q_{c}\right)$ for the same spray-flux formulation, N10 has the lowest values. This is partly due to the lower heat-transfer coefficient $\left(h_{a}\right)$ based on the weaker and in some cases unrealistic low wind speeds in the reanalysis data compared to observations (Table 2); but partly also due to the higher average air temperature. For instance would a reduction in the convective heat flux of about $2^{\circ} \mathrm{C}$, result in an overall reduction of $100 \mathrm{~W} \mathrm{~m}^{-2}$ with a heat-transfer coefficient of about $50 \mathrm{~W} \mathrm{~m}^{-2}{ }^{\circ} \mathrm{C}^{-1}$. The average values of the $Q_{c}$ were around 100$400 \mathrm{~W} \mathrm{~m}^{-2}$ for the different methods applied (Table 3). For the evaporative heat fluxes $\left(Q_{e}\right)$, the $\mathrm{N} 10$ has the lowest values when applying the Borisenkov spray-flux formulation compared to the other methods for the same spray-flux formulation. When applying the Horjen spray-flux formulation, HYBRID1 has lower $Q_{e}$-values than $\mathrm{N} 10$ has. This is a result of the lower water-vapour pressure and the higher brine surface temperature in N10 compared to HYBRID1, which is compensating for the lower evaporative heat-transfer coefficient calculated when applying N10 compared to HYBRID1.

\section{Discussion}

This study suggests an optimal combination of data and spray-flux formulation that can be applied for short-term icing predictions. In other marine-icing studies, reanalysis data from the NORA10 data set have been applied without discussing or testing the quality of these data during real icing events (Kulyakhtin and Tsarau, 2014; Teigen et al. 2015). Statistical relationship between wind and waves are also widely used without examining the applicability of these formulas in areas where icing occurs (Horjen, 2013, Zakrzewski, 1987). High-quality wave observations are difficult to obtain; the wave parameters from the KV Nordkapp ships are visually estimated. After performing a detailed inspection of the data and applying a correction method to the visually estimated wave parameters, it is believed that the quality has improved Appendix A. In order to test the applicability of the observations, the reanalysis data, and the statistical relationships between wind and waves, icing calculations were performed for different sets of input parameters in a newly proposed icing model called MINCOG. The intention of the model was to predict icing rates in categories for this fixed position on the ship for application in operational weather forecasting. 
Within the model there are uncertainties, in particular connected to a correct spray-flux estimate for this specific class of ships. From the available spray data in the literature, two spray-flux formulations were derived and applied in icing calculations. In particular the Borisenkov spray-flux formulation were adjusted to be more suitable for the ship type in consideration; e.g. droplet velocity was estimated by applying a trajectory model calculating the actual distance from the gunwale to the freezing plate on KV Nordkapp. Additionally, spray frequencies and spray-cloud duration times suitable for large ships were applied. When calculating the spray from both formulations, the calculations were done for the same height above sea level as the recordings of the ice-accumulation thickness on KV Nordkapp. Although there might be differences regarding bow shape and dimensions between KV Nordkapp and the ships providing spray data, the horizontal position of the spray data collected in Borisenkov et al. (1975) and Horjen et al. (1986), was presumably not far from the position of the freezing plate of KV Nordkapp. The fact that the mean absolute errors are as high as $0.4-0.5 \mathrm{~cm} \mathrm{~h}^{-1}$ in the prediction of the icing rates for the best method of input parameters, may suggest that one ideally should apply spray data from the KV Nordkapp ship type. Nevertheless, the errors may also be related to other uncertainties in the model. For instance atmospheric sources may contribute to an increased water flux relative to the flux of pure sea spray. On the contrary, the sensitivity test of applying pure spray-icing cases only $\left(I_{S}=1\right)$ indicated little changes in the icing-rate verification scores compared to that of all cases. However, in most of these events fog or snow was still observed in the present weather code, and the contribution from these water sources to the water flux may have been larger than that indicated by the applied icing cause code. Only in 2 of the 37 cases there were completely dry conditions according to the accumulated precipitation amount from NORA10. The question is therefore whether Arctic sea smoke or snow showers are important water sources contributing to more icing, or whether these phenomena just happen to be generated in the same weather conditions as icing, i.e. cold wind blowing over relatively warm water. This is a focus point which needs further investigation.

Regardless of the uncertainties in the application of these spray-flux formulations for this ship type, it seems problematic to apply the Horjen spray-flux formulation in the icing model used for the icing events in the present study. For the observed low waves the spray fluxes obtained from the Horjen spray-flux formulation are several orders of magnitude smaller than those obtained from the Borisenkov formulation (Figure 11). The comparison with the observed icing fluxes illustrates that these spray fluxes are too low, when assuming that there is no additional water flux contributing to the freezing. It is interesting to notice that these biases are less apparent when applying the empirical relationship between wind and waves from Horjen (2013) (Equation 34 and 35). This might therefore explain why the HORJEN method in general has higher verification scores and lower MAE for the Horjen spray-flux formulation compared with the Borisenkov formulation. For high waves it seems unrealistic that the water flux is several orders of magnitude higher than the observed icing flux. One possible explanation for this discrepancy is that the power-law dependency of a non-dimensional height above a significant wave $\left(z^{*}=\frac{2 z}{H_{s}}-1\right)$ might not be valid when $H_{s}$ exceeds $z$. It is therefore a question whether it is possible to apply the Horjen formula for wave heights outside the 2 to $5 \mathrm{~m}$ range observed in the 12 spray-flux cases collected by Horjen et al. (1986) (Table B.1) for $z=6.6-10.9 \mathrm{~m}$. Another reason might be that a continuous spray-icing model which applies a time-average of $Q_{d}$ is not a valid approach for the possible large spray-flux values derived from the Horjen formulation. Whatever the reason is, it is evident that there is an underesti- 
mation of icing rates, both for low waves due to the lack of available water, and for high waves due to a large negative $Q_{d}$. The underestimation of icing rates also explains the low equitable skill scores associated with the weak ability of the model in predicting the moderate or severe events when the Horjen formulation is applied. Although the prediction of the non-events is better when applying the Horjen relative to the Borisenkov spray-flux formulation, it could also be a result of the low icing rates calculated for both low and high waves. There are also uncertainties regarding the correctness of the observed no-icing events. In some of these events there may namely have been some accumulation followed by ice breaking off or melting during the 3-hour period between the observation times. The high amount of low-icing cases in the predictions during these events, is an indication that there might be problems with the validity of the no-icing observations.

Another aspect of uncertainty in the icing model is related to the preciseness of the applied heat-transfer coefficient. This is in particular a challenge since the local heat-transfer coefficient on surfaces of a ship or structure can vary considerably (Kulyakhtin 2014). In addition, since stochastic turbulent eddies are governing the heat transfer between the freezing brine and the atmosphere, a correct estimate of the heat-transfer coefficient is difficult to obtain. For this reason the difference between the reanalysis-calculated convective and evaporative heat fluxes, and these fluxes calculated from the observed values, may in reality be different. One could believe that the introduction of models applying computational fluid dynamics (CFD) which is applied for buildings (Defraeye et al., 2010) and in other marine-icing studies (Kulyakhtin 2014), may predict the heat transfer more precisely than that achieved from applying an estimate of the surface-averaged heat-transfer coefficient dependent on the relative wind speed and dimension. Especially since an estimate of the turbulent statistics may be included in CFD models. However, the turbulent processes involved in the heat transfer in the atmosphere are not possible to predict precisely at all time and length scales (Stull, 1988). In addition, the flow will be affected by convective plumes and clouds, snow showers, an irregular ocean-wave pattern, and the surface roughness of the ship and the ice itself. None of these factors are easily handled or parametrised even in CFD models. Additionally, mountain waves, gap winds, downslope windstorms and other atmospheric features can affect the local wind and turbulence pattern even at sea close to the coast or inside the fjords of Northern Norway (Samuelsen, 2007) or at the Svalbard archipelago (Barstad and Adakudlu, 2011; Skeie and Grønås, 2000). These features are not resolved in models with horizontal resolution around $10 \mathrm{~km}$ like the Hirlam model applied in NORA10. They can also happen at time scales below 1 hour, and could therefore appear in between the 3 to 9 hourly time scale of the observations. It is therefore difficult to state whether accuracy of the heat transfer derived from a parameterization as applied in the current study is different from the accuracy of the heat transfer obtained from state-out-the-art CFD models. When applying observations from all the 37 icing events in the formulation of the surface-averaged heat-transfer coefficient of an offshore rig column derived from CFD modelling (Equation 20 in Kulyakhtin and Tsarau (2014)), the average value of the $h_{a}$ was calculated to be about $53 \mathrm{~W} \mathrm{~m}^{-2{ }^{\circ}} \mathrm{C}^{-1}$ for a horizontal dimension of $4 \mathrm{~m}$. This value is almost similar to the average values of $h_{a}$ presented in Table 3 However, it is questionable whether this formulation from an offshore rig column is directly transferable to surfaces on KV Nordkapp.

Next, the radiative heat flux is contributing to more icing when using the longwave radiation from the reanalysis data instead of the normal approximation $\sigma\left(T_{a}+273.15\right)^{4}$. However, if adding the effect of radiation from the sea 
and from the ship, the actual incoming longwave radiation may be higher than that applied. However, the incoming longwave radiation from NORA10 is probably too high. As described in Table 2NORA10 had a positive temperature BIAS near the surface. In addition, there is a positive cloud cover BIAS in NORA10 compared to the observed cloud cover. NORA10 has namely 7 or 8 oktas for all 37 icing events, when there at times was observed less clouds (Table C.2. C.3 and C.4 . These effects may therefore compensate for the problems of not taking radiation from the sea and ship into account. Moreover, when applying NORA10 radiation data the effect of shortwave radiation was possible to estimate. Most of the time shortwave radiation was negligible, but the contribution was considerable in April. From this period of time there is twilight, daylight or sunlight 24 hours a day at high latitudes. If there are few clouds and a small sun-elevation angle, the heat flux may be high towards the almost vertical plate. In such circumstances the direction of the ship according to the sun would play an important role. Clouds covering a small portion of the sky where the sun appears would then be important to predict correctly. Reflected shortwave radiation from the sea may also play a role. All these effects greatly add complexity and uncertainty into the icing model, and the assumption about diffuse radiation only coming from the sky seems convenient in order to avoid making the model too complex.

Due to all the uncertainties both in the spray-flux formulations, heat-transfer coefficient, radiative heat flux and input parameters applied, there is a trade-off between how much complexity one can add to the icing model, and the overall gain in prediction quality. The physical representation of processes in the model may be even further improved leading to an enhancement of complexity of the model. Yet, the gain in quality from the increased complexity may be small due to the uncertainties in other terms. For this reason brine-film movement like in Horjen (2013) was neglected. Pulsed-spray conditions were handled by applying a time-averaged continuous spray flux. For pulsed-spray conditions the conductive heat flux may play an important role, especially for longer time intervals on light cylinders (Kulyakhtin et al., 2016). However, the importance of the conductive heat flux can also be different in the case of ice accumulation on a vertical wall on KV Nordkapp compared to accumulation at light cylinders. Pulsed-spray conditions may also reduce the effect of melting from the $Q_{d}$-term for high spray-flux conditions leading to more icing (Figure 35 Horjen (2015)). Nevertheless, such results must be tested against observations to justify the importance of taking them into account. It is also questionable whether it is reasonable to obtain an instantaneous spray flux from an in itself uncertain time-averaged version like in Horjen (2013) by approximating spray frequencies and spray-cloud duration time. In addition, the true spraying of a ship is probably not regular. This would therefore also influence the possibilities of precisely predicting the pulsed-spray conditions and the effect of the conduction term.

For this reason the application of a trajectory model (Equation 10 including the droplet-cooling equation (Equation 28) may seem unnecessary complicated. However, such a model was applied in order to add the effect of drag force, and achieve possibly more realistic droplet-flight times $(\tau)$, droplet velocities $\left(V_{d}\right)$ and droplet temperatures $\left(T_{d}\right)$. However, there are still uncertainties regarding the initial velocities and position of the droplets, especially in the vertical direction. Turbulence in the wind field around the ship may also disturb the trajectories. In reality there is a wide variety of droplet sizes, and these will probably follow different trajectories. It is also uncertain to what degree the droplets will follow trajectories like individual droplets, or work together and produce spray in combined splashes. Probably the real sea-spray is a combination of both. For this reason the spray temperature was estimated from the average value 
between the sea-surface temperature and the calculated droplet temperature. The trajectory model must therefore only be seen as a possible approximation of droplet cooling times, droplet velocities and droplet temperatures applied in $R_{w}$ and $Q_{d}$-terms. In addition, when using observed temperature and wind speeds from different heights and comparing them with $2 \mathrm{~m}$ temperature and $10 \mathrm{~m}$ wind speed in NORA10, possible vertical temperature and wind gradients around the ship are ignored. When the atmosphere is statically unstable, the vertical differences in wind and temperature are probably negligible in the lowest layers over open water. However, the local wind speed at the freezing plate may still be lower than the measured wind speed at the top of the mast, since the surface roughness of the ship has a higher effect on reducing the wind closer to the deck. The local temperature at the freezing plate, might also be different from the temperature measured $12 \mathrm{~m}$ above the sea level and at a different position on the ship.

Finally, during the accumulation period of 3 to 9 hours, the ship experiences changing meteorological and oceanographic conditions which may affect the instantaneous icing rate. It is hence not certain that the mean ice accumulation observed divided by the number of hours, is comparable to the mean of the instantaneous icing rates calculated for the start and end position of the trip. This method was applied since observed parameters between the start and end position were not available. In addition, since the data set only provides one single observation of severe icing, it is possible that:

- this large ship type rarely experiences severe icing

- that severe icing happens more frequently than the observations indicate, but not when averaging icing rates during several hours.

- that the categories for moderate or severe icing should be adjusted for this ship type or method of averaging

Despite all the aforementioned uncertainties both in the icing model and the observational data, the comparison of modelled and observed icing rates emphasises the importance of having correct wave parameters. Too high estimates of wave height and wave period when applying the empirically-based statistical relationships between wind and wave parameters (ZAKR and HORJEN) seem to lead to the higher errors in the predicted icing rates of these methods. Since some of the icing events are inside or near the marginal ice zone and are very fetch-limited, the empiricallybased statistical methods are probably less applicable than they otherwise would have been. Using methods with more realistic fetches or empirically derived from observations of wind and waves in the regions were icing was recorded, may give better results. However, the exact fetch, including duration time that a given wind speed is acting upon the waves, is difficult to estimate. In addition, effect from swell waves and waves generated by wind patterns elsewhere will still not be taken fully into account. Since the HYBRID2 is the best or second best method of input parameters when applying both spray-flux formulations for most verification methods and sensitivity tests applied in the current study, the final data set in the appendix (Table C.1. C.2. C.3, and C.4 present data from the HYBRID2-method.

\section{Conclusions}

Marine icing involves complex processes which in many cases are poorly understood. As a consequence state-of-theart icing models include parameterization and empirically-derived expressions having large uncertainties. In addition, 
the necessary meteorological and oceanographic parameters applied as input to the models may as well include con„siderable uncertainties which have often been neglected in other marine-icing studies (Teigen et al., 2015, Kulyakhtin and Tsarau, 2014, Horjen, 2013, Zakrzewski, 1987). In this study, a unique thoroughly screened and quality-checked marine-icing data set is presented. This data set includes 37 icing events with observations of icing rate from a fixed position on a particular ship type as well as observations or reanalysis data of important meteorological and oceanographic parameters. Icing rates are modelled based on a newly proposed icing model MINCOG using two different spray-flux formulations and meteorological and oceanographic parameters from the data set. Comparisons between the observed and modelled icing rates underline the problems of applying formulas based on empirical relationships between the local wind speed and significant wave height and wave period in marine-icing models. The predominantly best combination of input parameters in MINCOG measured from various verification scores and sensitivity tests, was a combination of observations and reanalysis data for the wave period and direction, regardless of the spray-flux formulation applied. Thus, the spray-flux formulation based on the spray data from Horjen et al. (1986) appears to underestimate the spray flux for low waves and overestimate it for high waves. This is especially apparent when applying more realistic wave parameters instead of empirically-derived versions based on the local wind speed from the North Sea and Tromsøflaket; i.e. areas with different wave characteristics including different fetch lengths than those of the icing measurements. Yet, this possible overestimation for high waves must be further tested against spray-flux observations in high-wave conditions in conjunction with icing-flux observations to be finally confirmed. Although the reanalysis data set from NORA10 underestimates wind speed and negative temperature, it obtains satisfactory verification scores for icing-rate prediction compared to that from observations when methods based on both data sets are applied in MINCOG. However, a more realistic spray-flux formulation or a more realistic handling of the heat transfer may affect this conclusion. Utilization of observed winds and temperatures and high-quality wave data if available is nevertheless encouraged.

\section{Acknowledgements}

This work was supported by Norwegian Research Council through the MAROFF program [grant number 226404], and MET Norway. The authors would like to thank all colleagues at UiT - The Arctic University of Norway, and collaboration partners at MET Norway for providing crucial help, feedback and discussions. The Norwegian deep water program is acknowledged for the use of the NORA10 hindcast data, in addition to the Department manager M. N. Jørgensen of the Norwegian Coast Guard (pers. comm., April 2014) for allowing publication of the observations from the KV Nordkapp ships. A special gratitude goes to Oddmar Eiksund for helping out with the trajectory model, Ole Johan Aarnes for discussions regarding the wave parameters, Hilde Haakenstad for help in applying the hindcast data, and Dag Kvamme for giving access to the original handwritten data. The authors also would like to thank the reviewers for providing crucial and fruitful feedback of the manuscript. 


\section{Appendices}

\section{Appendix A. Details about data selection}

\section{Appendix A.1. Screening and selection of ice-accumulation data}

As mentioned in the main part, observed icing rates were calculated from the difference in the ice-thickness parameter $\left(E_{S}\right)$. In the beginning of an icing event $E_{S}$ was reported with a certain thickness. However, it was not clear over how many hours this thickness had been accumulated. For instance could $E_{S}$ be reported in one observation, then being omitted in the next one, and then being reported in the following observation with the same thickness as the initial one. In order to be sure that the thickness had been accumulated over a controlled set of hours, only those observations were selected which had reported a clear increase in the ice thickness $E_{S}$ between two consecutive observations in time. In the selection process it was decided to use a maximum time difference of 9 hours between the observations. In one occasion there was a clear increase between the first $(2 \mathrm{~cm})$ and the third observation $(10 \mathrm{~cm})$ without $E_{S}$ being reported in the second observation. This case ( $\mathrm{nr}$ 26) was also included since it seemed plausible that the thickness had increased from the first to the third observation, and the time difference between the first and the third observation was only 6 hours. Observations where the start position of the trip had an ice concentration larger than 0.4 were also excluded to make sure that the ship was not inside thick ice cover during the trip.

In order to find the mean ship speed and direction, the distance between the two points where the ice accumulation had taken place was calculated from the position data using the WGS84 coordinate system (Kumar, 1988). The mean heading was found by assuming that the ship was travelling with a constant heading, i.e along a rhumb line. Since the ice accumulation occurred in the front of the ship between the front deck and the cannon deck, only those observations were applied where the angle $(\beta)$ between the wind and the mean heading was from $90^{\circ}-180^{\circ}$. Due to the uncertainty in the visual estimated wave direction $\left(D_{W}\right), \alpha$ was only applied in calculation of $V_{r}$ and $V_{\mathrm{gr}}$ (Equation 3 and 14 ) and not applied as criteria during the selection process. In other marine-icing studies the wave direction and wind direction are assumed to be the same (Lozowski et al., 2000, Horjen, 2013). In this study there were some differences between the wind direction $\left(D_{D}\right)$ and the wave direction $\left(D_{W}\right)$, although they were quite similar in most of the cases (Figure 12). The difference between wind and wave direction was also apparent when comparing observed wind direction with the wave direction from NORA10. Moreover, one case where $V_{s}=0$ was removed since the heading direction is ambiguous when the ship is not moving.

Ice concentration was reported in some of the cases in a code format from the ship-synop code. In table C.2. C.4 the $C_{I}$-code values are converted to fractions; e.g. $C_{I}=2$ (sea ice present in concentration less than $\frac{3}{10}$ (World Meteorological Organization, 2015) ) is converted to 0.2. When ice was not reported at all, it was believed that in general the ship was far away from the ice edge. In order to check that the ship was not positioned far into the ice cover, data reprocessed from OSISAF (2015) were applied as a supplement for the ice-concentration data presented in the data set (Table C.2 C.4). For instance in the cases where $C_{I}=1$ (ship in open lead more than 1.0 nautical miles wide, or ship in fast ice with boundary beyond limit of visibility (World Meteorological Organization, 2015) $)$ and $C_{I}=6$ (strips and patches of close or very close pack ice with open water between (World Meteorological Organization, 2015)) 
the ice-concentration data from OSISAF (2015) were applied. The application of the OSISAF (2015) strengthens the likelihood of avoiding selecting ships positioned in areas with an ice-concentration beyond 0.4. In fact 3 cases were removed where the end position had an ice concentration greater than 0.4 and the wave height was 0 . The start and end position of the final selected cases can be seen in Figure 7 d).

\section{Appendix A.2. Quality control and handling of the visual wave data}

In order to get more information about the data collected and to check the quality of the data stored in the electronic database, the original handwritten data from the years 1986 to 1995 were collected from an archive at Forecasting Division of Western Norway, MET Norway. These observations were compared with the electronically stored ones. All observations with icing were thoroughly checked. In some of the data investigated the ice-accretion parameters $\left(I_{S}, E_{S} R_{S}\right)$ were stored with incorrect values in the electronic database. At other places in the electronic database there were some full months that were missing, and these places needed to be filled with information from the handwritten data. In particular the parameters present weather code $\left(W_{W}\right)$, ice concentration $\left(C_{I}\right)$, and the parameters representing wave information were missing at some places in the electronic database. In one circumstance (case nr 24) the wave height had to be replaced based on information taken from nearby observations and the NORA10 data. This was done since it was suspected that the observer had written 11 and 12 half meters, when in fact it was 11 and 12 whole meters, since the previous and later wave heights were 23 and 24 half meters. A wind observation of above $25 \mathrm{~m} \mathrm{~s}^{-1}$ together with these wave-height observations supported this decision.

Salinity and precipitation amount were not observed on KV Nordkapp. Salinity was collected from the SVIM archive (Lien et al. 2013) and precipitation amount from the NORA10 (Reistad et al., 2011) with ERA-Interim (Dee et al. 2011) as boundary and initial condition. For relative humidity the original value from the handwritten data set is applied in the years 1986-1995. It was namely discovered some small differences between the dew-point temperature stored electronically and the dew-point temperature derived from the observed $R_{H}$ and $T_{a}$. This discrepancy was nevertheless not considered to have a large effect on the results in the years where the original data were not available. The observed sea-surface temperature $\left(T_{w}\right)$ was quality-checked by examining the sea-surface temperature collected from both the SVIM and the NORA10. Near the ice edge it is difficult to know which of the three sea-surface temperatures that are most correct. Small differences in the position of the ice edge may give large differences between the observed and modelled sea-surface temperature. In particular this is a problem south-west and west of Spitsbergen where the sea is relatively warm. It was discovered that the NORA10 in some cases had a different position of the ice edge, and hence the sea-surface temperature, than those from the SVIM. The ice-edge position in NORA10 was in these cases also different from the position in OSISAF (2015). In most circumstance the differences in sea-surface temperatures were the smallest when comparing the observed ones with the ones derived from SVIM. Thus, the $T_{w}$-values measured on the boat were selected as the true representation of the sea-surface temperature. In one of the cases (nr 21) the observed sea-surface temperature seemed unrealistic low $\left(-2.1^{\circ} \mathrm{C}\right)$, and was lower than the freezing point of sea water $\left(-1.9^{\circ} \mathrm{C}\right)$ calculated from the salinity derived from SVIM. Since the ship was located inside the marginal ice zone $\left(C_{I}=\right.$ 2), there is certainly a possibility that this was a local high saline sea-surface area. Thus, since the exact salinity value is 
uncertain and difficult to obtain, the $T_{w}$ was in this case replaced according to the aforementioned freezing temperature calculated from the SVIM-derived salinity.

While the observed wave parameters are visually estimated, the wind direction and wind speed are measured by a wind sensor. The wind speed is originally measured in whole knots and converted to $\mathrm{m} \mathrm{s}$ in this study. The wave height and wave period are divided into wind-wave height $\left(H_{\mathrm{ws}}\right)$ and wind-wave period $\left(P_{\mathrm{ws}}\right)$, and swell-wave height $\left(H_{\mathrm{sw}}\right)$, swell-wave period $\left(P_{\mathrm{sw}}\right)$ and swell-wave direction. Yet, all of these wave parameters were only reported at the same time in some of the inspected data points. Since the quality of the visually-estimated wave parameters is uncertain, the correction methods for these parameters from Gulev and Hasse (1998) are applied. Gulev and Hasse (1998) have specifically compared visually-estimated wave observations from ships in the North Atlantic with automatic buoy data at a maximum distance from the ships. Moreover, they conclude that the best results for wave-height data from ship observations is obtained by applying $H_{s}=\sqrt{H_{\mathrm{ws}}^{2}+H_{\mathrm{sw}}^{2}}$ when the difference between the wind direction and the swell direction is less than $30^{\circ}$, and obtained by selecting the maximum of these two parameters when the difference exceeds $30^{\circ}$. Gulev and Hasse (1998) also discovered that visually-estimated wave periods were in general a bit lower than the measured wave periods from buoy data, and they therefore suggested some empirically-derived correction methods to both the $P_{\mathrm{ws}}$ and $P_{\mathrm{sw}}$. The final $P_{s}$ was obtained by taking the maximum of the corrected $P_{\mathrm{ws}}$ and $P_{\mathrm{sw}}$ when the difference between the wind and swell direction was less than $30^{\circ}$. When the difference between the reported wind and swell direction exceeded $30^{\circ}$, only the wave-period parameter corresponding to the maximum reported wave height was selected. The final wave direction was also determined according to the same principles. Firstly by calculating the middle value of the wind and swell direction when the difference between these two directions was less than $30^{\circ}$, and secondly by selecting the direction that corresponded to the maximum value of the wave height when the difference in directions was larger than $30^{\circ}$.

\section{Appendix A.3. Model data selection}

NORA10 (6 or 9 hours prognosis) having ERA40 data (Uppala et al. 2005) as initial and boundary conditions was applied as the main source for the reanalysis data, although the radiation and precipitation data were collected from NORA10 with ERA-Interim (Dee et al. 2011). The reason for not applying NORA10 with ERA-Interim data as initial and boundary conditions for most parameters, was that this version did not provide any wave data. Moreover, it was discovered that the mean absolute differences between these two NORA10 versions for wind speeds and temperatures for the 37 icing events were in fact $1.0 \mathrm{~m} \mathrm{~s}^{-1}$ and $0.7^{\circ} \mathrm{C}$. The NORA10 with ERA40 provided in the mean the strongest winds namely $0.2 \mathrm{~m} \mathrm{~s}^{-1}$ more than NORA10 with ERA-Interim. The temperature was also $0.4^{\circ} \mathrm{C}$ higher in NORA10 with ERA40 compared to the version having ERA-Interim data as initial and boundary conditions. Since the differences between these parameters were relatively small for the two different NORA10 versions, applying the ERA-Interim version of the NORA10 would not change the results dramatically. In addition, the NORA10 data were in general extracted by using a bilinear interpolation method from grid points. When wave information from the model was missing at a certain location due to the model not resolving land and ice cover precisely, the wave height and period were set to 0 . 
Table B.1: Horjen spray-flux data collected from Horjen et al. (1986). The data set is supplemented with wave height and period from the climate database of the Norwegian Meteorological Institute. The spray is collected at the heights $z_{1}=6.6 \mathrm{~m}, z_{2}=7.5 \mathrm{~m}, z_{3}=9.1 \mathrm{~m}$, and $z_{4}=10.9 \mathrm{~m}$. Endre Dyr $\varnothing \mathrm{y}$ was located at or close to the position $74.5^{\circ} \mathrm{N} 31.0^{\circ} \mathrm{E}$ in the collection period. The following parameters are presented: Start time of water collection, Collection time $(T, \mathrm{~s})$, Wind speed $\left(V, \mathrm{~m} \mathrm{~s}^{-1}\right)$, Ship speed $\left(V_{s}, \mathrm{~m} \mathrm{~s}^{-1}\right)$, Relative heading angle $\left(\phi_{r},{ }^{\circ}\right)$, Wave height $\left(H_{s}, \mathrm{~m}\right)$, Wave period $\left(P_{s}, \mathrm{~s}\right)$, and Non-dimensional height above significant wave $\left(z^{*}=\frac{2 z}{H_{s}}-1\right)$ and Time-averaged spray flux $\left(R_{w}, \mathrm{~g} \mathrm{~m}^{-2} \mathrm{~s}^{-1}\right)$ for $z_{1}$ to $z_{4}$.

\begin{tabular}{|c|c|c|c|c|c|c|c|c|c|c|c|c|c|c|}
\hline Start time & $T$ & $V$ & $V_{s}$ & $\phi_{r}$ & $H_{S}$ & $P_{s}$ & $z_{1}^{*}$ & $z_{2}^{*}$ & $z_{3}^{*}$ & $z_{4}^{*}$ & $R_{w 1}$ & $R_{w 2}$ & $R_{w 3}$ & $R_{w 4}$ \\
\hline $1985-08-3008: 20$ & 3600 & 18.0 & 2.1 & 0 & 5.0 & 8.0 & 1.6 & 2.0 & 2.6 & 3.4 & 0.8 & 0.4 & $\mathrm{x}$ & $\mathrm{x}$ \\
\hline 1985-08-30 10:15 & 2700 & 16.0 & 3.8 & 0 & 4.7 & 8.0 & 1.8 & 2.2 & 2.8 & 3.6 & 2.5 & 1.0 & $\mathrm{x}$ & $\mathrm{x}$ \\
\hline $1985-08-30 \quad 16: 15$ & 3300 & 15.0 & 4.1 & 15 & 4.2 & 8.0 & 2.1 & 2.6 & 3.3 & 4.2 & $\mathrm{x}$ & 2.9 & 1.0 & 0.2 \\
\hline 1985-09-05 16:25 & 2100 & 16.0 & 4.1 & 45 & 4.0 & 6.0 & 2.3 & 2.8 & 3.5 & 4.5 & $\mathrm{x}$ & 5.7 & 5.5 & 2.4 \\
\hline 1985-09-06 06:45 & 1800 & 16.0 & 4.4 & 0 & 4.0 & 6.0 & 2.3 & 2.8 & 3.5 & 4.5 & 1.5 & 0.6 & 0.2 & 0.1 \\
\hline 1985-09-06 07:30 & 1800 & 15.0 & 4.6 & 15 & 4.0 & 6.0 & 2.3 & 2.8 & 3.5 & 4.5 & 8.0 & 3.3 & 0.7 & 0.2 \\
\hline 1985-09-06 08:35 & 1800 & 14.0 & 4.8 & 45 & 4.0 & 6.0 & 2.3 & 2.8 & 3.5 & 4.5 & 10.9 & 10.5 & 8.0 & 1.1 \\
\hline 1985-09-27 08:35 & 1800 & 10.5 & 4.6 & 0 & 2.0 & 5.0 & 5.5 & 6.4 & 8.0 & 9.8 & 0.4 & 0.3 & 0.1 & $\mathrm{x}$ \\
\hline 1985-09-27 09:10 & 1800 & 10.5 & 5.1 & 45 & 2.0 & 5.0 & 5.6 & 6.5 & 8.1 & 9.9 & 0.7 & 0.4 & $\mathrm{x}$ & $\mathrm{x}$ \\
\hline 1985-09-27 11:00 & 1800 & 10.5 & 5.1 & 15 & 2.0 & 5.0 & 5.6 & 6.5 & 8.1 & 9.9 & 0.5 & 0.2 & $\mathrm{x}$ & $\mathrm{x}$ \\
\hline 1985-09-27 11:45 & 1800 & 10.5 & 2.1 & 15 & 2.0 & 5.0 & 5.6 & 6.5 & 8.1 & 9.9 & 0.1 & 0.1 & 0.3 & 0.1 \\
\hline $1985-11-25$ 08:20 & 1800 & 10.5 & 4.6 & 45 & 2.0 & 5.0 & 5.6 & 6.5 & 8.1 & 9.9 & 0.4 & $\mathrm{x}$ & $\mathrm{x}$ & $\mathrm{X}$ \\
\hline
\end{tabular}




\section{Appendix C. Complete data set of the 37 icing events}

Table C.1, C.2, C.3, and C.4 present the complete data set of the 37 icing events from the HYBRID2 data set. For case nr 29 the reanalysis wave data was not defined, and the observed values are presented.

Table C.1: Parameters derived from raw data of observations or reanalysis data for the 37 icing events. The table is listing the following parameters: mean ship direction $\left(D_{\mathrm{ir}},{ }^{\circ}\right)$, mean ship speed $\left(V_{s}, \mathrm{~m} \mathrm{~s}^{-1}\right)$, wave-phase speed $\left(c, \mathrm{~m} \mathrm{~s}^{-1}\right)$, wave-group speed $\left(c_{g}\right.$, $\left.\mathrm{m} \mathrm{s}^{-1}\right)$, incoming longwave radiation $\left(\downarrow \mathrm{LW}, \mathrm{W} \mathrm{m}^{-2}\right)$ calculated from net-radiation data from NORA10, incoming diffuse shortwave radiation $\left(\downarrow \mathrm{SW}, \mathrm{W} \mathrm{m}^{-2}\right)$ towards a vertical plate with a tilt $\gamma$ from the horizontal (Figure 2), and mean icing rate $\left(\frac{d h}{d t}, \mathrm{~cm} \mathrm{~h}^{-1}\right)$. The icing rates are also divided into three categories: light (L), moderate $(\mathrm{M})$ and severe $(\mathrm{S})$ following the recommended categories of Overland et al. (1986)

\begin{tabular}{|c|c|c|c|c|c|c|c|c|}
\hline $\mathrm{Nr}$ & $D_{\text {ir }}$ & $V_{s}$ & $c$ & $c_{g}$ & $\downarrow$ LW & $\downarrow \mathrm{SW}$ & \multicolumn{2}{|c|}{$\frac{d h}{d t}$} \\
\hline 1 & 133 & 1.0 & $\begin{array}{l}10.8 \\
10.7\end{array}$ & $\begin{array}{l}5.4 \\
5.3\end{array}$ & $\begin{array}{l}254 \\
255\end{array}$ & $\begin{array}{l}0 \\
0\end{array}$ & 0.11 & $\mathrm{~L}$ \\
\hline 2 & 52 & 6.7 & $\begin{array}{l}10.7 \\
10.7\end{array}$ & $\begin{array}{l}5.5 \\
5.3\end{array}$ & $\begin{array}{l}264 \\
264\end{array}$ & $\begin{array}{l}0 \\
0\end{array}$ & 1.00 & M \\
\hline 3 & 163 & 4.9 & $\begin{array}{l}11.3 \\
12.1\end{array}$ & $\begin{array}{l}5.6 \\
6.0\end{array}$ & $\begin{array}{l}243 \\
236\end{array}$ & $\begin{array}{l}0 \\
0\end{array}$ & 0.17 & $\mathrm{~L}$ \\
\hline 4 & 175 & 7.3 & $\begin{array}{l}12.9 \\
11.7\end{array}$ & $\begin{array}{l}6.5 \\
5.8\end{array}$ & $\begin{array}{l}235 \\
226\end{array}$ & $\begin{array}{l}0 \\
0\end{array}$ & 1.00 & M \\
\hline 5 & 166 & 7.4 & $\begin{array}{l}11.7 \\
10.7\end{array}$ & $\begin{array}{l}5.8 \\
5.3\end{array}$ & $\begin{array}{l}224 \\
216\end{array}$ & $\begin{array}{l}0 \\
0\end{array}$ & 0.67 & $\mathrm{~L}$ \\
\hline 6 & 165 & 4.3 & $\begin{array}{l}7.9 \\
8.8\end{array}$ & $\begin{array}{l}3.9 \\
4.4\end{array}$ & $\begin{array}{l}242 \\
242\end{array}$ & $\begin{array}{l}0 \\
0\end{array}$ & 0.33 & $\mathrm{~L}$ \\
\hline 7 & 314 & 3.0 & $\begin{array}{l}7.4 \\
6.7\end{array}$ & $\begin{array}{l}3.7 \\
3.4\end{array}$ & $\begin{array}{l}197 \\
193\end{array}$ & $\begin{array}{l}0 \\
0\end{array}$ & 0.33 & $\mathrm{~L}$ \\
\hline 8 & 195 & 1.1 & $\begin{array}{l}9.3 \\
8.7\end{array}$ & $\begin{array}{l}4.6 \\
4.4\end{array}$ & $\begin{array}{l}235 \\
234\end{array}$ & $\begin{array}{l}14 \\
14\end{array}$ & 0.67 & $\mathrm{~L}$ \\
\hline 9 & 149 & 4.2 & $\begin{array}{l}9.6 \\
7.7\end{array}$ & $\begin{array}{l}4.8 \\
3.9\end{array}$ & $\begin{array}{l}224 \\
185\end{array}$ & $\begin{array}{l}126 \\
145\end{array}$ & 1.00 & M \\
\hline 10 & 166 & 2.1 & $\begin{array}{l}7.7 \\
7.4\end{array}$ & $\begin{array}{l}3.9 \\
3.7\end{array}$ & $\begin{array}{l}185 \\
182\end{array}$ & $\begin{array}{l}25 \\
26\end{array}$ & 0.33 & $\mathrm{~L}$ \\
\hline 11 & 155 & 8.0 & $\begin{array}{l}8.4 \\
8.7\end{array}$ & $\begin{array}{l}4.2 \\
4.3\end{array}$ & $\begin{array}{l}240 \\
240\end{array}$ & $\begin{array}{l}0 \\
0\end{array}$ & 0.33 & $\mathrm{~L}$ \\
\hline 12 & 193 & 6.4 & $\begin{array}{r}10.3 \\
9.8\end{array}$ & $\begin{array}{l}5.2 \\
4.9\end{array}$ & $\begin{array}{l}242 \\
243\end{array}$ & $\begin{array}{l}0 \\
0\end{array}$ & 0.33 & $\mathrm{~L}$ \\
\hline 13 & 318 & 6.9 & $\begin{array}{l}12.1 \\
12.8\end{array}$ & $\begin{array}{l}6.0 \\
6.4\end{array}$ & $\begin{array}{l}258 \\
261\end{array}$ & $\begin{array}{l}0 \\
0\end{array}$ & 0.33 & $\mathrm{~L}$ \\
\hline 14 & 315 & 7.3 & $\begin{array}{l}6.7 \\
7.5\end{array}$ & $\begin{array}{l}3.4 \\
3.7\end{array}$ & $\begin{array}{l}251 \\
255\end{array}$ & $\begin{array}{l}0 \\
0\end{array}$ & 0.67 & $\mathrm{~L}$ \\
\hline 15 & 183 & 5.2 & $\begin{array}{l}11.4 \\
10.4\end{array}$ & $\begin{array}{l}5.7 \\
5.2\end{array}$ & $\begin{array}{l}236 \\
230\end{array}$ & $\begin{array}{l}4 \\
4\end{array}$ & 2.33 & $\mathrm{~S}$ \\
\hline 16 & 183 & 6.2 & $\begin{array}{l}9.1 \\
8.7\end{array}$ & $\begin{array}{l}4.6 \\
4.3\end{array}$ & $\begin{array}{l}224 \\
220\end{array}$ & $\begin{array}{l}0 \\
0\end{array}$ & 1.67 & $\mathrm{M}$ \\
\hline 17 & 172 & 2.1 & $\begin{array}{l}8.5 \\
8.5\end{array}$ & $\begin{array}{l}4.3 \\
4.2\end{array}$ & $\begin{array}{l}225 \\
224\end{array}$ & $\begin{array}{l}0 \\
0\end{array}$ & 0.33 & $\mathrm{~L}$ \\
\hline 18 & 270 & 0.9 & $\begin{array}{l}9.1 \\
6.5\end{array}$ & $\begin{array}{l}4.5 \\
3.2\end{array}$ & $\begin{array}{l}218 \\
213\end{array}$ & $\begin{array}{l}0 \\
0\end{array}$ & 0.11 & $\mathrm{~L}$ \\
\hline 19 & 177 & 5.2 & $\begin{array}{l}9.9 \\
9.8\end{array}$ & $\begin{array}{l}4.9 \\
4.9\end{array}$ & $\begin{array}{l}232 \\
228\end{array}$ & $\begin{array}{l}0 \\
0\end{array}$ & 0.67 & $\mathrm{~L}$ \\
\hline
\end{tabular}

\begin{tabular}{|c|c|c|c|c|c|c|c|c|}
\hline $\mathrm{Nr}$ & $D_{\text {ir }}$ & $V_{s}$ & $c$ & $c_{g}$ & & $\downarrow$ SW & $\frac{d l}{d}$ & \\
\hline 20 & 270 & 0.3 & $\begin{array}{l}11.3 \\
11.7\end{array}$ & $\begin{array}{l}5.6 \\
5.9\end{array}$ & $\begin{array}{l}242 \\
242\end{array}$ & $\begin{array}{l}0 \\
0\end{array}$ & 0.67 & $\mathrm{~L}$ \\
\hline 21 & 160 & 3.3 & $\begin{array}{r}10.9 \\
9.5\end{array}$ & $\begin{array}{l}5.4 \\
4.7\end{array}$ & $\begin{array}{l}229 \\
223\end{array}$ & $\begin{array}{l}0 \\
0\end{array}$ & 0.67 & $\mathrm{~L}$ \\
\hline 22 & 297 & 2.3 & $\begin{array}{l}8.4 \\
8.8\end{array}$ & $\begin{array}{l}4.2 \\
4.4\end{array}$ & $\begin{array}{l}259 \\
249\end{array}$ & $\begin{array}{l}0 \\
0\end{array}$ & 0.67 & $\mathrm{~L}$ \\
\hline 23 & 286 & 3.8 & $\begin{array}{l}9.6 \\
9.0\end{array}$ & $\begin{array}{l}4.8 \\
4.5\end{array}$ & $\begin{array}{l}155 \\
150\end{array}$ & $\begin{array}{l}0 \\
0\end{array}$ & 1.67 & M \\
\hline 24 & 180 & 1.0 & $\begin{array}{l}15.4 \\
15.5\end{array}$ & $\begin{array}{l}7.7 \\
7.8\end{array}$ & $\begin{array}{l}263 \\
265\end{array}$ & $\begin{array}{l}0 \\
0\end{array}$ & 0.33 & $\mathrm{~L}$ \\
\hline 25 & 209 & 2.4 & $\begin{array}{l}9.8 \\
9.2\end{array}$ & $\begin{array}{l}4.9 \\
4.6\end{array}$ & $\begin{array}{l}225 \\
227\end{array}$ & $\begin{array}{l}0 \\
0\end{array}$ & 0.33 & $\mathrm{~L}$ \\
\hline 26 & 150 & 4.3 & $\begin{array}{l}10.6 \\
10.8 \\
10.8\end{array}$ & $\begin{array}{l}5.3 \\
5.4 \\
5.4\end{array}$ & $\begin{array}{l}242 \\
238 \\
236 \\
235\end{array}$ & $\begin{array}{l}0 \\
0 \\
0 \\
0\end{array}$ & 1.33 & M \\
\hline 27 & 172 & 6.3 & $\begin{array}{r}10.3 \\
9.7\end{array}$ & $\begin{array}{l}5.1 \\
4.8\end{array}$ & $\begin{array}{l}231 \\
232\end{array}$ & $\begin{array}{l}0 \\
0\end{array}$ & 0.33 & $\mathrm{~L}$ \\
\hline 28 & 298 & 2.2 & $\begin{array}{l}11.6 \\
11.2\end{array}$ & $\begin{array}{l}5.8 \\
5.6\end{array}$ & $\begin{array}{l}259 \\
265\end{array}$ & $\begin{array}{l}0 \\
0\end{array}$ & 0.17 & $\mathrm{~L}$ \\
\hline 29 & 154 & 2.3 & $\begin{array}{l}9.7 \\
4.7\end{array}$ & $\begin{array}{l}4.9 \\
2.3\end{array}$ & $\begin{array}{l}230 \\
225\end{array}$ & $\begin{array}{l}0 \\
0\end{array}$ & 0.33 & $\mathrm{~L}$ \\
\hline 30 & 132 & 4.6 & $\begin{array}{l}9.7 \\
9.4\end{array}$ & $\begin{array}{l}4.9 \\
4.7\end{array}$ & $\begin{array}{l}247 \\
243\end{array}$ & $\begin{array}{l}0 \\
0\end{array}$ & 0.67 & $\mathrm{~L}$ \\
\hline 31 & 160 & 7.7 & $\begin{array}{l}9.4 \\
8.6\end{array}$ & $\begin{array}{l}4.7 \\
4.3\end{array}$ & $\begin{array}{l}238 \\
220\end{array}$ & $\begin{array}{l}12 \\
16\end{array}$ & 1.00 & M \\
\hline 32 & 163 & 8.6 & $\begin{array}{l}11.1 \\
10.1\end{array}$ & $\begin{array}{l}5.5 \\
5.1\end{array}$ & $\begin{array}{l}291 \\
274\end{array}$ & $\begin{array}{l}0 \\
0\end{array}$ & 0.33 & $\mathrm{~L}$ \\
\hline 33 & 107 & 3.5 & $\begin{array}{l}12.4 \\
10.1\end{array}$ & $\begin{array}{l}6.2 \\
5.0\end{array}$ & $\begin{array}{l}234 \\
207\end{array}$ & $\begin{array}{l}0 \\
0\end{array}$ & 0.17 & $\mathrm{~L}$ \\
\hline 34 & 217 & 2.6 & $\begin{array}{l}9.5 \\
9.5\end{array}$ & $\begin{array}{l}4.7 \\
4.8\end{array}$ & $\begin{array}{l}283 \\
280\end{array}$ & $\begin{array}{l}0 \\
0\end{array}$ & 0.33 & $\mathrm{~L}$ \\
\hline 35 & 230 & 1.6 & $\begin{array}{l}12.7 \\
12.6\end{array}$ & $\begin{array}{l}6.3 \\
6.3\end{array}$ & $\begin{array}{l}273 \\
270\end{array}$ & $\begin{array}{l}0 \\
0\end{array}$ & 1.67 & M \\
\hline 36 & 270 & 1.7 & $\begin{array}{l}8.8 \\
8.0\end{array}$ & $\begin{array}{l}4.4 \\
4.0\end{array}$ & $\begin{array}{l}233 \\
235\end{array}$ & $\begin{array}{l}0 \\
0\end{array}$ & 0.67 & $\mathrm{~L}$ \\
\hline 37 & 270 & 2.0 & $\begin{array}{l}8.4 \\
8.3\end{array}$ & $\begin{array}{l}4.2 \\
4.1\end{array}$ & $\begin{array}{l}248 \\
256\end{array}$ & $\begin{array}{l}0 \\
0\end{array}$ & 0.33 & $\mathrm{~L}$ \\
\hline
\end{tabular}




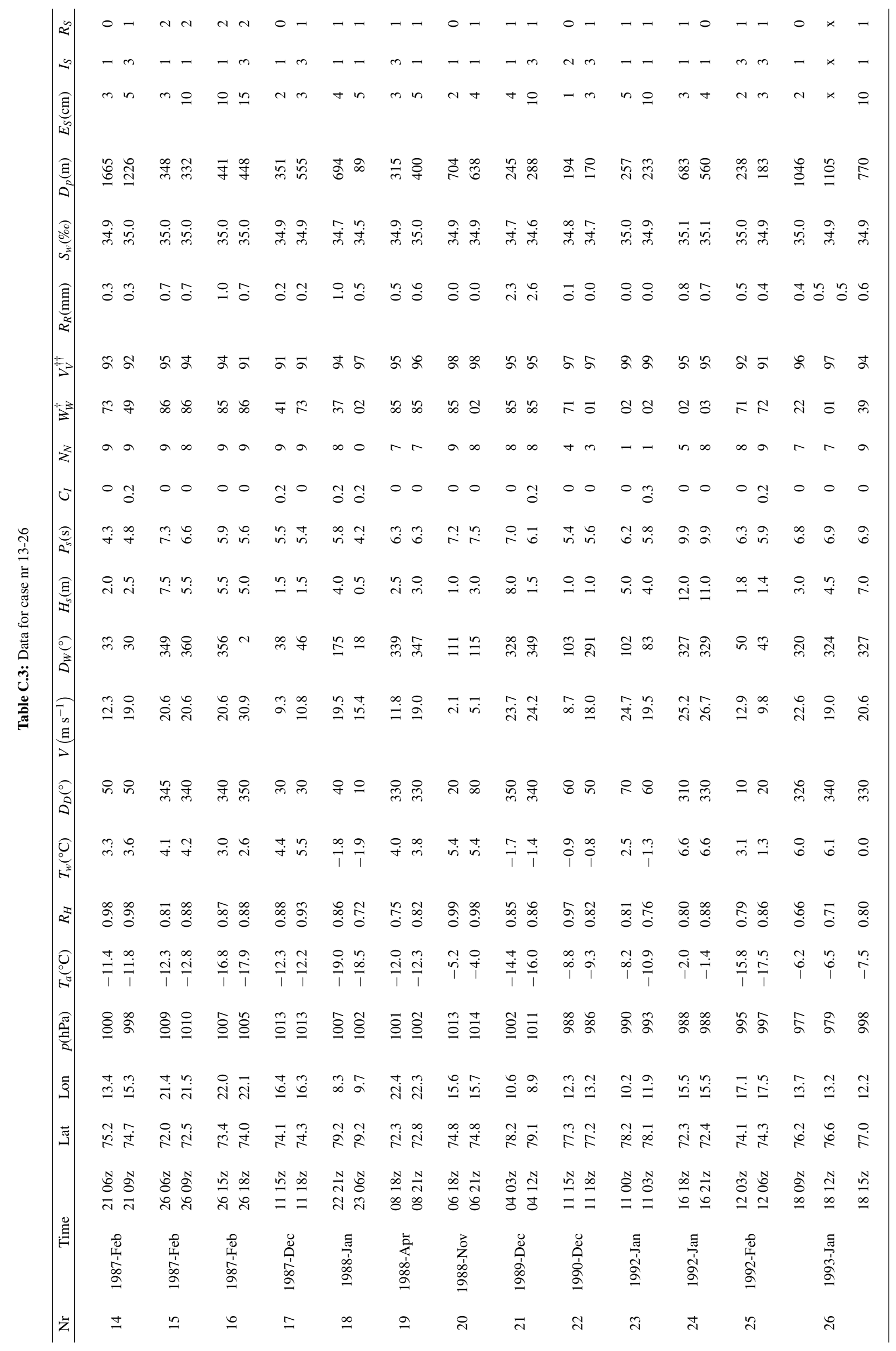




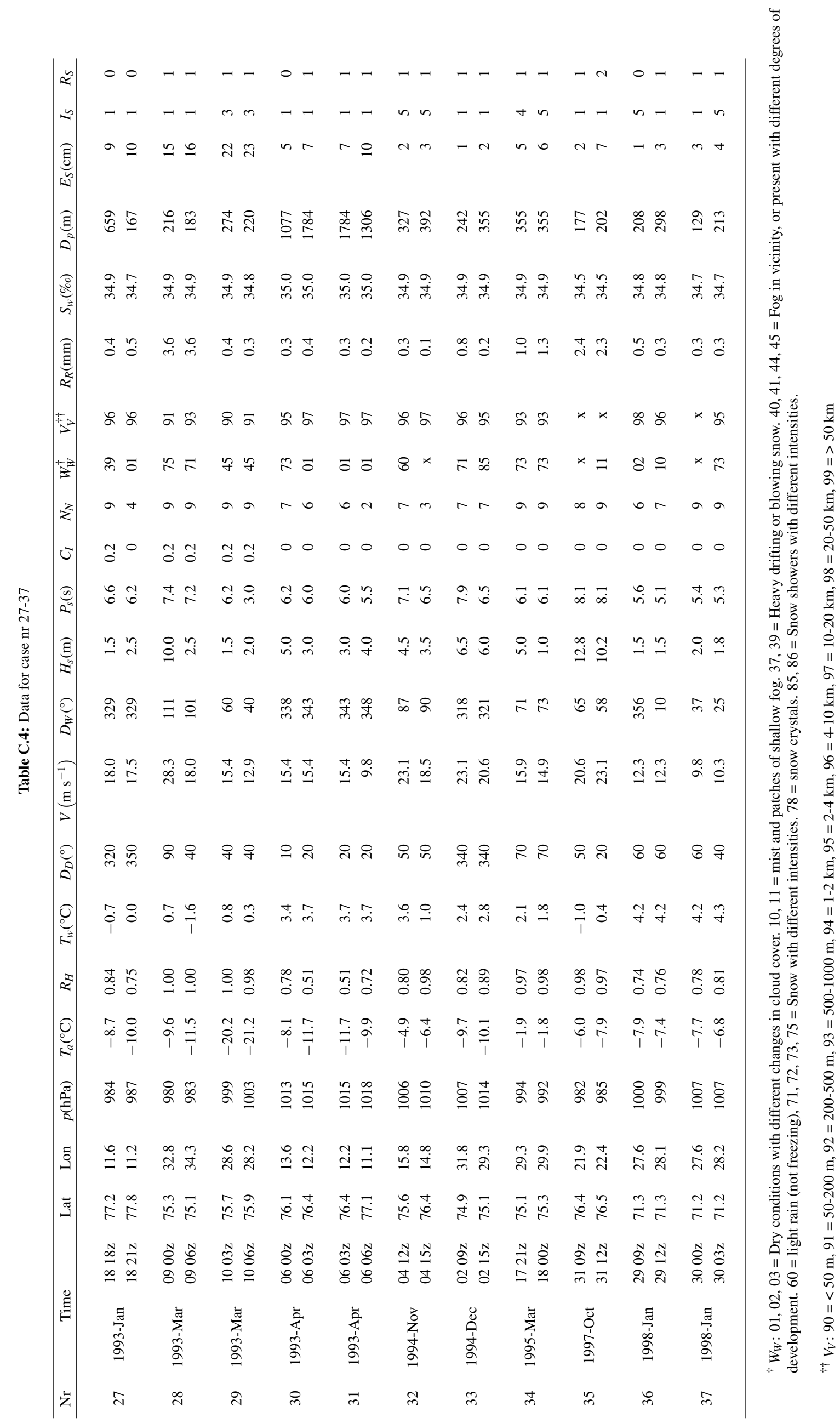




\section{References}

Aksyutin, L.R., 1979. Icing of ships (in Russian). Leningrad, Sudostroyenije Publishers.

Barstad, I., Adakudlu, M., 2011. Observation and modelling of gap flow and wake formation on Svalbard. Quarterly Journal of the Royal Meteorological Society 137, 1731-1738. URL: http://dx.doi.org/10.1002/qj.782 doi:10.1002/qj.782

Bialek, E.L., 1966. Handbook of oceanographic tables. Technical Report. U.S. Naval Oceanographic Office, Washington, D.C.

Bolton, D., 1980. The computation of equivalent potential temperature. Monthly weather review 108, 10461053. URL: http://dx.doi.org/10.1175/1520-0493(1980) 108<1046:TCOEPT>2.0.C0;2, doi:10.1175/ $1520-0493(1980) 108<1046:$ TCOEPT $>2.0$. C0 $; 2$

Borisenkov, Y.P., Zablockiy, G.A., Makshtas, A.P., Migulin, A.I., Panov, V.V., 1975. On the approximation of the spraycloud dimensions (In Russian), in: Arkticheskii i Antarkticheskii Nauchno-Issledovatelskii Institut. Gidrometeoizdat Leningrad, pp. 121-126.

Brent, R.P., 1973. Algorithms for minimizing without derivatives. Prentice-Hall, Englewood Cliffs, NJ.

Brown, R.D., Roebber, P., 1985. The ice accretion problem in Canadian waters related to offshore energy and transportation. Technical Report 85-13. Candian Climate Centre, Atmospheric Environment Service.

Cohen, I.M., Kundu, P.K., 2004. Fluid Mechanics. Third ed., Elsevier Academic Press.

Comstock, J.P., 1967. Principles of naval architecture. Society of Naval Architects and Marine Engineers.

Curry, J.A., Webster, P.J., 1999. Thermodynamics of Atmospheres and Oceans. volume 65. Academic Press.

Dee, D.P., Uppala, S.M., Simmons, A.J., Berrisford, P., Poli, P., Kobayashi, S., Andrae, U., Balmaseda, M.A., Balsamo, G., Bauer, P., Bechtold, P., Beljaars, A.C.M., van de Berg, L., Bidlot, J., Bormann, N., Delsol, C., Dragani, R., Fuentes, M., Geer, A.J., Haimberger, L., Healy, S.B., Hersbach, H., Hólm, E.V., Isaksen, L., Kållberg, P., Köhler, M., Matricardi, M., McNally, A.P., Monge-Sanz, B.M., Morcrette, J.J., Park, B.K., Peubey, C., de Rosnay, P., Tavolato, C., Thépaut, J.N., Vitart, F., 2011. The ERA-Interim reanalysis: configuration and performance of the data assimilation system. Quarterly Journal of the Royal Meteorological Society 137, 553-597. URL: http: //dx.doi.org/10.1002/qj.828 doi $10.1002 / q j .828$

Defraeye, T., Blocken, B., Carmeliet, J., 2010. $\{$ CFD $\}$ analysis of convective heat transfer at the surfaces of a cube immersed in a turbulent boundary layer. International Journal of Heat and Mass Transfer 53, 297308. URL: http://www.sciencedirect.com/science/article/pii/S0017931009005109, doi:dx.doi. org/10.1016/j.ijheatmasstransfer.2009.09.029.

Eide, L.I., 1983. Environmental conditions in the Barents Sea and near Jan Mayen. Technical Report. Norwegian Meteorological Institute.

Finstad, K.J., 1995. Collision Efficiencies of Drizzle-Size Drops. Technical Report. U.S. Army Cold Regions Research and Engineering Laboratory.

Forest, T.W., Lozowski, E.P., Gagnon, R.E., 2005. Estimating marine icing on offshore structures using RIGICE04, in: 
Proceedings of 11th International Workshop on Atmospheric Icing of Structures, Montreal, Quebec. pp. 1-9. URL: http://nparc $\cdot$ cisti-icist.nrc-cnrc.gc.ca/npsi/ctrl?action=rtdoc\&an=8894858\&lang=en

Forsythe, G.E., Malcolm, M.A., Moler, C.B., 1977. Computer methods for mathematical computations. Prentice-Hall series in automatic computation, Prentice-Hall.

Gulev, S.K., Hasse, L., 1998. North Atlantic wind waves and wind stress fields from voluntary observing ship data. Journal of physical oceanography $28,1107-1130$. doi $10.1175 / 1520-0485$ (1998) 028<1107:NAWWAW>2.0.C0; 2.

Hansen, E.S., 2012. Numerical modelling of marine icing on offshore structures and vessels. Master's thesis. NTNU Norwegian University of Science and Technology.

Herrero, J., Polo, M.J., 2012. Parameterization of atmospheric longwave emissivity in a mountainous site for all sky conditions. Hydrology and Earth System Sciences 16, 3139-3147. URL: http://www. hydrol-earth-syst-sci.net/16/3139/2012/, doi 10.5194/hess-16-3139-2012.

Horjen, I., 1990. Numerical modelling of time-dependent marine icing, anti-icing and de-icing. Doctoral thesis. NTH - Norges Tekniske Høgskole.

Horjen, I., 2013. Numerical modeling of two-dimensional sea-spray icing on vessel-mounted cylinders. Cold Regions Science and Technology 93, 20-35. URL: http://www.sciencedirect.com/science/article/pii/ S0165232X13000773, doi $10.1016 / j$.coldregions.2013.05.003

Horjen, I., 2015. Offshore drilling rig ice accretion modeling including a surficial brine film. Cold Regions Science and Technology 119, 84-110. URL: http://www.sciencedirect.com/science/article/pii/ S0165232X15001652, doi dx.doi.org/10.1016/j.coldregions.2015.07.006

Horjen, I., Carstens, T., 1989. Numerical Modelling of Sea Spray Icing on Vessels, in: Proceedings of the 10th International Conference on Port and Ocean Engineering under Arctic Conditions, pp. 694-704.

Horjen, I., Løset, S., Vefsnmo, S., 1986. Icing hazards on supply vessels and stand-by boats. Technical Report. Norwegian Hydrotechnical Labratory.

Hyndman, R.J., Koehler, A.B., 2006. Another look at measures of forecast accuracy. International journal of forecasting 22, 679-688. URL: http://www.sciencedirect.com/science/article/pii/S0169207006000239 doi: $10.1016 / j$.ijforecast. 2006.03 .001

Jessup, R.G., 1985. Forecast techniques for ice accretion on different types of marine structures, including ships, platforms and coastal facilities. Technical Report. World Meteorlogical Organization.

Jørgensen, T.S., 1981. Icing on fishing vessels (In Norwegian: Ising på fiskefartøyer). Technical Report. Technical research department of fisheries (Fiskeriteknisk Forskningsinstitutt).

Jørgensen, T.S., 1985. Sea spray characteristics on a semi-submersible drilling rig. Technical Report STF60-F-85015. NHL - Norwegian Hydrotechnical Laboratory. Trondheim.

Konzelmann, T., van de Wal, R.S.W., Greuell, W., Bintanja, R., Henneken, E.A.C., Abe-Ouchi, A., 1994. Greenland ice margin experiment (GIMEx) Parameterization of global and longwave incoming radiation for the Greenland Ice Sheet. Global and Planetary Change 9, 143-164. URL: http://www.sciencedirect.com/science/article/ 
pii/0921818194900132, doiddx.doi.org/10.1016/0921-8181(94)90013-2

Kulyakhtin, A., 2014. Numerical Modelling and Experiments on Sea Spray Icing. Ph.D. thesis. NTNU - Norwegian University of Science and Technology.

Kulyakhtin, A., Kulyakhtin, S., Loset, S., 2016. The role of the ice heat conduction in the ice growth caused by 1. periodic sea spray. Cold Regions Science and Technology 127,93-108. URL: http://www.sciencedirect.com/ science/article/pii/S0165232X16300532, doi:dx.doi.org/10.1016/j.coldregions.2016.04.001

Kulyakhtin, A., Tsarau, A., 2014. A time-dependent model of marine icing with application of computational fluid dynamics. Cold Regions Science and Technology 104-105, 33-44. URL: http://www.sciencedirect.com/ science/article/pii/S0165232X14000962, doi:10.1016/j.coldregions.2014.05.001.

Kumar, M., 1988. World Geodetic System 1984: A modern and accurate global reference frame. Marine Geodesy 12, 117-126. URL: http://dx.doi.org/10.1080/15210608809379580, doi $10.1080 / 15210608809379580$.

Lien, V.S., Gusdal, Y., Albretsen, J., Melsom, A., Vikebø, F.B., 2013. Evaluation of a Nordic Seas 4km numerical ocean model hindcast archive (SVIM), 1960-2011. Research report. Institute of Marine Research.

Lozowski, E.P., Szilder, K., Makkonen, L., 2000. Computer simulation of marine ice accretion. Philosophical Transactions of the Royal Society of London. Series A: Mathematical, Physical and Engineering Sciences 358, $2811-2845$. doi: $10.1098 /$ rsta. 2000.0687

Makkonen, L., 1987. Salinity and growth rate of ice formed by sea spray. Cold Regions Science and Technology 14, 163-171. URL: http://www.sciencedirect.com/science/article/pii/0165232X87900322, doi:10. $1016 / 0165-232 X(87) 90032-2$

Makkonen, L., 2010. Solid fraction in dendritic solidification of a liquid. Applied Physics Letters 96. URL: http: //scitation.aip.org/content/aip/journal/apl/96/9/10.1063/1.3306728 doi:10.1063/1.3306728

Mertins, H.O., 1968. Icing on fishing vessels due to spray. Marine Observer 38, 128-130.

Nacional Oceanic and Atmospheric Administration, 2015. NCEP MMAB Global Superstructure Ice Accretion Guid-

1) ance. Accessed 26 November 2015. URL: http://polar.ncep.noaa.gov/marine.meteorology/vessel. icing/

Norwegian Broadcasting Corporation (NRK), 2010. Freezing to ice immediately (In Norwegian). Accessed 29 August 2016. Electronic. URL: http://www.yr.no/nyheter/1.6969102

Norwegian Meteorological Institute, 2015. Text forecast for high seas. Accessed 4 December 2015. Electronic. URL: http://www.yr.no/hav_og_kyst/tekstvarsel/hav/

Norwegian Meteorological Institute, 2016. eKlima - Free access to weather- and climate data from Norwegian Meteorological Institute. From historical data to real time observations. Accessed 23 June 2016. Electronic. URL: http://eklima.met.no

OSISAF, 2015. EUMETSAT Ocean and Sea Ice Satellite Application Facility. Global sea ice concentration reprocessing dataset 1978-2015 (v1.2, 2015). Accessed 16 October 2015. Electronic. URL: http://osisaf .met.no

Overland, J.E., Pease, C.H., Preisendorfer, R.W., Comiskey, A.L., 1986. Prediction of Vessel Icing. Journal of Climate and Applied Meteorology 25, 1793-1806. URL: http://dx.doi.org/10.1175/1520-0450(1986) 025<1793: 
POVI >2.0.CO;2, doi $10.1175 / 1520-0450(1986) 025<1793$ :POVI $>2.0 . C 0 ; 2$

Pandey, C.K., Katiyar, A.K., 2009. A note on diffuse solar radiation on a tilted surface. Energy 34, 17641769. URL: http://www.sciencedirect.com/science/article/pii/S0360544209002801, doi.dx.doi. org/10.1016/j.energy.2009.07.006

Panov, V.V., 1971. On the frequency of splashing a medium-sized fishing vessel with sea spray (in Russian), in: Theoretical and Experimental Investigations of the Conditions of Icing of Ships. Gidrometeoizdat Leningrad, pp. 87-90.

Pease, C.H., Comiskey, A.L., 1985. Vessel icing data in Alaskan waters. 1979-1984 dataset. NOAA Data Report ERL PMEL-14. Pacific Marine Environmental Laboratory.

Pierson, W.J., Moskowitz, L., 1964. A proposed spectral form for fully developed wind seas based on the similarity theory of SA Kitaigorodskii. Journal of Geophysical Research 69, 5181-5190.

Reistad, M., Breivik, Ø., Haakenstad, H., Aarnes, O.J., Furevik, B.R., Bidlot, J.R., 2011. A high-resolution hindcast of wind and waves for the North Sea, the Norwegian Sea, and the Barents Sea. Journal of Geophysical Research: Oceans (1978-2012) 116. URL: http://dx.doi.org/10.1029/2010JC006402, doi 10.1029/2010JC006402

Roebber, P., Mitten, P., 1987. Modelling and measurement of icing in Canadian waters. Technical Report. Canadian Climate Centre, Atmospheric Environment Service.

Ryerson, C.C., 1995. Superstructure spray and ice accretion on a large U.S. Coast Guard cutter. Atmospheric Research 36, 321-337. URL: http://www.sciencedirect.com/science/article/pii/016980959400045F, doi:10. 1016/0169-8095(94)00045-F

Ryerson, C.C., 2013. Icing Management for Coast Guard Assets. Technical Report. DTIC Document.

Ryerson, C.C., Gow, A.J., 2000. Crystalline structure and physical properties of ship superstructure spray ice. Philosophical Transactions of the Royal Society of London A: Mathematical, Physical and Engineering Sciences 358, 2847-2871. doi:10.1098/rsta.2000.0688

Ryerson, C.C., Longo, P.D., 1992. Ship Superstructure Icing: Data Collection and Instrument Performance on USCGC Midgett Research Cruise. Technical Report. DTIC Document.

Samuelsen, E.M., 2007. A dynamical study of the storm Narve - a cold air outbreak in Finnmark - with the use of observations and numerical simulations (In Norwegian). Master's thesis. University of Bergen. Bergen.

Samuelsen, E.M., Løset, S., Edvardsen, K., 2015. Marine icing observed on KV Nordkapp during a cold air outbreak with a developing polar low in the Barents Sea, in: Proceedings of the 23rd International Conference on Port and Ocean Engineering under Arctic Conditions, Norwegian University of Science and Technology, Trondheim. pp. $1-14$.

Skeie, P., Grønås, S., 2000. Strongly stratified easterly flows across Spitsbergen. Tellus A 52, 473-486. URL: http://dx.doi.org/10.1034/j.1600-0870.2000.01075.x doi:10.1034/j.1600-0870.2000.01075.x

Stallabrass, J.R., 1971. Meteorological and Oceanographic Aspects of Trawler Icing off the Canadian East Coast. The Marine Observer 41, 107-121.

Stallabrass, J.R., 1980. Trawler icing - A compilation of work done at N.R.C. Mechanical Engineering Report MD-56. 
National Research Council Canada.

Stull, R.B., 1988. An introduction to Boundary Layer Meteorology. volume 13. Springer Science \& Business Media.

Teigen, S.H., Hansen, E.S., Roth, J.C., 2015. Marine icing severity in the Barents sea, in: Proceedings of the 23rd International Conference on Port and Ocean Engineering under Arctic Conditions, Norwegian University of Science and Technology, Trondheim. pp. 1-7.

The Norwegian Directorate of Fisheries, 2016. List of Norwegian fishing vessels 1986 in Hordaland. (In Norwegian: Register over merkepliktige norske fiskefarkoster 1986. Hordaland). Accessed 29 August 2016. Electronic. URL: http://hdl.handle.net/11250/129761

Uppala, S.M., Kållberg, P.W., Simmons, A.J., Andrae, U., Bechtold, V.D.C., Fiorino, M., Gibson, J.K., Haseler, J., Hernandez, A., Kelly, G.A., Li, X., Onogi, K., Saarinen, S., Sokka, N., Allan, R.P., Andersson, E., Arpe, K., Balmaseda, M.A., Beljaars, A.C.M., Berg, L.V.D., Bidlot, J., Bormann, N., Caires, S., Chevallier, F., Dethof, A., Dragosavac, M., Fisher, M., Fuentes, M., Hagemann, S., Hólm, E., Hoskins, B.J., Isaksen, L., Janssen, P.A.E.M., Jenne, R., Mcnally, A.P., Mahfouf, J.F., Morcrette, J.J., Rayner, N.A., Saunders, R.W., Simon, P., Sterl, A., Trenberth, K.E., Untch, A., Vasiljevic, D., Viterbo, P., Woollen, J., 2005. The ERA-40 re-analysis. Quarterly Journal of the Royal Meteorological Society 131, 2961-3012. URL:http://dx.doi.org/10.1256/qj.04.176 doi 10.1256/qj.04.176

Wilks, D.S., 2011. Statistical Methods in the Atmospheric Sciences. volume 100 of International Geophysics Series. Third ed., Academic Press.

World Meteorological Organization, 1962. Commission for Synoptic Meteorology abridged final report of the third session. General summary. Rec. 26-28 CSM-III (Mar. 1962). Accessed 29 August 2016. WMO Report No.122. Rp.50. World Meteorological Organization (WMO).

World Meteorological Organization, 2015. Manual on Codes. International on codes. Manual 306. Volume I.1. Part A - Alphanumeric codes.. World Meteorological Organization (WMO).

Zakrzewski, W.P., 1987. Splashing a ship with collision-generated spray. Cold Regions Science and Technology 14, 65-83. URL: http://www.sciencedirect.com/science/article/pii/0165232X87900450, doi:10.1016/ $0165-232 \mathrm{X}(87) 90045-0$

Zakrzewski, W.P., Lozowski, E.P., 1989. Soviet marine icing data. Technical Report. Canadian Climate Centre, Atmospheric Environment Service.

Zakrzewski, W.P., Lozowski, E.P., Horjen, I., 1989. The use of ship icing models for forecasting icing rates on seagoing ships, in: Proceedings of the 10th International Conference on Port and Ocean Engineering under Arctic Conditions, Luleå University of Technology. pp. 1454-1467.

Zakrzewski, W.P., Lozowski, E.P., Thomas, W., Bourassa, M., Blackmore, R., Szilder, K., Kobos, A., 1993. A threedimensional time-dependent ship icing model, in: Proceedings of the 12th International Conference on Port and Ocean Engineering under Arctic Conditions, Hamburg. pp. 857-873. 


\section{Figure captions}

\section{Caption Figure 1}

Illustration photo of KV Senja. Photo: Eirik Mikal Samuelsen, Troms $\varnothing$, July 2015

\section{Caption Figure 2}

Wave-ship-collision-icing process. The figure illustrates how sea spray is generated in the collision process and droplets are transported to the freezing surface in consideration. Important parameters involved in the process are listed.

\section{Caption Figure 3}

Front part of KV Nordkapp. The images are collected from the General arrangement provided by the Norwegian Coast Guard, and they are showing a) the side view, and b) the above view with $\mathrm{x}$ and $\mathrm{y}$ coordinates used in the trajectory model to find the start position of the droplets hitting the mid point of the freezing plate. Dimensions, distances and heights are measured from the General arrangement. A mathematical expression for $s$ is provided in Equation 12

\section{Caption Figure 4}

Relationship between observed and predicted spray-cloud duration times $\left(t_{\text {dur }}\right)$. a) Variations in the calculated Const. in Equation 8 by applying the observations from Ryerson (1995). b) Comparing the results of calculated spray-cloud duration time from Equation 8 (blue dots) with the results from Equation 9 (red dots) against the observed duration times in Ryerson (1995). The determination coefficient $\left(R^{2}\right)$ of both methods is presented in the upper right corner.

\section{Caption Figure 5}

Non-dimensional $z^{*}=\frac{2 z}{H_{s}}-1$ vs. non-dimensional spray flux for different relative heading angles $\left(\phi_{r}\right)$ from Horjen (2013). a) Reproduction of Figure 4 in Horjen (2013) by using observations from table A.2 in Horjen et al. (1986). b) Same as a) but now using observed wave height and wave period from Norwegian Meteorological Institute (2016) instead of calculated values obtained from the wind speed (Table B.1 in the current study). The determination coefficient $\left(R^{2}\right)$ is calculated from the logarithm of the power-law functions for each of the relative headings $\left(\phi_{r}\right)$. For b) both the combined $R^{2}$ and the combined $R_{\mathrm{cv}}^{2}$ are presented.

\section{Caption Figure 6}

Model-system flow chart. The model system includes input parameters (rectangles) from the atmosphere (green), the waves (blue), other ocean parameters (turquoise) and the ship (yellow), and the final calculated $\frac{d h}{d t}$. Important processes like the trajectory model (Traj.), $R_{w}$, and calculation of heat fluxes, are marked with red circles. Dotted arrows represent more indirect or weaker effects. Blue arrows mark processes only involved when applying the Borisenkov spray-flux formulation. Grey arrows mark processes only involved when applying the Horjen spray-flux formulation. Black arrows mark processes involved when applying both spray-flux formulations. 


\section{Caption Figure 7}

Selection process of icing cases. These maps illustrate the position and quantity of the observations recorded on the KV Nordkapp ships during the years 1983 to 2000 when a) all observations are plotted, b) at least one of the icing parameters is registered, c) visual icing rate is slow or fast, and d) the start and end position of the 37 selected icing events are shown. For a) only observations inside the same square as the maximum and minimum latitude and longitude of the observations in $\mathrm{b}$ ) are presented.

\section{Caption Figure 8}

Predicted (Pred.) icing rate against observed (Obs.) icing rate with the use of the 6 different methods for input parameters. Error bars are calculated from the round-off error in the two ice-accumulation-thickness values $\left(E_{S}\right)$ divided by the time difference between these two observation points $\left(\frac{ \pm 1.0}{\Delta t} \mathrm{~cm} \mathrm{~h}^{-1}\right.$, where $\Delta t=3,6$ or $\left.9 \mathrm{~h}\right)$. Gray dashed lines and the letters N, L, M, and S mark the icing-rate categories: none, light, moderate, and severe. Blue crosses mark the results from calculations applying the spray flux derived from the Borisenkov data (Equation 11, and red circles mark the results applying the spray flux derived from the Horjen data (Equation 15]. The verification scores BIAS, MAE, and $R^{2}$ are plotted in the upper right corner in blue and red respectively. BIAS and MAE have units $\mathrm{cm} \mathrm{h}^{-1}$, while $R^{2}$ is unitless.

\section{Caption Figure 9}

Multi-categorical verification scores calculated from $4 \times 4$ contingency tables for the 37 ice-accretion events. a) illustrates the skill scores for the icing rates calculated from the Borisenkov spray flux, and b) from the Horjen spray flux. For the proportion correct (PC) the score must be above the probability of random hits to show quality, which is 0.25 for a $4 \times 4$ contingency table (grey dashed line). For the other three scores values above zero indicate prediction skills above randomness. The Gandin-Murphy Skill Score (GMSS) was also calculated for $3 \times 3$ contingency tables where moderate and severe icing events were merged together (red open line bar with number in parenthesis).

\section{Caption Figure 10}

Multi-categorical verification scores including non-events. As Figure 9 but now including both icing and no-icing events. a) illustrates the skill scores for the icing rates calculated from the Borisenkov spray flux, and b) from the Horjen spray flux for all the 78 events.

\section{Caption Figure 11}

Spray-flux formulation comparison. Mean value of wave height $\left(H_{s}\right)$ between the two observation points in time against spray flux $\left(R_{w}\right)$ with units of $\mathrm{g} \mathrm{m}^{-2} \mathrm{~s}^{-1}$ for the Borisenkov spray-flux formulation (Equation 1 ) marked with blue crosses, and the Horjen spray-flux formulation (Equation 15) marked with red circles. In addition, the formulation from Horjen (2013) described in Table 1 are marked with green squares. The wave heights plotted are the wave heights that correspond to the method applied, e.g. the visual estimated wave heights are applied for OBS and HYBRID2 (Table 2). For comparison, the icing flux $\left(R_{i}\right)$ in $\mathrm{g} \mathrm{m}^{-2} \mathrm{~s}^{-1}$ derived from the observed icing rates is plotted with black 
triangles. The lines visualise the sensitivity of these spray-flux expressions when applying the median values of $V, P_{s}$, $V_{s}, \beta, \alpha$, and $c$ from Table 2 as constants when $H_{s}$ varies between 0.1 and $12.0 \mathrm{~m}$. In accordance with the model the mean value of $R_{w}$ is applied when $z$ is varied between 6.5 and $8.5 \mathrm{~m}$.

\section{Caption Figure 12}

Wind and wave roses. These figures visualise: a) wind rose from observations, b) wave rose from observations, and c) wave rose from NORA10. The bar length indicates frequency in a given direction interval.

\section{Figures}

\section{Figure 1}

Single column

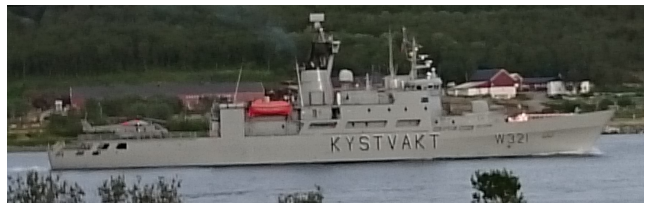

Figure 1: Illustration photo of KV Senja. Photo: Eirik Mikal Samuelsen, Tromsø, July 2015

\section{Figure 2}

1.5 column

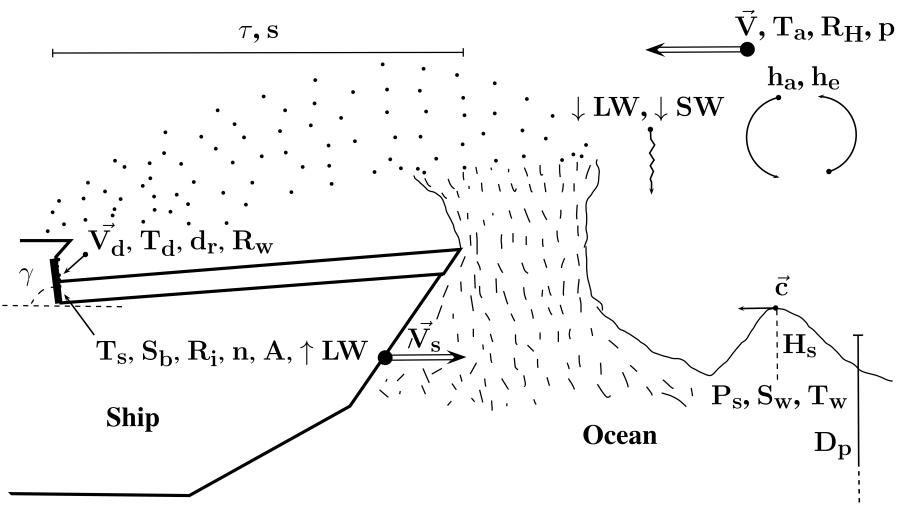

Figure 2: Wave-ship-collision-icing process. The figure illustrates how sea spray is generated in the collision process and droplets are transported to the freezing surface in consideration. Important parameters involved in the process are listed. 


\section{Figure 3}

1.5 column/Double column

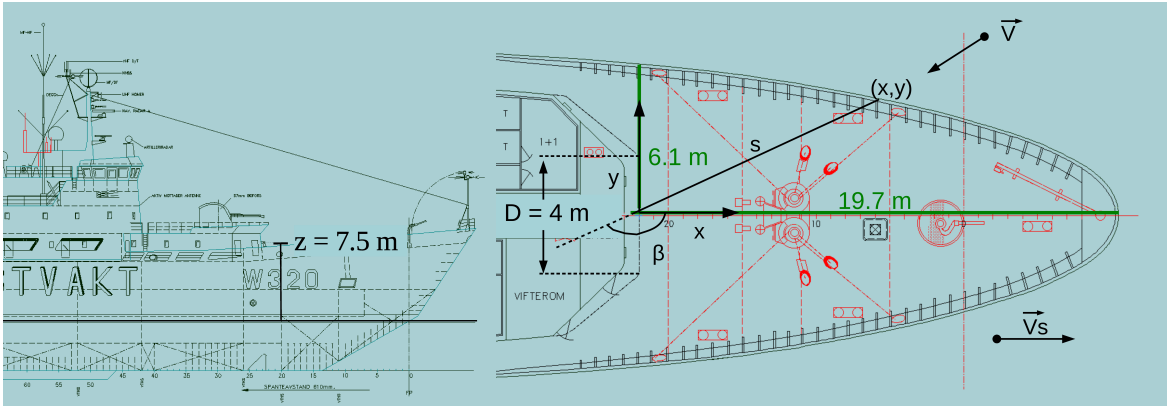

(a)

(b)

Figure 3: Front part of KV Nordkapp. The images are collected from the General arrangement provided by the Norwegian Coast Guard, and they are showing a) the side view, and b) the above view with $\mathrm{x}$ and y coordinates used in the trajectory model to find the start position of the droplets hitting the mid point of the freezing plate. Dimensions, distances and heights are measured from the General arrangement. A mathematical expression for $s$ is provided in Equation 12

\section{Figure 4}

\section{5 column}

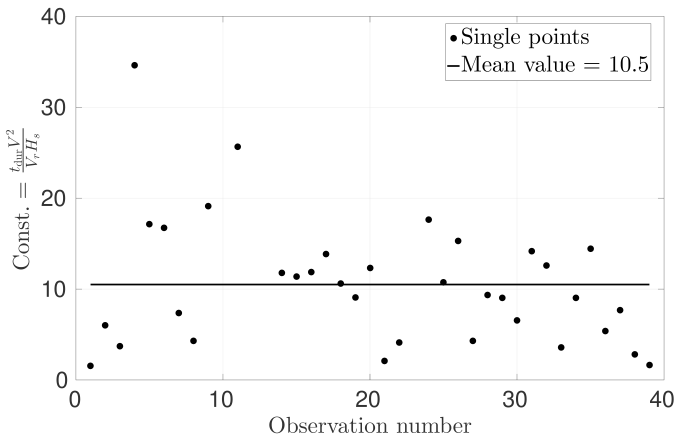

(a)

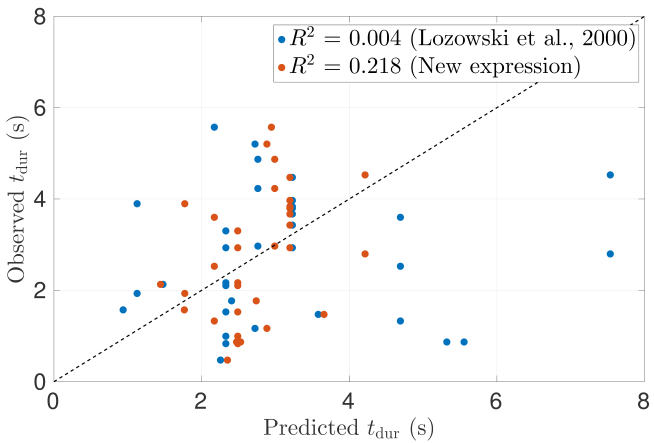

(b)

Figure 4: Relationship between observed and predicted spray-cloud duration times $\left(t_{\text {dur }}\right)$. a) Variations in the calculated Const. in Equation 8 by applying the observations from Ryerson (1995). b) Comparing the results of calculated spray-cloud duration time from Equation 8 (blue dots) with the results from Equation 9 (red dots) against the observed duration times in Ryerson (1995). The determination coefficient $\left(R^{2}\right)$ of both methods is presented in the upper right corner. 


\section{5 column}

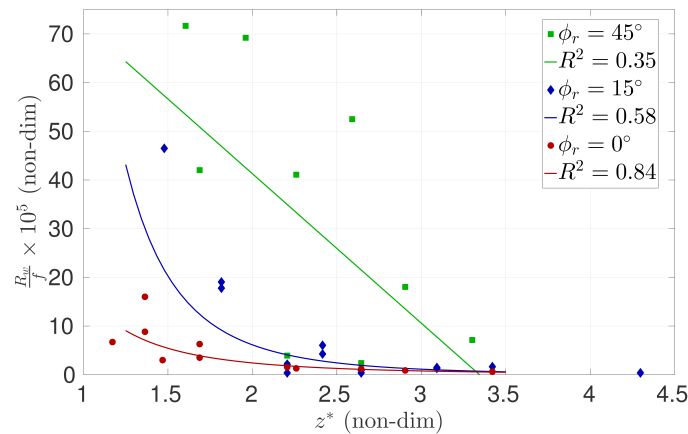

(a)

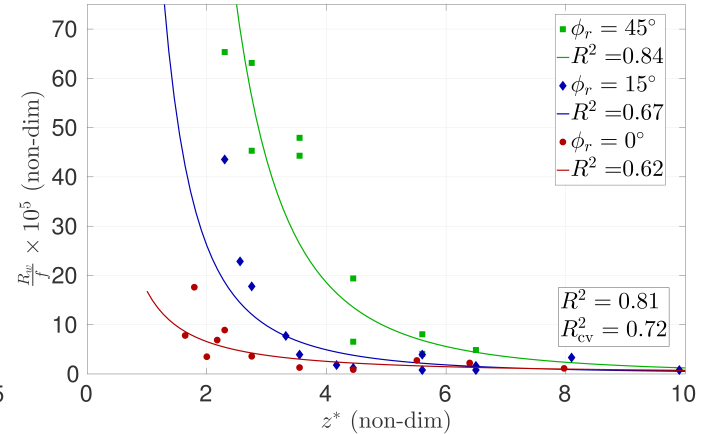

(b)

Figure 5: Non-dimensional $z^{*}=\frac{2 z}{H_{\mathrm{s}}}-1$ vs. non-dimensional spray flux for different relative heading angles $\left(\phi_{r}\right)$ from Horjen (2013). a) Reproduction of Figure 4 in Horjen (2013) by using observations from table A.2 in Horjen et al. (1986). b) Same as a) but now using observed wave height and wave period from Norwegian Meteorological Institute (2016) instead of calculated values obtained from the wind speed (Table B.1 in the current study). The determination coefficient $\left(R^{2}\right)$ is calculated from the logarithm of the power-law functions for each of the relative headings $\left(\phi_{r}\right)$. For b) both the combined $R^{2}$ and the combined $R_{\mathrm{cv}}^{2}$ are presented.

\section{Figure 6}

\section{5 column}

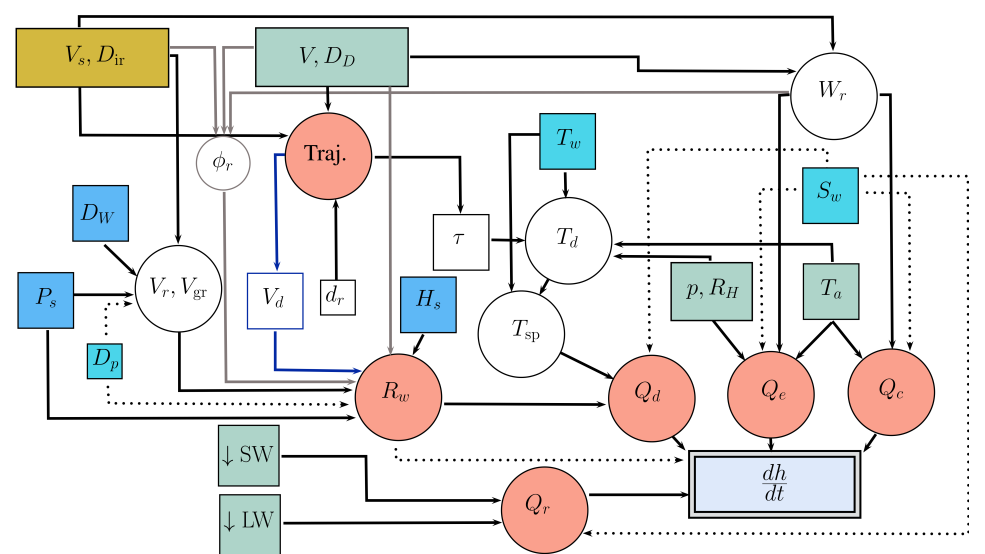

Figure 6: Model-system flow chart. The model system includes input parameters (rectangles) from the atmosphere (green), the waves (blue), other ocean parameters (turquoise) and the ship (yellow), and the final calculated $\frac{d h}{d t}$. Important processes like the trajectory model (Traj.), $R_{w}$, and calculation of heat fluxes, are marked with red circles. Dotted arrows represent more indirect or weaker effects. Blue arrows mark processes only involved when applying the Borisenkov spray-flux formulation. Grey arrows mark processes only involved when applying the Horjen spray-flux formulation. Black arrows mark processes involved when applying both spray-flux formulations. 


\section{Figure 7}

Single column

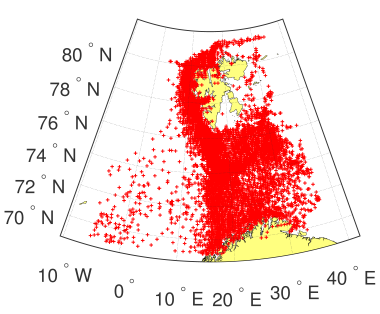

(a) 13911 cases

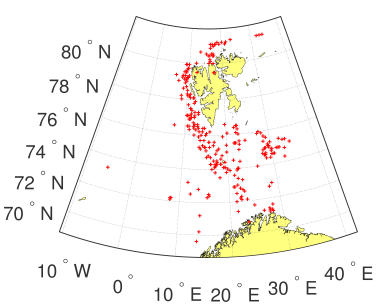

(c) 262 cases

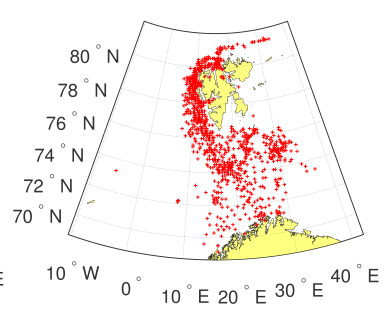

(b) 1151 cases

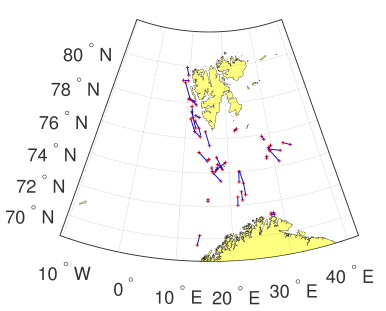

(d) 37 cases

Figure 7: Selection process of icing cases. These maps illustrate the position and quantity of the observations recorded on the KV Nordkapp ships during the years 1983 to 2000 when a) all observations are plotted, b) at least one of the icing parameters is registered, c) visual icing rate is slow or fast, and d) the start and end position of the 37 selected icing events are shown. For a) only observations inside the same square as the maximum and minimum latitude and longitude of the observations in $b$ ) are presented.

\section{Figure 8}

\section{Double column}
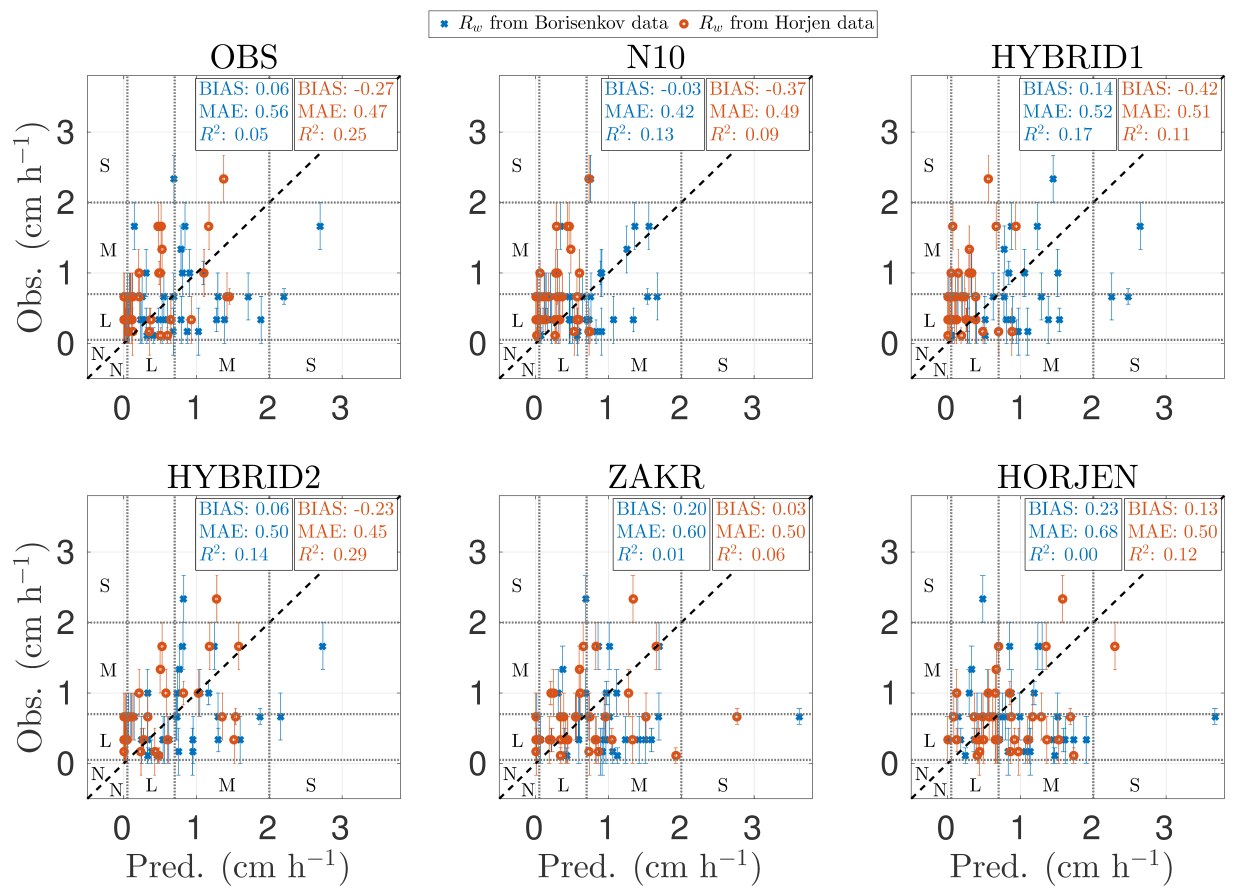

Figure 8: Predicted (Pred.) icing rate against observed (Obs.) icing rate with the use of the 6 different methods of input parameters. Error bars are calculated from the round-off error in the two ice-accumulation-thickness values $\left(E_{S}\right)$ divided by the time difference between these two observation points $\left(\frac{ \pm 1.0}{\Delta t} \mathrm{~cm} \mathrm{~h}^{-1}\right.$, where $\Delta t=3,6$ or $\left.9 \mathrm{~h}\right)$. Gray dashed lines and the letters $\mathrm{N}, \mathrm{L}, \mathrm{M}$, and $\mathrm{S}$ mark the icing-rate categories: none, light, moderate, and severe. Blue crosses mark the results from calculations applying the spray flux derived from the Borisenkov data (Equation 1 , and red circles mark the results applying the spray flux derived from the Horjen data (Equation 15 . The verification scores BIAS, MAE, and $R^{2}$ are plotted in the upper right corner in blue and red respectively. BIAS and MAE have units $\mathrm{cm} \mathrm{h}^{-1}$, while $R^{2}$ is unitless 


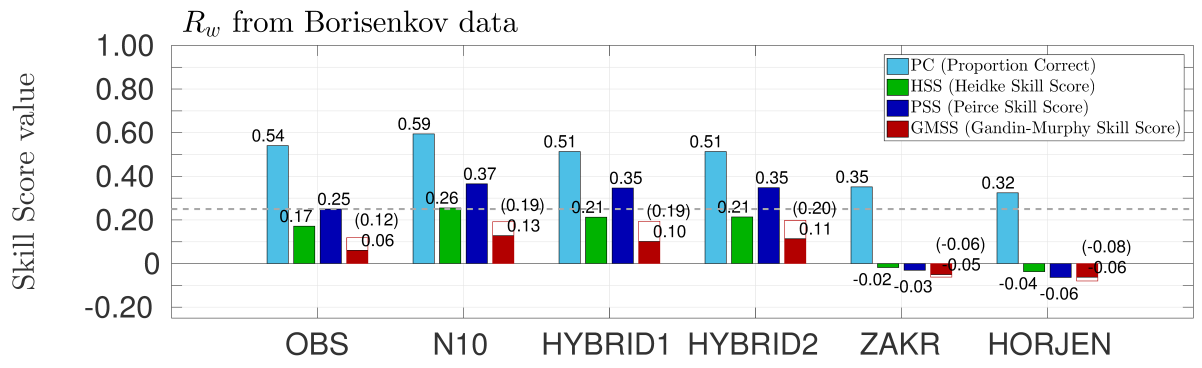

(a)

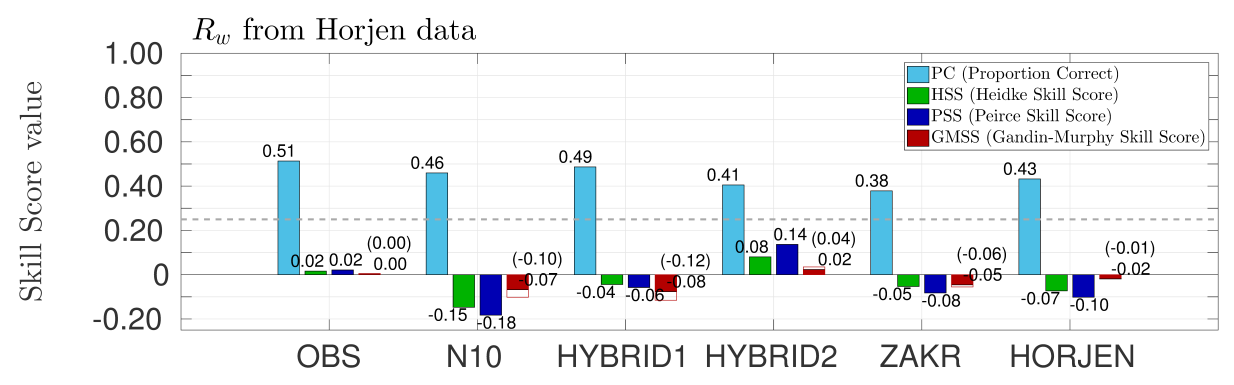

(b)

Figure 9: Multi-categorical verification scores calculated from $4 \times 4$ contingency tables for the 37 ice-accretion events. a) illustrates the skill scores for the icing rates calculated from the Borisenkov spray flux, and b) from the Horjen spray flux. For the proportion correct (PC) the score must be above the probability of random hits to show quality, which is 0.25 for a $4 \times 4$ contingency table (grey dashed line). For the other three scores values above zero indicate prediction skills above randomness. The Gandin-Murphy Skill Score (GMSS) was also calculated for $3 \times 3$ contingency tables where moderate and severe icing events were merged together (red open line bar with number in parenthesis).

\section{Figure 10}

\section{5 column}

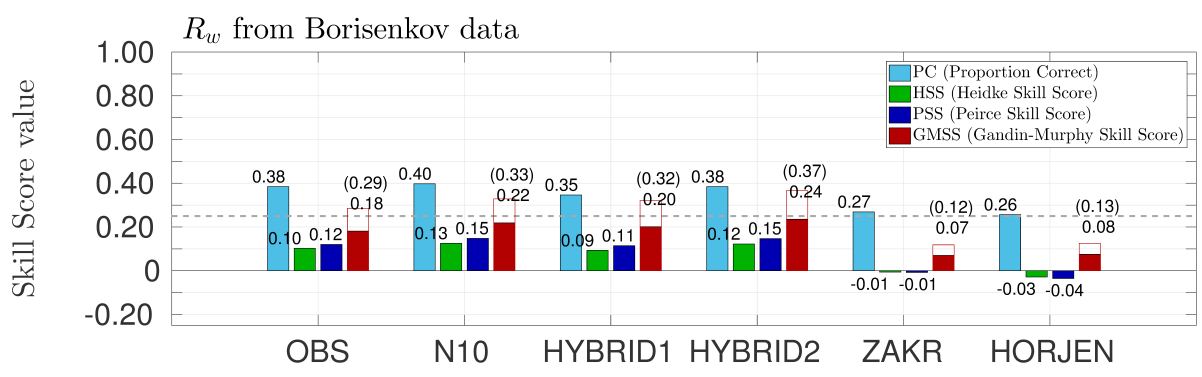

(a)

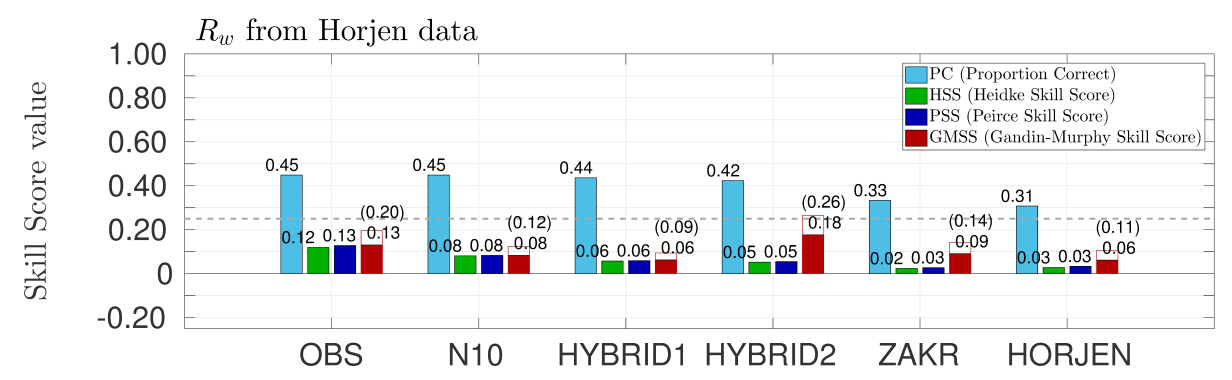

(b)

Figure 10: Multi-categorical verification scores including non-events. As Figure 9 but now including both icing and no-icing events. a) illustrates the skill scores for the icing rates calculated from the Borisenkov spray flux, and b) from the Horjen spray flux for all the 78 events. 


\section{Figure 11}

Double column
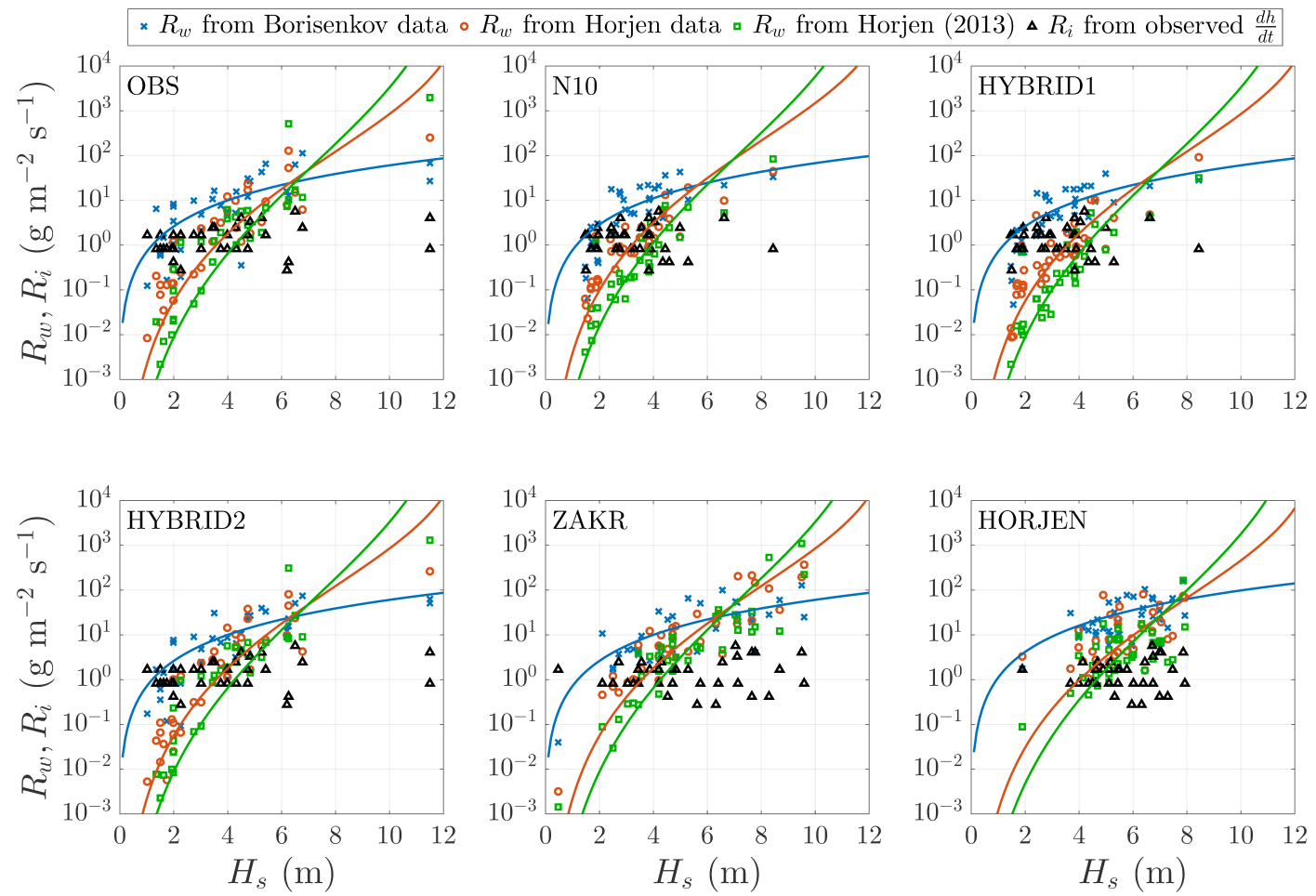

Figure 11: Spray-flux formulation comparison. Mean value of wave height $\left(H_{S}\right)$ between the two observation points in time against spray flux $\left(R_{w}\right)$ with units of $\mathrm{g} \mathrm{m}^{-2} \mathrm{~s}^{-1}$ for the Borisenkov spray-flux formulation (Equation 1) marked with blue crosses, and the Horjen spray-flux formulation (Equation 15 marked with red circles. In addition, the formulation from Horjen (2013) described in Table 1 are marked with green squares. The wave heights plotted are the wave heights that correspond to the method applied, e.g. the visual estimated wave heights are applied for OBS and HYBRID2 (Table 2). For comparison, the icing flux $\left(R_{i}\right)$ in $\mathrm{g} \mathrm{m}^{-2} \mathrm{~s}^{-1}$ derived from the observed icing rates is plotted with black triangles. The lines visualise the sensitivity of these spray-flux expressions when applying the median values of $V, P_{s}, V_{s}, \beta, \alpha$, and $c$ from Table 2 as constants when $H_{s}$ varies between 0.1 and $12.0 \mathrm{~m}$. In accordance with the model the mean value of $R_{w}$ is applied when $z$ is varied between 6.5 and $8.5 \mathrm{~m}$.

Figure 12

\section{5 column (Figure for Appendix A)}

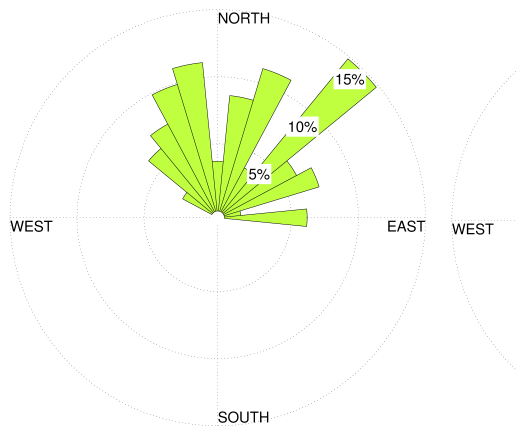

(a)

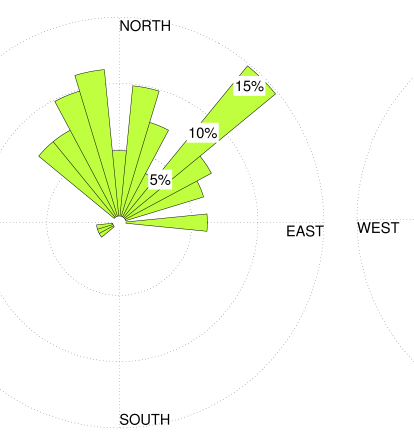

(b)

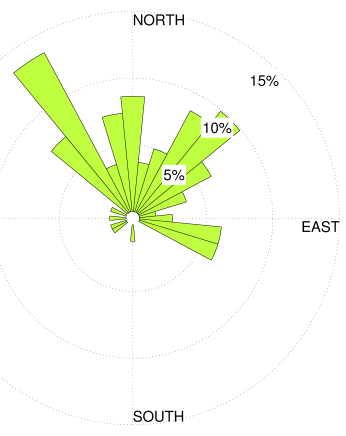

(c)

Figure 12: Wind and wave roses. These figures visualise: a) wind rose from observations, b) wave rose from observations, and c) wave rose from NORA10. The bar length indicates frequency in a given direction interval. 